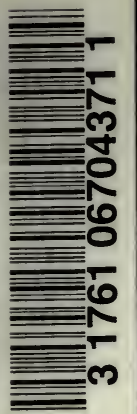


Toronto University Library

Presented by

Thiversity lovlege London through the Committee formed in The Od Country.

to aid in replacing the loss caused by The disastrous Tire of February the 14 th 1890 



$$
\frac{10706}{411290}
$$




\section{PREFACE.}

IN the new edition of the Syllabus of my Lectures on Physiology, I have followed the same arrangement as in the last, with the exception that in the chemical part the descriptions of immediate principles, which were before printed separately, have now been incorporated in the text. The whole has been revised, and some parts have been much extended. Under the title "Practical Exercises," I have added to the Syllabus instructions for laboratory work relating to the chemical properties of the animal liquids, and of the most important foodstuffs ; and to the physiological endowments of living tissues and organs. The experiments I have selected are of so simple a character that, with the directions given and such aid as he will readily obtain in the laboratory, every man who takes pains will find it easy to carry them out successfully. The chemical series already form part of the Course of Practical Physiology. The others, which relate chiefly to the properties of the excitable and contractile tissues, have been hitherto omitted; not because they are regarded as of less importance, but for want of space-a difficulty which will be removed as soon as our new laboratories are completed. I cannot too strongly recommend their use to all who desire to acquire a serviceable knowledge of the elementary facts of physiology. They will also fulfil another but less important purpose, that of aiding candi- 
dates in their preparation for the higher examinations in physiology, of the University.

To the "Practical Exercises" I have added a series of "Demonstrations." Under this heading I have given an account of experiments which, although they are of such fundamental importance that every student ought to witness them, cannot be advantageously repeated. These are given during the winter session, all students who have already attended the summer practical course being invited to attend them. 


\section{CONTENTS.}

PART I.

PAGE

Tile Chemical Processes-

Immediate Principles of Food • • . . . . 2

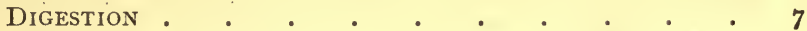

INTESTINAL ABSORPTION • . . . • . . 16

BLOOD . • . . . . . . . . . 17

The Spleen . . . . . . . . . 22

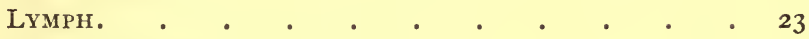

Chemical Process of Respiration . . . . . 23

URINE . . . . . . . . . . . . 26

Muscular Tissue . . . . . . . . . . 31

Nervous Tissue. $. \quad . \quad . \quad . \quad . \quad . \quad \cdot 32$

Exchange of Material . . . . . . . 33

Production of Heat . . . . . . . . $4 \mathrm{I}$

Practical Exercises relating to Food Stuffs . • . 44

", ,,$\quad$ Animal Liquids . . 48

PART II.

Mechanical Processes-

Muscular Contkaction . . . . . . . . 55

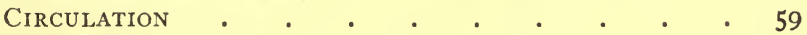

The Heart . . . . . . . . . 66

RESPIRATION . . . . . . . . . . . 68

Bodily Motion . . . . . . . . . 70

VoICE AND SPEECH . . . . . . . . 72 


\section{PART III.}

Functions of Nervous System-

NERVES

Functions of Nerve Centres

$\cdot \cdot \cdot 78$

" " Roots of Spinal Nerves • • • . 80

" " White Column of Spinal Cord . . . 8r

Centres of Medulla Oblongata . . • . 82

DEATH BY AsphyXia . . . . . . • . 90

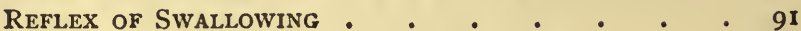

Regulation of Peristaltic Action • • • $\quad$ • 92

INFluencb OF Nervous System ON Processes OF

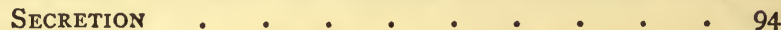

Regulation of Locomotion • • • • • • 97

Motions of the Eyeballs . . 98

Functions of the Brain. . . . . . . . 100

Sensations and Perceptions . . . . . . . 103

Tactile Sensation . . . . . . . . 104

Muscular " . . . . . . . . . . 105

VISION . . . . . . . . . . . . IO5

HEARING • . . . . . . . . . II5

TASTE . . . . . . . . . . . 119

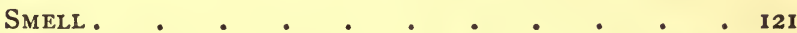

Practical Exercises relating to the Physiological

Properties of the Organs and Tissues of the Nervous

and Muscular Systems . . . • . • • . I 123

DemONSTRATIONS • • • • • • • • • • I39 
$-$

+ 1 +

. 
N.B.-Before using the Syllabus the Student must make the following corrections :-

P. 2, 1. 12 from bottom, for "when boiled" read "at temperatures above $73^{\circ} \mathrm{C}$."

P. 3, 1. 4, for "bases " read "basis."

P. 3, 1. 4 from bottom, for "by the prolonged " read " by prolonged."

P. 9, 1. 22, for "dried gastric mucous membrane and hydrochloric acid" read "expressed juice of gastric mucous membrane dried at a low temperature."

P. I0, 1. 5, for "bases, by " read "by basic."

P. I2, 1. I I from bottom, for "stercobolin " read "stercobilin."

P. 14, 1. 5 from bottom, omit " having."

P. 15, 1. I, for " $\mathrm{C}_{6}$ " read "C $\mathrm{C}_{8}$ " line I I, for " $\mathrm{H}_{50}$ " read " $\mathrm{H}_{5}$."

P. 12, 1. 25, for "solubility" read " insolubility."

P. 42, in the table, for " 9069 " read "9.069," and for " 230 " read " 5.230."

P. 43 , in the table, for " at 582 " read " $\times 0.582$." 


\title{
SYLLABUS OF A COURSE OF LECTURES
}

\author{
ON \\ P H Y S I O LO G Y.
}

PART I.

\section{THE CHEMICAL PROCESSES.}

ANImAL life, as observed in man and the higher animals, is an aggregate of chemical processes for which food and oxygen afford materials, the products being heat, muscular action, carbonic anhydride, water and ammonia. Food essentially consists of albuminous bodies, carbonic hydrates and fat, all of which undergo chemical disintegration in the animal body, in addition to water and certain inorganic salts. The fats and carbonic hydrates are the sources from which the organism derives the material for muscular action and the production of heat. Their carbon and hydrogen leave the body as $\mathrm{CO}_{2}$ and $\mathrm{H}_{2} \mathrm{O}$. Of the proteid material used by the body, a part is represented in the discharges by bodies of known chemical constitution containing nitrogen (nitrogenous "metabolites"): the remainder eventually leaves the organism as $\mathrm{CO}_{2}$ and $\mathrm{H}_{2} \mathrm{O}$, but may, in the meantime, take part in the production of fat, or of other non-nitrogenous immediate principles.

Vegetable life is also a chemical process. Green plants build up their tissues out of carbonic anhydride, ammonia and certain inorganic salts. Colourless plants do not dissociate carbonic anhydride, but derive their carbon entirely from the soil on which they grow. The most important 
constituents of the tissues of plants are albuminous bodies, and carbonic hydrates; for these exist in all plants. The characteristic property of a plant is its power of forming its tissues out of inorganic materials.

The term protoplasm is used to denote the apparently, but not really, homogeneous substance which forms the active parts of the tissues of plants and animals. It consists chiefly of albuminous bodies, and exhibits in itself all the essential phenomena of life: for in it, not only the general actions which belong to the organism as a whole, but the specific actions of particular parts, such as those of muscle, nerve and gland, have their seat.

\section{IMMEDIATE PRINCIPLES OF FOOD.}

* * The tern "immediate principle" or "proximate principle" (oroเxsır) is applied to any "substance," in the chemical sense, which exists as such in living organisms. It is understood to be applicable to bodies which are met with in the secreted liquids, as well as to the constituents of the blood and tissues.

\section{Albuminous Bodies (Proteids).}

Proteids are non-crystallizable bodies of unknown constitution, of which the centesimal composition is about Carbon 53, Hydrogen 7.5 , Nitrogen I5.5, Oxygen 23, Sulphur I'o. They are soluble, or capable of imbibition with water, insoluble in alcohol or ether. They are all stained yellow by nitric acid, and then disintegrated, leaving a yellow precipitate which dissolves orange red in ammonia.

Aqueous solutions of proteids are lævo-rotatory. When a solution is separated from water by a septum of colloid membrane, the proteid diffuses with extreme slowness into the water.

They occur in the tissues or fluids of plants and animals under two principal forms, distinguished from each other according as they are coagulated or remain in solution when boiled.

The coagulable proteids comprise the albumins proper, which are soluble in water, and the globulins, which are insoluble, but are readily held in solution in presence of neutral salts, particularly $\mathrm{NaCl}$. From these (often called native albumins) the mass of the proteid material of animal and vegetable tissues is formed.

The albuminatcs are soluble in aqueous liquids, only when these are acid or alkaline : they are precipitated by neutralization. They must be regarded as derivates from the others; for bodies which correspond entirely in their characters with those albuminates which exist in the tissues of plants and animals can be obtained by the prolonged action of alkalies or acids on coagulable proteids. 
Albuminoids. - There exist in the animal body several substances which, although close allied to the proteids, are separated from them by several wellmarked differences. One of these, Collagen, is of great importance, as yielding Gelatin. It constitutes the "organic bases" of bone, and is the most important constituent of the connective tissues generally. Gelatin is the product of boiling "collagen." It swells in cold water, but does not dissolve ; its solution in hot water "gelatinizes" on cooling. It is precipitated by tannin and corrosive sublimate, not by acetic acid and potassic ferrocyanide. Chondrin, a similar product obtained from cartilage, is distinguished from gelatin by being precipitated by acetic acid.

\section{Carbohydrates.}

Cellulose. The material of the outer membrane of the plant-cell is unaffected by dilute acids or alkalies, but is converted by strong sulphuric acid into a body which is coloured blue by iodine.

Starch is the chief constituent of the "Starch grains" contained in the cells of plants ; in these grains it is enclosed in concentric envelopes of an insoluble body resembling cellulose ; it is soluble in water, the solution being opalescent ; it is coloured blue by iodine ; the blue colour disappears on heating, but reappears on cooling, unless the heating has been long continued. Starch is converted by prolonged action of weak acids into Dextrin (a body which is coloured red by iodine), and eventually into grape sugar. It is converted in presence of diastatic ferments, e.g., those of the salivary glands, pancreas, and liver into grape sugar.

Grape Sugar or Dextrose or Starch Sugar $\left(\mathrm{C}_{6} \mathrm{H}_{12} \mathrm{O}_{6}\right)$ occurs in extremely small quantity in blood, muscle, and other tissues, and (according to Briicke) in normal urine. It is distinguished by its power of reducing certain metallic salts, by its dextro-rotatory action, by its splitting, when subjected to the action of the yeast-plant at a suitable temperature, into alcohol and carbonic acid, and by its yielding lactic acid in presence of albuminous bodies in process of putrefaction. It is soluble in $\mathbf{I} \frac{1}{2}$ parts of cold water, and to any extent in boiling water. From its solution in boiling alcohol, it readily crystallizes. On the power of reduction possessed by grape sugar depends the important test known as "Trommer's Test," which consists in adding solution of potassic hydrate to the liquid supposed to contain sugar, and then weak solution of cupric sulphate, so long as the precipitate of cupric hydrate first formed redissolves on agitation. On gently heating, a yellow precipitate is formed of cuprous hydrate, or a deposit of cuprous oxide (see Practical Part, Section II.)

Milk Sugar or Lactose constitutes about 15 per cent. of the solids of milk : it can be obtained directly from whey, after separation of albuminous compounds, by crystallization in rhombic prisms $\left(\mathrm{C}_{12} \mathrm{H}_{22} \mathrm{O}_{11}+\mathrm{H}_{2} \mathrm{O}\right)$ : it is converted by the prolonged boiling with weak acids into fermentescible sugars (galactose and dextrose); it is transformed very readily into lactic acids under the influence of a ferment usually present in milk.

Cane Sugar does not occur in the animal body, but is an important con- 
stituent of food. When boiled with dilute acids, cane sugar is converted into dextrose and levulose. A similar change takes place in gastric digestion.

\section{FATS.}

Palmitin $\left(\mathrm{C}_{3} \mathrm{H}_{5}\left(\mathrm{C}_{16} \mathrm{H}_{31} \mathrm{O}\right)_{3} \mathrm{O}_{3}\right)$ and Stearin $\left(\mathrm{C}_{3} \mathrm{H}_{5}\left(\begin{array}{llll}\mathrm{C}_{18} & \mathrm{H}_{35} & \mathrm{O}\end{array}\right)_{3} \mathrm{O}_{3}\right)$, which in solution in olein constitute animal fat, are insoluble in water, soluble in hot alcohol, ether, chloroform, benzole, \&c. Under the influence of superheated steam they are decomposed, taking up water and yielding glycerine and Palmitic and Stearic acids respectively. $\left(\mathrm{C}_{3} \mathrm{H}_{5}\left(\mathrm{C}_{16} \mathrm{H}_{31} \mathrm{O}\right)_{3} \mathrm{O}_{3}+3 \mathrm{H}_{2} \mathrm{O}\right.$ $=\mathrm{C}_{3} \mathrm{H}_{5}\left(\mathrm{H}_{3}\right) \mathrm{O}_{3}+3 \mathrm{C}_{16} \mathrm{H}_{32} \mathrm{O}_{2}$. $) \quad$ A similar change takes place more gradually under the influence of pancreatic secretion in the intestine, as well as in presence of albuminous bodies in putrefaction. Alkaline palmitates and stearates (Soaps) are obtained when fat is dissolved in potash or soda with the aid of heat; such soaps exist in bile. When fat becomes rancid, it not only undergoes transformation into acids and glycerine, but takes up oxygen, in consequence of which volatile and pungent acids belonging to the same series $\left(\mathrm{C}_{\mathrm{n}} \mathrm{H}_{2 \mathrm{n}} \mathrm{O}_{2}\right)$, but containing less carbon, are formed.

Palmitin fuses at $40^{\circ} \mathrm{C}$., Stearine at about $60^{\circ} \mathrm{C}$. According to the proportion in which they exist in different kinds of fat, the fusing points of such fats vary. Thus, while beef fat fuses at $37^{\circ} \mathrm{C}$., and contains three parts of Stearin and Palmitin to one part of olein, human fat, which contains less Stearin and relatively more olein, fuses at $25^{\circ} \mathrm{C}$. Olein $\left(\mathrm{C}_{3} \mathrm{H}_{5}\left(\mathrm{C}_{18} \mathrm{H}_{33} \mathrm{O}\right)_{3}\right.$ $\mathrm{O}_{3}$ ), is the fluid fat in which stearin and palmitin are dissolved. Olein solidifies a few degrees above freezing point, and is more soluble than the other fats in ether. Palmitic Acid $\left(\mathrm{C}_{16} \mathrm{H}_{32} \mathrm{O}_{2}\right)$ and Stearic Acid $\left(\mathrm{C}_{18} \mathrm{H}_{36} \mathrm{O}_{2}\right)$ are crystalline bodies, chiefly distinguished from each other by their relation to heat, the former fusing at $62^{\circ} \mathrm{C}$, the latter at $70^{\circ} \mathrm{C}$. 'Their relations to solvents correspond with those of the fats. Palmitic acid crystallizes from its solution in hot alcohol in bunches of fine needles; stearin in shining plates. Oleic Acid $\left(\begin{array}{lll}\mathrm{C}_{18} & \mathrm{H}_{34} & \mathrm{O}_{2}\end{array}\right)$, which belongs to the series $\mathrm{C}_{\mathrm{n}} \mathrm{H}_{2 \mathrm{n}-2} \mathrm{O}_{2}$, fluid at ordinary temperatures, is decomposed by strong potash, potassic palmitate and acetate being produced.

Butyrine $\left(\mathrm{C}_{3} \mathrm{H}_{5}\left(\mathrm{C}_{4} \mathrm{H}_{7} \mathrm{O}\right) \mathrm{O}_{3}\right)$ and the corresponding glycerides of other volatile acids (capronic, caprylic, and myristinic) occur in small proportion in butter.

FOOD.

Flesh owes its nutritive value to its albuminous and collagenous constituents, its fat and its salts. Lean meat (beef) contains about 25 per cent. of solids, of which 18 per cent. is albumin, and yields about 2 per cent. of gelatin to boiling water. Flesh of young animals (veal) yields 5 to Io per cent. The interstitial fat of meat varies in quantity from 4 to 15 per cent. 
Meat yields to warm water at $60^{\circ} \mathrm{C}$. about 3 per cent. of albuminous material and nearly as much extractive. On boiling the aqueous extract, the albumin coagulates (as scum), but when the boiling is long continued some of it redissolves (Mulder). Consequently the quantity of albuminous material contained in bouillon, always small, varies according to the mode of preparation. It may be increased by the addition of a trace of hydrochloric acid to the water used. Bouillon, beef tea, and other similar products owe their value, partly to the gelatin, but chiefly to the salts and cxtractive which they contain. "Liebig's Extract" contains neither proteid nor gelatin.

Meat, when roasted, retains its juice, which, from the comparatively low temperature of the internal parts (indicated by the colour) does not coagulate. The tenderness which meat acquires by keeping is due to conversion of some of its myosin into albuminate. Cooking is useful, not only as preparatory to digestion, but as destructive of parasites and of morbid and septic products.

Milk.-All of the constituents of milk are of nutritive value. Cream consists chiefly of casein and butter; Butter contains, in addition to the ordinary fats (Palmitin, Stearin, and Olein), about 2 per cent. of the glycerides of the volatile acids; Butter milk consists of sugar, casein and salts; Whey of sugar and salts; Cheese of casein with variable quantities of butter, and of the products of decomposition of both. Human milk contains less than 4 per cent. of casein, between 3 and 4 per cent. of butter, and from 4 to 5 per cent. of sugar. In Colostrum the casein is partly replaced by serum albumin. Cows' milk contains much more casein than human milk, but no more sugar: consequently, when the former is diluted, as a substitute for the latter, milk sugar (which as crystallized from whey always contains calcic and potassic phosphates) must be added. Cows' milk always contains a small percentage of albumin. 
Eggs.-Eggs contain about 73 per cent. of water, I5 of albumin, and 12 of fat. Yolk of egg yields lecithin (see "Nervous Tissue") in considerable quantity, and vitellin, a proteid body analogous to paraglobulin (see "Blood").

Vitellin is obtained when yolk of egg, which has been previously extracted with ether, is treated with solution of common salt. It is precipitated on the addition of water.

Cereals, Pulses and other Vegetable Foods. - Wheat flour derives its alimentary value from its large percentage of proteids ( 3 per cent.) and starch ( 73 per cent.), but chiefly from its containing gluten, and its consequent adaptedness for bread-making. In the fermentation of dough, grapesugar splits into alcohol and carbonic acid under the influence of the yeast-plant. By this means the dough is raised. In baking, the dough is subjected to a very high temperature $\left(150^{\circ} \mathrm{C}\right.$. to $200^{\circ} \mathrm{C}$.). Most of the starch becomes soluble, and much of it is converted, especially in the crust, into dextrin. Notwithstanding the destruction of sugar in fermentation, a loaf weighs about a quarter more than the flour used to make it. Rye flour, nearly as rich in proteids and starch as wheat, is also used for bread-making, but yields a less perfect product. It contains more cellulose and less albuminous substances. Barley and Oatmeal cannot be so used, as they yield no gluten. They also contain less proteids ( 5 to Io per cent.) Barley owes its importance to its being a source of diastase and grapesugar. Maize, although poor in albuminous bodies, is rich in starch, but in both these respects it is exceeded by rice. Rye and maize are severally liable to a parasitic disease which renders the grain morbific. The Pulses owe their value to the legumin they contain, and to their large percentage of proteid (23 to 25 per cent.) Potato contains 75 per cent. of water. In the dry state it contains about 8 per cent. of proteid and 70 per cent. of starch. Its cellulose becomes gelatinous by boiling, and is thus soluble 
in the digestive liquids. Fruits and succulent vegetables owe their nutritive value to the sugar and to the organic acids and the salts which they contain. Their percentage of albuminous material is very small.

Inorganic Salts of Food.-Beef yields, when dry, about 4 per cent. of ash, potash constituting more than two-thirds of the total bases. The most important potassium salts are phosphate and chloride. The proportion of sodium salts is very small. In boiling meat, nearly the whole of its alkaline salts pass into the bouillon. Wheat flour contains about 2 per cent. of ash, of which one-third is reckoned as potash and nearly half as phosphoric anhydride. The constitution of the ash of potatoes and other juicy vegetables is similar, but the yield of phosphoric acid is relatively less; the percentage of potash is about four times as great as that of all the other bases together. Milk yields about 2.5 per thousand of ash, of which about I per thousand is reckoned as potash, 0.25 as soda, and about 0.4 as lime.

In an adequate diet comprising 250 grammes of meat, and 400 grammes of bread, the former would yield $I^{\circ} \cdot 5$ gramme of potash, the latter I. 6 . An adequate diet of milk (two and a half litres) would yield about 3 grammes.

\section{DIGESTION,}

inchuding the Physiology of the Livor and Pancreas.

Human saliva, the mixed secretion of the submaxillary, parotid, and sublingual glands, and of the mucous glands of the mouth, is a tenacious, slightly turbid, and slightly alkaline liquid; it contains about half per cent. of solids, of which about half is inorganic. The organic constituents are albumin, globulin, mucin, and a diastatic ferment; the salts are those of the blood, but the proportion of earthy bases is larger. Ferric salts colour saliva blood-red: this reaction is due to sulphocyanate of potassium, which it 
derives from the parotid. Its mucin is derived from the submaxillary, and its ferment chiefly from the same source. Its turbidity is due to salivary corpuscles, and epithelial elements. The salivary secretion of the dog (submaxillary) contains no ferment, and no sulphocyanate. It yields a very large proportion of $\mathrm{CO}_{2}$ to the mercurial vacuum.

Saliva owes its value in digestion chiefly to its diastatic ferment, but it is also of use as a solvent and lubricant.

\section{Digestion in the Stomach.}

The relative importance of gastric as compared with salivary digestion varies in different classes of animals according to the nature of their food. In the carnivora the food enters the stomach unchanged, and remains there for many hours. The stomach is of relatively large size, and its whole surface is provided with peptic glands. In the herbivora, as, e.g., in the horse, the thoroughly masticated and insalivated food is retained only for a very short time in the stomach. The organ is accordingly very small, and only a part of its mucous lining is digestive.

Human gastric juice is a colourless transparent liquid of very low specific gravity (1005). It contains neither albumin nor mucin, and may be regarded as a solution of pepsin, hydrochloric acid, chloride of sodium, and other salts. It is secreted by the peptic cells of the glands of which the digestive part of the mucous membrane chiefly consists. The secretion takes place in answer to mechanical or chemical stimulation of the mucous surface; the act is attended with increased circulation of blood in the mucous membrane.

The process of gastric digestion consists in the transformation of the albuminous bodies of the food into acidalbumin and peptone (parapeptone), under the combined influence of pepsin and of a free acid. In the dog, the 
gastric juice can be proved to contain free hydrochloric acid, for the quantity of chlorine in it is considerably more than sufficient to combine with all the metals present. As regards human gastric juice the proof is less complete. Lactic acid is present in chyme whenever carbohydrates are being digested. It has been found that hydrochloric acid can be replaced by phosphoric acid, as well as by acetic and other acids of the same series.

Pepsin, although resembling the albuminous bodies in chemical composition, exhibits none of their distinctive characters. It exists in gastric juice in a state of imperfect solution, so that it can be removed from it by mechanical means; on this fact Brücke's method of preparing pure pepsin is founded. It is capable of taking part in the digestion of albuminous substances, even in the smallest quantity, provided that the liquid is not too dilute, and that it does not contain too large a proportion of the product of digestion-peptone. In the process, the pepsin neither increases, diminishes, nor undergoes any loss of activity.

The substance commercially known as pepsin consists of dried gastric mucous nembrane, and hydrochloric acid. A solution of pepsin which possesses its digestive properties is obtained by extracting fresh mucous membrane with glycerine.

In animals that die during digestion, the stomach digests itself after death. During life such digestion is prevented by the alkalinity of the tissues. Chyme, as it leaves the stomach, contains remains of animal and vegetable structure, unaltered starch grains, fat particles, and (after milk diet) curd particles. It does not normally contain bile. It yields a mixture of gases in which there is much less oxygen than in common air, and a larger proportion of $\mathrm{CO}_{2}$.

Peptone differs from proteids in the readiness with which it diffuses through animal membranes. It resembles them in chemical composition 
(approximate composition of gastric peptone in 100 parts-Carbon 49 , Hydrogen 7, Nitrogen 15, Oxygen 28, Sulphur 1). It is soluble in water in all proportions; insoluble in alcohol or ether. Its solution diffuses readily : it is unaffected by heat; and, when acidulated with acetic acid, is not precipitated by ferrocyanide of potassium. It is precipitated by tannin bases, by lead acetate, and by solution of $\mathrm{Hg} \mathrm{I}_{2}$ in iodide of potassium.

\section{Secretion of Bile.}

Human bile contains Io per cent. of solids, of which about 4 per cent. is bilin, $\mathrm{I} I / 2$ per cent. fat, 2 per cent. mucus and colouring matter, I to 2 per cent. alkaline soaps, I per cent. salts. It is believed that about two pounds of bile are secreted daily. The density of bile differs according to the mode of collection and the time of secretion. Bilin and fat originate, along with other bodies, from proteid in the living substance of the liver cells. The colouring matter is derived from that of the blood. The mucin is secreted by the mucous membrane of the gall bladder. In the intestines the bilin is decomposed under the influence of septic ferment organisms: glycin and taurin are absorbed, and either return to their source, or may take part in the production of such bodies as hippuric acid, and tauro-carbamic acid, which appear in the urine; cholalic acid is in great part lost in the fæces. The fats and soaps are absorbed. The colouring matter is transformed by reduction into a body having the characters of hydrobilirubin.

In intestinal digestion the bile is antiseptic, and there is reason to believe that it also promotes the absorption of fat.

Nothing is as yet known as to the influence of the nervous system on the secretion of bile.

\section{BILIN.}

Bilin (or Bile crystals), as obtained from ox bile, consists chiefly of sodic glycocholate $\left(\mathrm{C}_{26} \mathrm{H}_{42} \mathrm{Na} \quad \mathrm{NO}_{6}\right)$, with a much smaller proportion of taurocholate $\left(\mathrm{C}_{26} \mathrm{H}_{44} \mathrm{Na}^{\mathrm{NO}} \mathrm{N}_{7} \mathrm{~S}\right)$. Bilin of dogs' bile consists exclusively of taurocholate. These soap-like bodies crystallize from the alcoholic solution 
of the dry residue of ox bile on the addition of ether. The crystals are very soluble in water and have the peculiar bitter sweetness of bile. The solution is dextrorotatory. With concentrated sulphuric acid it becomes resinous and yields after a time a yellow liquid having a green fluorescence. If, after adding a trace of cane-sugar, a liquid containing bilin is mixed with sulphuric acid and kept at a temperature between $50^{\circ} \mathrm{C}$. and $60 \% \mathrm{C}$, , a purplish violet solution is obtained, which shows before the spectroscope an absorption band at $\mathrm{E}$ and another near F. Solution of ox-bile crystals is precipitated by the addition of neutral acetate of lead. The heavy precipitate consists of lead glycocholate. By treating its solution in hot alcohol with sulphuretted hydrogen, filtering and adding water to the filtrate, glycocholic acid $\left(\mathrm{C}_{26} \mathrm{H}_{43}\right.$ $\mathrm{NO}_{6}$ ) is obtained as a resinous precipitate. Glycocholic acid is sparingly soluble in water, readily in hot alcohol, from which it crystallizes. When it is boiled with strong hydrochloric acid it is converted into a soluble compound of hydrochloric acid and glycocoll, which is very soluble in water, and a resinous product, often called bile-resin, consisting of cholalic acid and dyslysin (see Cholalic Acid). When the liquid from which the lead glycocholate has been precipitated is treated with basic lead acetate, with the addition of ammonia, a second precipitate is obtained of lead taurocholate. By suspending the lead precipitate of dogs' bile in alcohol, decomposing it with $\mathrm{H}_{2} \mathrm{~S}$, filtering, concentrating the filtrate, taurocholic acid $\left(\mathrm{C}_{25} \mathrm{H}_{45} \mathrm{NO}_{7} \mathrm{~S}\right)$ is obtained in solution. On the addition of ether a syrupy precipitate is formed, which afterwards crystallizes. It differs from glycocholic acid in being excessively soluble in water, and splitting much more readily into cholalic acid and taurin, than glycocholic acid does into cholalic acid and glycocoll.

Glycocoll, Glycin or Gelatin-sugar $\left(\mathrm{C}_{2} \mathrm{H}_{5} \mathrm{NO}_{2}\right.$ or (as Amido-acetic acid) $\mathrm{C}_{2}$ $\left.\mathrm{H}_{3}\left(\mathrm{NH}_{2}\right) \mathrm{O}_{2}\right)$ is obtained from glycocholic acid by prolonged boiling with strong hydrochloric acid. The firm resin which is formed consists of cholalic acid and dyslysin (see Cholalic Acid); this having been separated, the remaining liquid yields on evaporation glycocoll-hydrochlorate $\left(\mathrm{C}_{2} \mathrm{H}_{5} \mathrm{NO}_{2}, \mathrm{H}\right.$ $\mathrm{Cl}$ ). From the aqueous solution of this substance glycocoll is obtained by treating it with hydrate of lead oxide and then decomposing the soluble lead glycocoll, after separating the chloride, with sulphuretted hydrogen. Glycocoll is soluble in five parts of cold water, and insoluble in absolute alcohol and ether. It crystallizes from hot dilute alcohol in hard rhombohedral crystals. Its solution in water has an acid reaction and sweetish taste. It is called "gelatin-sugar" because, along with the body Leucin, it is a product which is obtained when gelatin is acted on by sulphuric acid. Glycocoll has been obtained synthetically by the action of monochloracetic acid on ammonia. $\left(\mathrm{C}_{2} \mathrm{H}_{3} \mathrm{Cl} \mathrm{O}_{2}+\mathrm{NH}_{3}=\mathrm{HCl}+\mathrm{C}_{2} \mathrm{H}_{3}\left(\mathrm{NH}_{2}\right) \mathrm{O}_{2}\right.$. $)$

Taurin $\left(\mathrm{C}_{2} \mathrm{H}_{7} \mathrm{NSO}_{3}\right)$ is best obtained from the bile of the dog, in which the whole of the bilin consists of taurocholate. By boiling bilin with hydrochloric acid, separating the resin and evaporating the acid liquid, a residue is obtained from which (after the glycocoll-hydrochlorate has been removed by extracting it with absolute alcohol), taurin can be procured by treating it with boiling water. Taurin is soluble in fifteen parts of cold, and very soluble in hot water, sparingly in cold alcohol. It crystallizes very readily in large 4- or 6-sided shining prisms, each of which ends in a 4-sided pyramid. The 
constitution of taurin can be best understood by remembering how it is obtained synthetically, viz., by subjecting ammonic isethionate $\left(\mathrm{NH}_{4}, \mathrm{C}_{2} \mathrm{H}_{5}\right.$, $\mathrm{SO}_{4}$ ) to a high temperature, in consequence of which it loses the elements of a molecule of water. Neither the origin nor the destiny of Taurin in the organism is known. It was, until lately, supposed that it was represented in the urine by sulphates, and that its amide took part in the constitution of urea; but it has been recently proved experimentally that when dogs are fed with Taurin, that hody leaves the organism partly as such, but chiefly in the form of Tauro-carbamic acid $\left(\mathrm{C}_{3} \mathrm{H}_{8} \mathrm{~N}_{2} \mathrm{O}_{4}\right)$.

Cholalic Acid $\left(\mathrm{C}_{24} \mathrm{H}_{40} \mathrm{O}_{5}\right)$ is insoluble in water, very soluble in alcohol, sparingly in ether. It crystallizes from its solution in dilute alcohol, in tetrahedra or octahedra, which, at first transparent, soon become opaque on exposure. At high temperatures, it loses $\mathrm{H}_{2} \mathrm{O}$ and yields dyslysin $\left(\mathrm{C}_{24} \mathrm{H}_{66}\right.$ $\mathrm{O}_{3}$ ) and undergoes a similar change when boiled with hydrochloric acid. It is contained in decomposed bile as alkaline cholalate, and is precipitated therefrom on the addition of acetic acid. From this precipitate it can be extracted by alcohol.

Bilirubin (Cholepyrrhin $\mathrm{C}_{32} \mathrm{H}_{36} \mathrm{~N}_{4} \mathrm{O}_{6}$ ) can be obtained directly from human bile, or from that of the dog by shaking it with chloroform. On separating the solution thus obtained from the bile and then distilling off the chloroform, a pitchy residue is left, which, after it has been exhausted by alcohol, is found to contain crystals of bilirubin. The alcohol contains cholesterin and a brown colouring matter which has been called bilifuscin. Bilirubin is a principal constituent of biliary calculi ; powdered gall stone is first extracted with ether to remove the cholesterin, and then treated with dilute hydrochloric acid and washed : the residue yields, when treated with chloroform, a yellowish-brown solution, from which bilirubin is precipitated on the addition of alcohol, or crystallizes on evaporation, in red needles. It is insoluble in water, nearly insoluble in boiling alcohol and in ether, more soluble in bisulphuret of carbon, and most of all in chloroform. Its solution shows no absorption bands. It further dissolves readily in potash or soda, and when the alkaline solution is exposed to air, it gradually becomes green, and gives, when treated with hydrochloric acid, a green precipitate (biliverdin), which is insoluble in chloroform but soluble in alcohol. Bilirubin, in dilute alkaline solution, when acted on by sodium-amalgam, yields Maly's Hydro-bilimebin, a red body insoluble in water, of which the solution in absolute alcohol shows before the spectroscope a broad absorption band, between E and F. It is supposed by its discoverer to be identical with the colouring matter of fæces (stercobolin) and with the urobilin of Jaffe, from both of which, however, it differs in some particulars. The physiological origin and destiny of the colouring matter in the bile is known. It has been observed that when crystalline hæmoglobin in solution is injected into the circulation, the rate at which colouring matter is secreted by the liver increases enormously, and that bile pigment appears in the urine. In the intestines most of the bilirubin secreted is converted into stercobilin and discharged, but the chemical relations between it and the excreted colouring matters are as yet uncertain. Liquids which contain bilirubin change colour on the addition of nitric acid containing a trace of nitrous acid : at first green, the colour passes through blue, violet and red, finally fading into 
yellow (see Practical Part, Section VI.). During the change the liquid shows, when examined spectroscopically, first two absorption bands near the line $\mathrm{D}$, which are due to the blue colour (cholecyanin), and subsequently a single band between $\mathrm{b}$ and $\mathrm{F}$, referable to the yellowish red colour (Jaffe's choletelin). Bilirubin, or a body undistinguishable from it, occurs in tissues in which blood has been extravasated in rhombohedral crystals (called Hæmatoidin).

Biliverdin $\left(\mathrm{C}_{32} \mathrm{H}_{36} \mathrm{~N}_{4} \mathrm{O}_{8}\right)$ occurs along with bilirubin in the bile of man and many animals, especially in those of which the bile is green. Its relative quantity increases in inanition. Both colouring matters are met with in the placenta of the bitch.

\section{Intestinal Digestion.}

Pancreatic juice is an alkaline liquid resembling saliva. It is, however, of greater density, and probably contains no globulin. It owes its activity to two ferments-a diastatic and a peptic-both of which are contained in the precipitate which is thrown down when pancreatic juice is treated with alcohol. They can be extracted either from the gland itself (Hüfner) or from the precipitate (v. Wittich) by glycerine. From either extract a substance is precipitated by alcohol, which, at the temperature of the body, digests fibrin and other albuminous bodies in alkaline liquids, and acts diastatically on starch. This substance is called Pancreatin. It contains a proteid body, to which the name Trypsin has been given by Kühne, and to which its peptic property appears to attach itself. From the glycerine extract a substance containing the ferments is precipitated by alcohol. Pancreatic juice emulsionizes and decomposes neutral fats.

It has lately been proved (Heidenhain) that the cellsubstance of the living pancreas is inert, but acquires peptic activity by keeping, and more rapidly when acted on by dilute acids.

Proteids, subjected to pancreatic digestion, split into two products, viz., a body having globulin properties, and a peptone. The former passes into a peptone (called by Kühne antipeptone), which undergoes no further change 
in the intestine; the latter is decomposed, yielding leucin and tyrosin and other products.

Simultaneously with the changes which are due to the action of the pancreatic ferments, others go on which are associated with the development in the liquid of septic organisms (bacteria), and with the disengagement of offensive odours. These are the production of volatile bodies, Indol and Skatol, the disengagement of $\mathrm{CO}_{2}$ and $\mathrm{CH}_{4}$ from the decomposition of certain carbohydrates, of $\mathrm{H}$ from butyric acid fermentation, \&c. The products of pancreatic digestion of proteids are also incidents of the septic decomposition of the same bodies, but the former process is distinguished from the latter by its great rapidity.

The liquid which is obtained when raw fibrin is digested for a few hours, or at the proper temperature with pancreatic juice or solution of pancreatin, contains, after it has been freed from undissolved residue, besides common albumin, alkali-albuminate and peptones, crystalline organic bodies, of which the most important are Leucin and Tyrosin. To obtain them, the albumin is first got rid of by slightly acidulating the liquid, boiling and filtering. The filtrate is then reduced to a small bulk by evaporation, and heated with strong alcohol to precipitate the peptone. On again filtering, an extract is obtained in which, if left to itself, Leucin and Tyrosin crystallize.

Leucin $\left(\mathrm{C}_{6} \mathrm{H}_{13} \mathrm{NO}_{2}\right)$, when pure, crystallizes in colourless pearly scales, which sublime in flocks at $170^{\circ} \mathrm{C}$. like oxide of zinc. In impure solution it forms spheroidal clumps, which, under the microscope, are seen to be made up of round grains, each of which consists of fine needles radiating from a centre. Tyrosin crystallizes, on cooling from its solution in boiling water, in bunches or stellate groups of long slender needles; it does not sublime when heated.

Leucin is soluble in 27 parts of cold water and in hot alcohol. Tyrosin requires 150 parts of hot water to dissolve it. In boiling alcohol Lęucin dissolves, Tyrosin remains, so that by means of it the two bodies can be separated from each other. Leucin, when heated in a sealed tube with fuming hydriodic acid, yields ammonic iodide and caproic acid, and is therefore regarded as amido-caproic acid $\left(\mathrm{C}_{6} \mathrm{H}_{13} \mathrm{NO}_{2}+3 \mathrm{HI}=\mathrm{C}_{6} \mathrm{H}_{12} \mathrm{O}_{2}+\mathrm{NH}_{4}\right.$ $\mathrm{I}+2 \mathrm{I})$. Tyrosin $\left(\mathrm{C}_{9} \mathrm{H}_{11} \mathrm{NO}_{3}\right)$, when acted on in the same way, yields a body $\left(\mathrm{C}_{9} \mathrm{H}_{10} \mathrm{O}_{3}\right)$ which may be regarded as oxyphenylpropionic acid, having ammonic iodide and iödine. The physiological destiny of Leucin is unknown. As regards Tyrosin, the recent researches of Kïssner have shown that when it is introduced into the circulation it reappears in the urine as such : it cannot therefore be regarded as a step in the production of urea. 
Indol $\left(\mathrm{C}_{6} \mathrm{H}_{7} \mathrm{~N}\right)$ is obtained by digesting large quantities of albumin with ox-pancreas and distilling the product. The distillate contains Indol, which may be separated from it by agitating it with its bulk of ether. Indol fuses at $52^{\circ} \mathrm{C}$. and boils at $245^{\circ} \mathrm{C}$. It is soluble in water, and crystallizes from its solution in shining plates. When introduced into the circulating blood or alimentary canal, an "indigo-producing substance" appears in the urine. It exists, under normal circumstances, in extremely small quantity in the intestinal contents.

Skatol, a crystallizable body of offensive odour, resembling Indol, has been lately discovered by Brieger as a constituent of human fæces. It has also been shown that Phenol (Carbolic Acid, $\mathrm{C}_{6} \mathrm{H}_{51} \mathrm{OH}$ ) is constantly present in fæces.

An alkaline liquid, called Succus entericus, of low specific gravity, is secreted by the mucous membrane of the small intestine. Its digestive properties are as yet uncertain.

\section{Glycogen.}

Glycogen, or animal starch, is under normal conditions always present in the living cell-substance of the liver; in inanition it gradually disappears; it is present in the livers of animals fed exclusively on flesh. The glycogen of the liver increases after each period of digestion. Its quantity is in general determined by the quantity of dextrose-producing material or of lactose in the food, so that these sugars are the normal but not the only source of glycogen. The processes by which glycogen disappears from the liver in inanition, and by which it is normally disintegrated in the animal organism, are not known. After death, the glycogen of the liver is converted into dextrose under the influence of a diastatic ferment.

Glycogen or animal starih is soluble in water, yielding an opalescent solution. It is coloured brown or reddish-brown by iodine. Glycogen is obtained in quantity, by throwing the rapidly comminuted liver of an animal just killed, during the period of greatest digestive activity of the organ, into boiling water slightly acidulated with acetic acid. From the pale yellow filtered and concentrated extract, glycogen is precipitated by the addition of alcohol. 


\section{Intestinal Absorption.}

In intestinal absorption the dissolved constituents are absorbed by the blood stream, the particulate by the lacteals. The proteids of chyle are absorbed partly as peptone, partly as alkali-albuminate. They enter the circulation both by the veins and lacteals, but it cannot be stated in what proportion. It is not known whether coagulable albumin is absorbed or not.

There is reason to believe that most of the dextrose into which all carbohydrates are converted in digestion is absorbed by the veins, but direct evidence is wanting : the remainder undergoes the lactic acid fermentation in the intestine.

The fats are absorbed both as glycerides in the state of emulsion, and as alkaline soaps and glycerine. The absorption of water, in consequence of which the intestinal content becomes more and more concentrated as it advances, takes place by the capillaries, and is mainly due to "diffusion." Consequently it may be diminished or reversed by the presence in the intestinal liquid of salts of high "osmotic equivalent."

Fæces consist of insoluble residues of food and bile, and of insoluble salts; particularly calcic, magnesic, and ammonio-magnesic phosphates. They yield certain gases, viz., $\mathrm{CO}_{2}$, marsh gas and a trace of sulphuretted hydrogen. In human excrement a crystalline body called excretin occurs.

Diffusion of liquids. - When two liquids (of which one $\mathrm{A}$ is water, the other $\mathrm{B}$ a solution) are separated by a membrane, an exchange takes place between them through the membrane. So long as the two liquids remain unaltered (as would be the case if the liquid on either side of the membrane were con. tinually replaced by fresh of the same quality) the relation between the weight of water which passes from $A$ to $B$, and of the body in solution which passes from $\mathrm{B}$ to $\mathrm{A}$, is constant. This relation is called the osmotic equivalent. If $\mathrm{B}$ holds $\mathrm{NaCl}$ in solution, the former is greater than the latter, and the equivalent is said to be positive; if $\mathrm{HCl}$, it is less, and the equivalent is said to be negative. 
BLOOD.

Blood is an opaque fluid mass, each cubic millimeter of which contains some five millions of corpuscles floating in an alkaline liquid. Of these about one in 400 are colourless. In circulating blood the corpuscles are equally distributed. Out of the living body, blood coagulates, that is, separates into clot and serum; or, if coagulation is prevented by a freezing temperature, into corpuscles and plasma. If blood is agitated before coagulation, the fibrin is collected on the agitating surfaces, and thus separated from the cruor. The coagulum varies in character according to the number of corpuscles, the time occupied, and the form of the recipient. It consists essentially in the concretion of the plasma into a felt-work of transparent fibres, each of which is scarcely a micromillimeter in width, and shortens immediately after it is formed. In the circulating blood coagulation is prevented by the influence upon it of the living tissues, with which it is in relation. If blood is received into non-contaminated vessels, coagulation is delayed or prevented. It is not dependent on the access or escape of any gas or vapour. It is indefinitely deferred at $0^{\circ} \mathrm{C}$., most accelerated at $40^{\circ} \mathrm{C}$. By subsidence at about $6^{\circ} \mathrm{C}$. blood separates into plasma and corpuscles, of which the weights in normal human blood are nearly equal. It contains three albuminous substances, viž.: (I) common albumin ; (2) a little alkali-albumin; and (3) the substance which becomes fibrin. Plasma coagulates at ordinary temperatures, becoming gelatinous if diluted, yielding a fim clot of fibrin if concentrated. The substance which thus assumes the solid form is called, in its dissolved state, plasmin, or the substratum of coagulation. It has the properties of a globulin. Two kinds of globulin exist in the plasma, one, named fibrinogen, in very small quantity ( $0^{3} 3$ per cent.), which disappears in the act of coagulation; the other, which is much more abundant, and may consti- 
tute, according to recent researches, more than a third of the total weight of proteid.

Serum albumin is soluble in water, and is not precipitated either by dilute acids, by alkaline carbonates, or by $\mathrm{NaCl}$. As it exists in the blood, it is precipitated by boiling or by addition of alcohol. It is lævorotatory, and differs from albumin of egg, in not being coagulated by ether, and in being more soluble in $\mathrm{HCl}$. Serum albumin can be separated from the soluble salts, which are present in the serum, by prolonged diffusion with water. In this state, however, its properties are altered; it is neither coagulated by heat, nor precipitated by alcohol.

Globulins. - The globulins are distinguished from common serum albumin by the fact that while insoluble in concentrated solutions of neutral salts, particularly $\mathrm{NaCl}$ and $\mathrm{MgSO}_{4}$ and in distilled water, they are soluble in weak solutions : they are also soluble in dilute alkalies. They are all coagulable by heat, but at different temperatures.

Paraglobulin is the precipitate produced in serum by saturating it with $\mathrm{NaCl}$ or $\mathrm{MgSO}_{4}$, or by diluting it and then neutralizing with acetic acid, or by passing through it a current of $\mathrm{CO}_{2}$. This precipitate is soluble in one per cent. solution of $\mathrm{NaCl}$ and coagulates at $73^{\circ} \mathrm{C}$. It is contained, along with serum albumin, in all the tissues and liquids of the body.

Fibrinogen is distinguished from paraglobulin by the greater difficulty with which it is precipitated by dilution in neutral solution. It is contained in all the coagulable liquids. Its solution in $\mathrm{NaCl}$ is coagulated by heat at $55^{\circ} \mathrm{C}$. (Hammarsten).

Fibrin differs from fibrinogen in its filamentous structure, and its solubility in dilute $\mathrm{NaCl}$ solution. Like myosin, it is soluble in strong solutions of $\mathrm{NaCl}$, but with great difficulty: the solution coagulates at about $60^{\circ} \mathrm{C}$. It is convertible with difficulty by acids or by alkalies into albuminate. Crude fibrin decomposes solution of $\mathrm{H}_{2} \mathrm{O}_{2}$ : it is converted by boiling into a body resembling coagulated albumin.

The liquids contained in uninflamed serous cavities, which coagulate imperfectly (pericardial fluid) or not at all (hydrocele fluid), also contain both forms of globulin. These liquids for the most part coagulate on the addition of serum. Their percentage of fibrin-yielding material is, however, small.

From blood which has been a short time withdrawn from the circulation a ferment-like substance can be prepared, the solution of which, although it contains no globulin, promotes the coagulation of coagulable fluids.

In coagulation many of the colourless corpuscles of the 
blood undergo disintegration: it is believed that they take an important part in the process, and even contribute the material out of which fibrin is formed. They appear also to be the source of the ferment above mentioned, for plasma filtered at a few degrees above $0^{\circ} \mathrm{C}$. loses its power of coagulating at ordinary temperatures: this power is restored to it by the addition of a ferment, but the quantity of fibrin obtained is less than that yielded by unfiltered plasma.

The Plasma of blood contains about 0.5 per cent. of the total blood-weight of soluble salts, of which between 0.3 and $0^{\circ} 4$ is sodic chloride, and about $O^{\circ}$ I sodic phosphate, the remainder consisting chiefly of sodic carbonates. The insoluble calcic and magnesic phosphates, of which plasma contains about 0.04 per cent. of the blood-weight, are held in solution by combination with albumin. Serum also contains a trace of sulphates.

Serum, i.e., plasma which has been deprived of its plasmin by coagulation, differs from plasma in the absence of fibrinogen. It contains serum-albumin, paraglobulin, and probably alkali-albuminate, besides salts and extractive. The whole of the proteid of serum (albumin and globulin), with the exception of a trace of albuminate, is separated by heat at about $73^{\circ} \mathrm{C}$. It is also precipitated by alcohol and by strong mineral acids.

Plasma contains oxygen and nitrogen in about the proportion in which these gases are severally found in water. It contains somewhat more free $\mathrm{CO}_{2}$ than the serum would absorb if it were so much water.

Blood-disks.-The coloured blood-corpuscles consist of stroma and hæmoglobin. They constitute about a third of the weight of the blood, and contain about 43 per cent. of solids, and 39 per cent. of hæmoglobin. The stroma is made up for the most part of substances soluble in ether, viz., lecithin and cholesterin, and of globulins resembling those of plasma. The blood-corpuscles also 
contain inorganic salts, which differ from those of the plasma, in the replacement of sodium by potassium.

The body of the corpuscles consists chiefly of globulins associated with lecithin and cholesterin. The globulin is of two kinds, the greater part resembling paraglobulin, the remainder having the characters of myosin. The colourless corpuscles also contain glycogen, and are, like the coloured corpuscles, relatively rich in potassic salts. The nuclei contain a non-crystallizable nitrogenous body (nuclein-not a proteid) which is insoluble in weak acids, and hence in gastric juice, but dissolves very readily in weak alkalies. The chemical relations of this substance are as yet unknown. It is found in all nuclear structures, e.g., in spermatozoids. The "protoplasm" of the colourless corpuscles consists chiefly of globulin associated with lecithin and cholesterin. It contains glycogen.

In normal blood, hæmoglobin exists only in the corpuscles, but in certain diseased states it is dissolved in the plasma and is then crystallizable: the nature of the change it undergoes is not known. A similar change is produced artificially by repeated freezing and thawing, by subjecting blood to a temperature of $60^{\circ} \mathrm{C}$., or by the action of ether or chloroform. The property which the blood possesses of absorbing oxygen from the inspired air, and of giving it up to the living tissues with which it is brought into contact in the circulation, is due to its hæmoglobin.

Hamoglobin crystallizes from its solution, in forms which vary according to the animal from which it is derived. The crystals are of the colour of arterial blood, but become dark, without changing their form, when placed in vacuo at a low temperature. They then exhibit two colours, looking green along the edges, purplish-red elsewhere : on the admission of air or oxygen, the colour is restored.

Hæmoglobin is very soluble in warm water, much less so in cold, but, in this respect, crystals obtained from different animals differ : thus, the hæmoglobin of the rat or guinea-pig is less soluble than that of man, and is much more prone to crystallize. 
Hrmoglobin contains $\frac{1}{2 \frac{3}{8}}$ of its weight of iron. Solution of hæmoglobin exhibits before the spectroscope characteristic absorption bands. Very dilute solution shows one band to the blue side of the D line; if the solution is stronger, a second band appears to the red side of the $\mathrm{E}$ line; by still more concentrated liquids, the blue and violet rays are entirely absorbed, while the two bands become confluent.

When blood is allowed to stand at ordinary temperatures, its hæmoglobin is soon decomposed, yielding hæmatin, a proteid body, and other products. The same thing happens much more rapidly when solution of hæmoglobiu is acted on by alkalies, in which case hæmatin and alkali-albuminates are formed. In presence of weak acids, hæmoglobin yields hæmatoin (so-called "acid hæmatin ") and acid albuminate.

Hamatin $\left(\mathrm{C}_{32} \mathrm{H}_{34} \mathrm{~N}_{4} \mathrm{Fe} \mathrm{O}_{5}\right)$ is obtained when weak potash solution acts on blood or solution of hæmoglobin with access of air. On neutralizing, solid hæmatin is precipitated. It is insoluble in water, alcohol, and ether, and uncrystallizable.

The absorption spectrum of hæmatin presents a broad band to the red side of the D line. After reduction by alkaline sulphides it shows two characteristic bands, one in the yellow, the other in the green part of the spectrum. When dried blood is warmed with glacial acetic acid, it yields crystals of hamin (hæmatin $+\mathrm{HCl}$ ).

Solution of hæmoglobin associates nitric oxide and carbonic oxide in the same volume as oxygen. When oxygenated solution of hæmoglobin or of blood is acted on by carbonic oxide, its associated oxygen is replaced by that gas. The solution acquires a colour which closely resembles that of arterial blood, but is not affected by reducing agents.

The quantity of oxygen yielded to the barometer vacuum by any quantity of aerated defibrinated blood is equal to the quantity associated by the hæmoglobin contained in the blood, plus the quantity absorbed by the plasma; (hence for every 5 centigrammes of iron $18 \% 7$ cubic centimeters of oxygen at $0^{\circ}$ and $760 \mathrm{~m} . \mathrm{m}$.) In ordinary arterial blood the yield of oxygen is a little less. Arterial blood at $40^{\circ}$ yields about 40 per cent. of its volume of $\mathrm{CO}_{2}$, as measured at $0^{\circ}$ and $760 \mathrm{~m} . \mathrm{m}$. The alkaline carbonates are decomposed in the vacuum without the addition of an acid. The human body contains about ${ }_{1}^{\frac{1}{4}}$ of its weight of blood.

In the examination of blood for clinical purposes, it is chiefly important to determine the percentage of hæmoglobin and the alkaline reaction. 
Arterial blood becomes venous by contact with living protoplasm. Venous blood is distinguished from arterial by its crimson colour, its slight dichroism, the less proportion of oxygen which is associated with its hæmoglobin, its large proportion of combined $\mathrm{CO}_{2}$, its less proneness to coagulation, and by containing fewer blood-corpuscles. Venous blood differs somewhat in composition according to its source. As compared with ordinary venous blood, that of the hepatic vein contains less albumin and more extractives (e.g., urea and grape-sugar). In that of the splenic vein, also, differences exist, which indicate that in this organ the coloured blood-corpuscles are disintegrated, and colourless corpuscles formed.

\section{The Spleen.}

The following are the facts best ascertained as to the spleen-pulp, and the blood which flows from it:-

The spleen-pulp contains much hæmoglobin, to which the richness of its ash in iron is due (Malassez). The aqueous extract of spleen-pulp contains uric acid, and the allied body hypoxanthin, in quantities which, although very small, are larger than those met with in any other tissue (Strecker). The splenic blood contains fewer blooddisks and more colourless corpuscles than the blood of any other organ. There exist in the spleen structures which are destined to become colourless corpuscles. It also contains structures which are concerned in the breaking up of blood-disks, and are the sources of the pigment with which the pulp is provided. The enlargement of the spleen which takes place a few hours after every considerable meal, is chiefly if not entirely due to vascular dilatation (Mosler). 


\section{LYMPH.}

Lymph or tissue juice resembles blood in being coagulable and in containing colourless corpuscles. It differs from it in being of lower specific gravity, in the tardiness with which it coagulates, in the absence of blood-disks, and consequently of hiemoglobin, and in its containing relatively to its weight less proteid, more urea and other extractives, more sodic carbonates, and in yielding to the mercurial vacuum more $\mathrm{CO}_{2}$. Its corpuscles are derived partly from the tissues, but chiefly from the lymphatic glands.

Chyle differs from lymph chiefly in respect of the larger proportion of fat (about I per cent.) which is present in it. Each of the minute granules to which chyle owes its opacity consists of a fat particle enclosed in an envelope of proteid.

\section{Chemical Process of Respiration.}

In respiration each quantity of air respired undergoes the following changes:-Its oxygen is diminished by about a quarter, viz., from $2 \mathrm{I}$ per cent. to $\mathrm{I} 6$ per cent. Its $\mathrm{CO}_{2}$ is increased a hundred-fold, viz., from about 0.04 per cent. to over 4 per cent. It becomes nearly saturated with moisture. It acquires nearly the temperature of the body. It becomes more or less charged with organic impurity, acquiring thereby a peculiar smell. Its volume is diminished by $\frac{1}{2} \frac{1}{50}$ or thereabouts. Its weight is increased in proportion to the weight of $\mathrm{CO}_{2}$ discharged.

The percentage of $\mathrm{CO}_{2}$ is dependent on the length of time that the expired air has remained in the respiratory cavity. (It can be increased by voluntary retention to 7.5 per cent.) Consequently, as the frequency of respiration increases the percentage diminishes, though the total discharge increases. 
Example :-

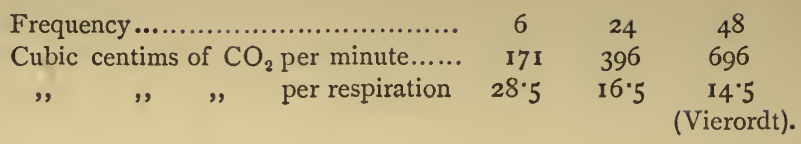

The frequency remaining the same, the $\mathrm{CO}_{2}$ increases with the amplitude of the respirations.

Example :-

Frequency-I 2 respirations per minute.

$\begin{array}{cccc}\text { Amplitude. } & \mathrm{CO}_{2} \text { per min. (c.c.) } & \text { Percentage. } & \\ 3 \text { Litres } & \text { I62 } & 5^{\circ} 4 & \\ 6 \quad " & 240 & 4^{\circ} 5 & \\ \text { I2 } & 480 & 4^{\circ} 0 & \\ 24, & 816 & 3^{\circ} 4 & \text { (Vierordt). }\end{array}$

In the compressed air chamber the respirations become more ample and the $\mathrm{CO}_{2}$ discharge increases.

Respiratory exchange of gases. - If a liquid is exposed to a gas, the former absorbs the latter until equilibrium is established. As soon as this is the case the tension of the gas in the liquid is said to be equal to its tension outside of it. If a liquid is exposed to a gaseous mixture, the absorption of each gas takes place as if there were no other. If a very small volume of a gaseous mixture is exposed to an indefinitely large volume of a liquid containing gases, the latter will be absorbed from, or given off into the former until the tension of each gas in the mixture is equal to its tension in the liquid. When in this experiment the liquid is the circulating blood, and the mixture atmospheric air, the oxygen of the latter diminishes, for the tension of oxygen in such blood scarcely amounts to 30 millimeters $\left(=\frac{1}{2}\right.$ atmosphere), while the $\mathrm{CO}_{2}$ increases until its tension amounts to about 40 millimeters.

The tension of carbonic acid in the air contained in the air cells is so little inferior to that of ordinary venous blood, that the discharge of $\mathrm{CO}_{2}$ would probably be in 
sufficient, unless the $\mathrm{CO}_{2}$ tension were greater in the pulmonary capillaries than anywhere else in the circulation. The nature of the agency by which this is brought about is indicated by the fact that the addition of oxygenated hæmoglobin to serum in vacuo decomposes its carbonates, setting free $\mathrm{CO}_{2}$, so that venous blood yields more $\mathrm{CO}_{2}$ to oxygen than to the barometer vacuum. Consequently the discharge of $\mathrm{CO}_{2}$ in pulmonary respiration is directly promoted by the absorption of oxygen.

Respiration can be maintained without difficulty in an atmosphere which contains much less than the normal proportion of oxygen, so that an animal supplied with a limited quantity of air continues to breathe in it until it has used all but a fraction of the oxygen it contains.

The process by which the circulating blood gives oxygen to the living protoplasm with which it comes into relation in the capillary blood-vessels, and receives $\mathrm{CO}_{2}$, is often called "internal respiration." The existence of such an exchange of gases in the tissues is proved by the observation that venous blood differs, in the proportion of oxygen and $\mathrm{CO}_{2}$ which it contains, according to the tissue through which it has circulated.

The separation of $\mathrm{CO}_{2}$ by protoplasm, and the absorption of oxygen, are distinct and independent processes, and do not go on pari passu. The former is variable; its variations are dependent on the functional activity of the tissue; the latter is constant and is associated with restitution. The independence of the two processes is proved (I) as regards muscular tissue, by the observation that muscle which has been entirely deprived of oxygen can be thrown into functional activity (i.e., contraction) without receiving any supply, and that in contracting it gives off $\mathrm{CO}_{2}$ (Hermann) ; and (2) as regards the entire organism, by the observation that a frog, if kept at a low temperature, continues to discharge $\mathrm{CO}_{2}$ at nearly the normal rate, in an atmosphere of pure nitrogen (Pflüger). 
In the investigation of the chemical process of respiration in man or the lower animals, three quantities are to be determined, viz., the discharge of $\mathrm{CO}_{2}$, the absorption of oxygen, and the discharge of water. In the most complete methods (e.g., that of Régnault and Reiset) all three are determined. In Pettenkofer's method, the $\mathrm{CO}_{2}$ and $\mathrm{H}_{2} \mathrm{O}$ discharge only are determined; but the method has the advantage of being applicable to large animals and to man.

\section{URINE.}

The average daily discharge of urine of an adult male on full diet is 1500 grammes, containing about 36 grammes of urea, 0.7 gramme of uric acid, I6 grammes of sodic chloride, and about 6 grammes of other inorganic salts, besides colouring matter and other organic constituents. Hence urine contains about $4^{\circ} \mathrm{O}$ per cent. of solids, including 2.4 per cent. of urea. Its acidity is equal to that of a 0.2 per cent. solution of oxalic acid.

The salts of the urine are, common salt, potassic chloride, sudic, calcic, and magnesic phosphates; and sodic and potassic sulphates. The discharge of sodic chloride varies with the store of chlorine in the body. It is markedly diminished by abnormal transudation of blood plasma.

The discharge of alkaline phosphates also varies with the quantity stored in the blood plasma ; that of earthy phosphates with the disintegration of proteids of food. Hyposulphites and sulphates occur in the urine as results of a process of oxidation which has its seat in the kidneys, for sulphates are met with only in traces in the blood or tissues. Of the two alkaline bases about 8 grammes (reckoned as potash and soda) are discharged daily, the soda constituting a little more than half. In fever and all conditions attended with increased disintegration of tissue or blood-corpuscles, the proportion of potash is larger. If carbonates exist in the urine they are derived from the oxidation of vegetable acids used as food. 
Urine, if uncontaminated, may be kept for an indefinite period without any change, excepting that its acidity and colour increase slightly soon after it is passed (acid fermentation). Under ordinary circumstances urine becomes eventually alkaline when kept, in consequence of the production of ammonic carbonate. This change takes place rapidly in presence of a ferment which exists in the urine in certain pathological conditions. The alkaline fermentation is attended by the formation of triple phosphate.

It is by the discharge of urea that the rate at which nitrogen is discharged from the organism is estimated. Thus we learn that the discharge of nitrogen is subject to regular diurnal variations; that it is largest when food is albuminous and abundant; that it is diminished rapidly by inanition, gradually by a diet containing a large proportion of carbonic hydrates; that it is increased by ingestion of water, sodic chloride, and ammonium salts, and that it is very slightly augmented by muscular exercises.

Urea exists in all the animal liquids, and in most tissues, excepting the muscular and nervous, in a proportion not exceeding 0.03 per cent. This proportion is increased by any interference with the renal excretion. Urea is a direct product of the life of protoplasm. It is not as yet proved that it is more actively produced in the liver than elsewhere.

\section{Crystalline Organic Bodies of the Urine.}

Urea or Carbamide $\left(\mathrm{CO}\left(\mathrm{NH}_{2}\right)_{2}\right)$ exists as such in urine-so abundantly in that of the carnivora, that it crystallizes therefrom on evaporation. In human urine it can be crystallized from the alcoholic extract of the dry residue. Urea $(U)$ is excessively soluble in water, soluble in alcohol, insoluble in ether; it is isomeric with ammonic cyanate $\left(\mathrm{NH}_{4} \mathrm{CNO}\right)$; takes up water in contact with certain ferments, and is transformed into normal ammonic carbonate $\left(\mathrm{CO}\left(\mathrm{NH}_{2}\right)_{2}+2 \mathrm{H}_{2} \mathrm{O}=\mathrm{CO}_{3}\left(\mathrm{NH}_{4}\right)_{2}\right)$. A corresponding change occurs when $\mathrm{U}$ is acted on by alkalies or by strong sulphuric acid, ammonia being given off in the former case, carbonic anhydride in the latter. On the addition of nitric acid to strong solution of $U$, a snow-white precipitate is formed of Urea-nitrate $\left(\mathrm{U}, \mathrm{NO}_{3} \mathrm{H}\right)$, consisting of rhombic plates having a characteristic imbricated 
arrangement and mother-of-pearl lustre. Oxalic acid acts'similarly, producing Urea-oxalate ( $\mathrm{U}, \mathrm{C}_{2} \mathrm{H}_{2} \mathrm{O}_{4}$ ), but the crystals are not so characteristie. Both bodies are quite insoluble in the acid liquids. An important compound $(2 \mathrm{U}+$ $\left.\mathrm{Hg}\left(\mathrm{NO}_{3}\right)_{2}+3 \mathrm{Hg} \mathrm{O}\right)$ is obtained as a heavy amorphous white precipitate, when a dilute solution of $U$ is acted upon by dilute solution of mercuric nitrate in excess. This body is insoluble in neutral or slightly acid liquids, but soluble in nitric acid. On adding sodic carbonate to the solution it is precipitated. Hence, if a solution of mercuric nitrate of known strength is added, drop by drop, to a solution of $\mathrm{U}$ acidulated with nitric acid, and the mixture tested from time to time by mixing a drop of it with a drop of sodic carbonate, such mixture will be attended with the formation of an additional white precipitate, so long as there remains any uncombined urea. The moment that all has been used up, the test will indicate the presence of excess of mercuric nitrate in the mixture, by the formation of a precipitate of basic nitrate.

Uric acid exists in urine chiefly as an acid sodium salt which is deposited in the cold. When this is decomposed by a stronger acid the free acid crystallizes. Ammonium urate occurs only in ammoniacal urine. Uric acid is absent in the urine of herbivorous mammalia, but in that of birds and reptiles it takes the place of urea as the channel for the discharge of nitrogen. In man it is discharged in relatively larger quantities in early infancy than in adult life ; its relative proportion to urea is increased a few hours after a full meal.

The daily discharge of uric acid is increased by certain kinds of dyspepsia, in fever, and in certain chronic diseases. It undergoes oxidation into urea and oxalic acid in the body.

Uric Acid $\left(\mathrm{C}_{5} \mathrm{H}_{4} \mathrm{~N}_{4} \mathrm{O}_{3}\right.$, also called lithic acid) being soluble in water only in the proportion of one part to $\mathbf{1 4}, 000$, exists as such in extremely small quantities in urine. Uric acid crystallizes readily in urine to which enough hydrochloric acid has been added to decompose its urates. The most common forms of crystals are the so-called whetstone crystals and the sheaf-like bundles of flattened needles, which (as formed in urine) are always of an amber brown colour. Acid sodic urate $\left(\mathrm{C}_{5} \mathrm{H}_{2} \mathrm{~N}_{4} \mathrm{O}_{3}, \mathrm{HNa}\right)$ is always present in normal urine. In urine of which the urea has undergone transformation into ammonic carbonate, ammonic urate $\left(\mathrm{C}_{5} \mathrm{H}_{3} \mathrm{~N}_{4} \mathrm{O}_{3}, \mathrm{NH}_{4}\right)$ is deposited in needle-shaped crystals which are often in stellate groups. In ordinary urine, when concentrated by evaporation and then cooled, an amorphous deposit falls, which consists chiefly of sodic urate. The same body often occurs as a natural subsidence in disease (lateritious sediment). Uric acid and urates reduce 
cupric oxide and other metallic oxides and salts. When uric acid is moistened with nitric acid, the excess of acid gently evaporated, and the residue after cooling breathed on, and then held over strong ammonia, a bright red colour is produced, which is due to the formation of murexide; if potash or soda be added instead of ammonia, the colour produced is violet.

Allantoin exists, along with uric acid and urea, in the urine discharged during the first few days of life.

Hippuric acid, which in the urine of many herbivorous mammalia replaces uric acid, also occurs in human urine in very small proportion. It is of importance as affording a channel for the discharge of glycin from the organism. Taurin, in like manner, appears in the urine as Taurocarbamate. The body cystic oxide or cystin, which also contains sulphur, occurs occasionally either as a crystalline deposit or as a concretion. Its physiological relations are unknown.

Hippuric acid $\left(\mathrm{C}_{9} \mathrm{H}_{9} \mathrm{NO}_{3}\right)$ occurs in very small proportions (less than $\mathrm{O}^{\cdot} \mathbf{I}$ per cent.) in human urine or in that of the carnivora, but so abundantly as alkaline hippurates in that of herbivora, that on the addition of hydrochloric acid it crystallizes out. It is obtained by boiling the urine of the horse or the cow with milk of lime, filtering, concentrating the filtrate, and adding hydrochloric acid. It crystallizes in four-sided prisms, which have their edges bevelled off at the ends. Hippuric acid is scarcely soluble in cold water, more readily in hot, but its salts are very soluble. It appears in the urine of man and other non-herbivorous animals, whenever benzoic acid $\left(\mathrm{C}_{7} \mathrm{H}_{6} \mathrm{O}_{2}\right)$ enters the organism, glycin being taken up and water given off. $\mathrm{C}_{7} \mathrm{H}_{6} \mathrm{O}_{2}+\mathrm{C}_{2} \mathrm{H}_{3}\left(\mathrm{NH}_{2}\right)$ $\mathrm{O}_{2}=\mathrm{C}_{9} \mathrm{H}_{9} \mathrm{NO}_{3}+\mathrm{H}_{2} \mathrm{O}$. On the other hand, it very readily undergoes decomposition, yielding benzoic acid and glycin whenever urine containing it becomes putrid. In the formation of hippuric acid from benzoic acid in the living organism the glycin produced in the liver takes part, but it has not yet been proved that the process by which it is normally produced in such large quantity in herbivora is of the same kind; it has, however, been shown that sufficient sources of benzoyl exist in the food of such animals. As regards the origin of hippuric acid in the carnivora and in man nothing is known. In all animals of which the urine contains much hippuric acid (e.g., in the horse), "indigo-producing substance" is also present in relatively large quantities.

The urine also contains an organic base, creatinin, the percentage of which depends upon the quantity of creatin taken as food. 
Creatinin is an alkaline body which exists in small quantity (about $O^{\prime} I$ per cent.) in urine. It is soluble in cold water, still more so in hot. From its solution in boiling alcohol it crystallizes on cooling. On the addition of syrupy solution of zinc chloride to its aqueous solution, characteristic warty clumps are formed of the combination of zinc-chloride $\left(\left(\mathrm{C}_{4} \mathrm{H}_{7} \mathrm{~N}_{3} \mathrm{O}\right)_{2} \mathrm{Zn} \mathrm{Cl} \mathrm{Cl}_{2}\right)$ and creatinin, each of which is seen under the microscope to consist of açicular crystals radiating from a centre (see Creatin, p. 32).

Human urine contains a soluble yellow colouring matter (urochrome) which is precipitated from its solution by acetate of lead; it also usually contains a colourless chromogenous substance, which when treated with hydrochloric acid yields indigo-blue. Grape-sugar exists normally in urine, but in very small quantity. As, however, both uric acid and creatinin reduce cupric oxide, the presence of sugar cannot be proved by the copper test unless these bodies have been previously removed.

The yellowe colouring matter of the urine is obtained by treating the liquid with milk of lime, and allowing it to stand. After separation of the deposit, the clear filtrate is precipitated by solution of plumbic acetate to which ammonia has been added. The lead precipitate, having been treated with just sufficient sulphuric acid to decompose it, yields a yellow solution, which owes its colour to a body to which the name urochrome was given by Thudichum. This body is soluble in water, insoluble in alcohol. Its solution exhibits no absorption bands before the spectroscope. On boiling it for some hours with sulphuric acid, various brown or black substances are formed, the most characteristic of which (called uromelanine) is soluble in ammonia, and is re-precipitated on neutralizing the solution with sulphuric acid. Of the chemical relations of urochrome little is known.

Indigo-forming substance.-Urine (particularly that of the horse) when mixed with half its volume of strong hydrochloric acid, becomes dark, and after some hours exhibits a scum or sediment which contains indigo-blue $\left(\mathrm{C}_{8} \mathrm{H}_{5} \mathrm{NO}\right)$. If this scum is collected on a filter and treated with ammonia, a blackish substance with which it is mixed is dissolved and removed. If after washing the filter with cold alcohol fwhich dissolves out a red colour) the filter and residue are boiled in the same solvent, a beautiful blue solution is obtained, which, on cooling, deposits flocks of indigo-blue.

The materials which constitute urinary deposits and concretions may be divided into those of acid and of alkaline urine, the former comprising uric acid, urates, and calcic oxalate, the latter the calcic and magnesic phosphates, triple phosphate, and calcic carbonate. 


\section{Muscular Tissue.}

Muscular substance consists chiefly of a globulin named myosin, which differs little from fibrinogen. This body is fluid in living muscle, but coagulates when life ceases. Frozen muscle carefully thawed, yields a juice which coagulates (whether with the aid of a ferment is not known) at ordinary temperature. The coagulum dissolves readily in salt solution.

Muscle contains, in addition to myosin, serum-albumin and other proteids which coagulate at lower temperatures. The aqueous extract of dead, i.e. coagulated, muscle contains a free acid (sarcolactic) which is not present during life. The extract yields creatin by direct crystallization in the proportion of about 0.2 per cent. of the weight of the muscle employed. The glycogen which all muscle contains in the perfectly fresh state is replaced by dextrose in dead muscle. The extractive contains also Inosite, Xanthin, Hypoxanthin, Taurin, and a trace of uric acid.

Myosin is obtained in quantity by thoroughly washing comminuted muscle with water and then treating the insoluble residue with strong salt solution (one part of brine to two of water), filtering the solution and then precipitating by the addition of salt in substance. It is readily soluble in dilute $\mathrm{HCl}$, or alkalies, which soon convert it into acid or alkali-albumin. Its solution coagulates in weak $\mathrm{NaCl}$ at $55^{\circ}$ to $60^{\circ} \mathrm{C}$.

Sarcolactic acid.-A body resembling lactic acid of milk, even in chemical structure, but differing from it in being dextrorotatory, and in the solubility, hydration and crystalline form of some of its salts. It is contained in the alcoholic extract of the concentrated water extract of flesh from which the creatin has been crystallized and separated. The syrupy mother liquor, after treatment with sulphuric acid, is extracted with ether. The ether extract leaves sarcolactic acid on evaporation.

Inosite or Muscle sugar exists sparingly in all muscle, and occurs pathologically in the urine in uræmia; it is obtained in quantity from unripe beans. It differs from grape-sugar in not affecting polarized light, in not reducing metallic oxides, and in being incapable of alcoholic fermentation; it, however, yields sarcolactic acid by a process analogous to lactic fermentation. When a solution of inosite is evaporated with nitric acid in a porcelain capsule, then moistened with calcic chloride solution and again evaporated after the addition of a little ammonia, a bright rose-coloured patch remains (Scherer's test). 
When the aqueous extract of muscle from which the creatin has been crystallized out (see Creatin) is precipitated by neutral lead acetate, a filtrate is obtained from which inosite is precipitated by the addition of the basic acetate test. It crystallizes from its solution in alcohol in rhombic plates or prisms represented by the formula $\mathrm{C}_{6} \mathrm{H}_{12} \mathrm{O}_{6}+2 \mathrm{H}_{2} \mathrm{O}$.

Creatin $\left(\mathrm{C}_{4} \mathrm{HI}_{9} \mathrm{~N}_{3} \mathrm{O}_{2}\right)$ is obtained by direct crystallization from the waterextract of meat. To prepare it, the extract must be first freed from albumin by boiling, after which the phosphates and sulphates must be precipitated by adding to the strained liquid a mixture of baryta water and baric nitrate. The liquid having been filtered, the filtrate is evaporated over a water-bath to a small bulk, when creatin separates in hard brilliant crystals. Creatin, when treated with boiling solution of baryta, splits into Sarkosin (Methylglycin) and Urea $\left(\mathrm{C}_{4} \mathrm{H}_{9} \mathrm{~N}_{3} \mathrm{O}_{2}+\mathrm{H}_{2} \mathrm{O}=\mathrm{C}_{3} \mathrm{H}_{7} \mathrm{NO}_{2}+\mathrm{CO}\left(\mathrm{NH}_{2}\right)_{2}\right)$. When heated with acids, it loses water, and is converted into Creatinin $\left(\mathrm{C}_{4} \mathrm{H}_{7} \mathrm{~N}_{3} \mathrm{O}\right)$.

Hypoxanthin $\left(\mathrm{C}_{5} \mathrm{H}_{4} \mathrm{~N}_{4} \mathrm{O}\right.$ ) (Sarkin of Strecker), occurs in the tissue of the spleen and in muscle. It exists in the mother liquor of creatin, and can be precipitated from it as an impure compound of argentic nitrate and hypoxanthin by treating the extract with solution of nitrate of silver rendered slightly alkaline by ammonia. Hypoxanthin, like xanthin, is soluble in nitric and hydrochloric acids yielding crystalline compounds. Heated and evaporated with fuming nitric acid, it gives the same yellow residue as xanthin.

Xanthin $\left(\mathrm{C}_{5} \mathrm{H}_{4} \mathrm{~N}_{4} \mathrm{O}_{2}\right)$ the xanthic oxide of Prout, exists in extremely small quantity in urine, in the tissues of certain organs, and as an occasional constituent of calculi. It is very insoluble in water, but soluble in hydrochloric and nitric acids, giving crystallizable compounds with both. When it is heated with fuming nitric acid, and the product evaporated to dryness, a pale yellow patch is left; from this circumstance it derives its name. Xanthin can be prepared artificially by the action of oxidizing agents on Hypoxanthin.

\section{Nervous Tissue.}

Of the proteids of the brain little is known. The grey substance is said to be acid, even when perfectly fresh. All nervous tissue contains, in addition to Cholesterin and Lecithin, which exist everywhere, a body called Cerebrin, which is peculiar to the nerve fibres.

\section{CRystalline Products of the alcohol-ether extract of Brain.}

Neurin or Cholin $\left(\mathrm{N}\left(\mathrm{C} \mathrm{H}_{3}\right)_{3}\left(\mathrm{C}_{2} \mathrm{H}_{5} \mathrm{O}\right) \mathrm{OH}\right)$ is a strongly basic, colourless syrupy fluid, which forms crystalline salts with acids. It is soluble in alcohol and water, not in ether. It is readily decomposed by heat, yielding trimethylamine, ethylene oxide, glycol $\left(\mathrm{C}_{2} \mathrm{H}_{4}(\mathrm{HO})_{2}\right)$ and water. It is obtained by 
heating trimethylamine and ethylene oxide in aqueous solution $\left(\mathrm{N}\left(\mathrm{C} \mathrm{H}_{3}\right)_{3}+\right.$ $\mathrm{C}_{2} \mathrm{H}_{4} \mathrm{O}+\mathrm{H}_{2} \mathrm{O}=$ Neurin). Glycero-phosphoric acid $\left(\mathrm{C}_{3} \mathrm{H}_{9} \mathrm{PO}_{6}\right.$ or $\mathrm{C}_{3} \mathrm{H}_{7} \mathrm{O}_{3} \mathrm{PO}(\mathrm{OH})_{2}$ ), the product which is obtained when phosphoric anhydride or glacial phosphoric acid acts on glycerine, is a syrupy body, soluble in water not in alcohol. Taking up $\mathrm{H}_{2} \mathrm{O}$, it splits readily when warmed into glycerine and phosphoric acid. Along with Neurin and a fatty acid, it is a product of the decomposition of Lecithin, a body which may be regarded as glycero-phosphoric acid in which $\mathrm{H}_{2} \mathrm{O}$ is replaced by Neurin, and 2 atoms of $\mathrm{H}$ in the radical by 2 atoms of stearyl $\left(\mathrm{C}_{18} \mathrm{H}_{35} \mathrm{O}\right)$. Lecithin is consequently called Neurin-distearyl-glycero-phosphate. Lecithin is an imperfectly crystallizable body which fuses readily, is soluble in ether and swells out in water, like starch, without dissolving. It is obtained by treating the ether alcohol extract of yolk of egg, after first freeing it from fats, with alcoholic solution of platinic chloride. A chloride of platinum and of Lecithin separates, of which the ethereal solution, when decomposed by sulphuretted hydrogen, yields Lecithin hydrochlorate as a wax-like mass. The alcoholic solution of this substance, when poured into boiling baryta water, splits into glycerophosphate, Neurin and stearate. Bodies of similar constitution in which the radical of stearic acid is replaced by that of palmitic or of oleic acid are also called Lecithins.

Cholesterin $\left(\mathrm{C}_{26} \mathrm{H}_{44} \mathrm{O}\right)$ crystallizes readily from ether-extract of powdered gall-stones (of which it is usually the chief constituent) in rhombic plates, which in mass have a mother-of-pearl lustre. These crystals contain a mol. of $\mathrm{H}_{2} \mathrm{O}$, which they lose at $100^{\circ} \mathrm{C}$. It fuses at $145^{\circ} \mathrm{C}$., is insoluble in water, soluble in alcohol, ether, chloroform, \&c. When evaporated with nitric acid, the residue on the addition of ammonia acquires a dull red colour. If sulphuric acid is added to its volume of solution of cholesterin in chloroform, the solution becomes first red then purplish, while the subjacent layer of acid acquires a distinct green fluorescence. A body resembling Cholesterin (Excretin) has been discovered by Marcet in human fæces, to which the formula $\mathrm{C}_{20} \mathrm{H}_{36} \mathrm{O}$ is now attributed.

Cerebrin is a body of imperfectly known constitution, which is distinguished from Lecithin with which it is associated by its solubility in boiling absolute alcohol, its insolubility in cold alcohol, and its not being decomposed or acted upon by boiling baryta water.

EXChANGE OF MATERIAL.

The term "exchange of material" is used to denote the results of the chemical processes ("functions"), which constitute the life of the animal body, as they exhibit themselves in the entrance and discharge of material at its surface. Its total amount is known by the direct or indirect measurement of the quantities of carbon and 
nitrogen discharged, and of oxygen taken in daily, by the organism, when the body-weight is constant.

\section{The Discharge of Carbon.}

The influence of food on the rate of discharge of $\mathrm{CO}_{2}$ is direct and immediate. The increase after each meal, which may amount to 20 per cent., reaches its maximum in about 2 hours. The effect is most marked when the diet consists largely of carbohydrates.

About 95 per cent. of the carbon discharged leaves the organism as $\mathrm{CO}_{2}$, and forms part of the "insensible loss," that is, the loss of weight of the body when no food is taken and no liquid or solid excreta are discharged. The insensible loss is made up of the sum of the $\mathrm{CO}_{2}$ and water discharged, minus the weight of oxygen absorbed. In man it amounts to about 25 grammes per'hour.

Of the total hourly discharge of $\mathrm{CO}_{2}$ less than half per cent. is cutaneous. The hourly discharge of $\mathrm{CO}_{2}$ by weight of an adult male when at rest, is about 32 grammes, the weight of oxygen absorbed in the same time being from 25 to 28 grammes. The hourly discharge of water vapour is about 20 grammes.

As a volume of $\mathrm{CO}_{2}$ contains the same weight of $\mathrm{O}$ as an equal volume of $\mathrm{O}$, it is obvious that if all the inspired $\mathrm{O}$ were discharged as $\mathrm{CO}_{2}$, the quotient (by volume)--called the "Respiratory Quotient" - $\frac{\mathrm{CO}_{2}}{\mathrm{O}}$ would be $=\mathrm{I}$. This, however, is never the case. The volume of $\mathrm{O}$ absorbed exceeds very considerably that of the $\mathrm{CO}_{2}$ discharge, the ratio between them being determined by the composition of the food. In animals which feed exclusively upon carbohydrates, equality is approached. The excess of oxygen is greatest when the diet consists largely of fats.

On a mixed diet comprising 100 grammes of proteid, 100 grammes of fat, and 250 grammes of carbohydrates (see Table I.), with a $\mathrm{CO}_{2}$ discharge of 770 grammes daily, the assumption of $O$ by the organism amounts to 666 
grammes daily, of which 560 grammes are discharged as $\mathrm{CO}_{2}$, about 9 grammes in urea, 97 grammes in $\mathrm{H}_{2} \mathrm{O}$, of which last 78 grammes are formed at the expense of the hydrogen of the fat. Hence the quotient $\frac{\mathrm{CO}_{2}}{\mathrm{O}}=0.84$. In inanition, when (as in the case represented in Table II. the proteids and fat of the organism take the place of food, and the $\mathrm{CO}_{2}$ discharge is reduced to 660 grammes daily, the assumption of $\mathrm{O}$ required is 649 grammes, of which 480 grammes are discharged in $\mathrm{CO}_{2}, 4.5$ in urea, and $164^{\circ}$ in $\mathrm{H}_{2} \mathrm{O}$; of this last $15^{6}$ grammes are due to the oxidation of fat.

In the state of hibernation the respiratory quotient is smaller than in any other known condition (often less than $0.5)$, for the hibernating animal lives almost entirely on its own fat. In the similar state of inanition the excess of the oxygen absorption is not so great, for here the proteid constituents of the tissues waste in much larger proportion.

The "insensible loss" is increased by muscular work; for, although the quantity of $\mathrm{O}$ absorbed is large during exertion, this is far more than counterbalanced by the greater increase of the $\mathrm{CO}_{2}$ discharge (diminution of the respiratory quotient), and the still greater augmentation of the evaporation of water from the pulmonary and cutaneous surfaces.

Diminution of the bodily temperature, however produced, determines increased $\mathrm{CO}_{2}$ discharge. In small animals the $\mathrm{CO}_{2}$ discharge is greater in proportion to the body-weight than in large ones.

\section{The Discharge of Nitrogen.}

The whole of the nitrogen which enters the circulating blood by intestinal absorption (with the exception of so much of the $\mathrm{N}$ of the fæces as is derived from unabsorbed secretions) is discharged by the urine. The rate of discharge is observed to vary according to the rate at which nitrogen has been absorbed during the previous period, sc that under normal conditions the processes balance each other. But in order to the establishment of this state of 
" nitrogen equilibrium," it is necessary that the daily weight of nitrogen absorbed should not fall below a certain limit, determinable in resfect of each species of animal by experiment. In man the minimum daily allowance of $\mathrm{N}$ is about 15 grammes, or 0.02 per cent. of the body-weight; in the carnivora about 0.1 per cent.; in the ox 0.005 per cent. (Henneberg).

When the diet consists of proteid exclusively, a larger quantity is required for the maintenance of the equilibrium than when it also contains fat or carbohydrates. Accordingly, in those animals or races of mankind whose food consists largely of either of these constituents-particularly the latter-the nitrogen requirement is lower than in others. The reason why this is so is not understood.

When the animal body is deprived of food, its "stored proteid" rapidly disappears. During this process (the first stage of inanition, and which lasts a few days only) the nitrogen discharge as rapidly diminishes. During the second stage it continues to diminish, but only in proportion to the diminution of the total body-weight.

In an animal fed exclusively with flesh the nitrogen discharge at first increases pari passu with the absorption of proteid, the absorption of $\mathrm{O}$ being increased in exact proportion to the increase which has taken place in the quantity of material to be disintegrated, so that the respiratory quotient remains nearly unaltered (Bidder and Schmidt). Although, however, the overfed animal maintains its nitrogen equilibrium, it usually gains weight, and therefore must "lay on" fat.

Relation of Muscular Work to the Discharge of Nitrogen and Carbon.-The chemical changes on which the performance of work by muscle depends, manifest themselves in the production of $\mathrm{CO}_{2}$ and $\mathrm{H}_{2} \mathrm{O}$. Consequently, in muscular exertion both constituents of the "insensible loss" are so augmented that (irrespectively of the secondary effect produced on the skin) they more than 
balance the increased absorption of oxygen (Pettenkofer). The quantity of proteid required by the organism daily for its maintenance is proportional to the weight of active living material (protoplasm) that it contains, so that, in general, those organisms are most vigorous which are capable of producing the largest quantity of urea in proportion to their weight; but, in the case of muscle, the proteid so used is not the source of the work done; for even if the whole of the proteid material which enters the organism in a day, were devoted to this purpose, and employed in the most advantageous way, it would not afford the material for a day's work.

The facts above stated are most easily understood on the hypothesis that the disintegration of food proteid, i.e., the production of urea and other "nitrogenous metabolites," is exclusively a function of "living material," and that this process is carried on in the organism with an activity which is dependent on the activity of the living substance itself, and on the quantity of material supplied to it. No evidence at present exists in favour of a "luxus consumption " of proteid.

Use of Gelatine.-In carnivorous animals on a diet of flesh and fat, nitrogen equilibrium can be maintained with a much smaller daily allowance of proteid with than without gelatine. Hence gelatine is capable of partly replacing proteid. But normal nutrition cannot be maintained either with gelatine alone or with any mixture of gelatine and fat, or of gelatine and proteid.

Relation of Fat to the Exchange of Material.-Fat is stored for the purposes of nutrition in the adipose tissue, which, without any disturbance of its histological integrity, gives or receives fat according to the requirements of the organism. Tissue fat is not, however, as a rule, derived from food fat of the same kind, for even when animals previously starved receive fatty food, the fat "laid on" is not necessarily chemically identical with that given. In the fattening 
of herbivorous or omnivorous animals, the fat is largely produced from carbohydrates. In lean carnivorous animals it is deposited when they are well fed even with flesh without fat. Hence it must be concluded that in such animals the formation of fat from proteids is a normal process.

\section{The Balance of Income and Discharge.}

The relation between the income and expenditure of the animal organism is best expressed in the form of balance sheets, in which the quantities of proteid, fat and carbohydrates of the food, are stated on one side, and $\mathrm{CO}_{2}$, urea, and other excreta on the other, the value of each item being computed according to the weight of $\mathrm{C}$ and $\mathrm{N}$ which it contains. The income and discharge of $\mathrm{H}$ are left out of account for the sake of simplicity.

This mode of statement is applicable to all the conditions of nutrition which have been above referred to, viz. (I) that in which the quantity and quality of the food taken is sufficient, and not more than sufficient, for the maintenance of the weight of the body without loss or gain, and in which the diet is said to be adequate ; 2 ) the condition of inanition in which the body, in the absence of food, nourishes itself at its own expense; (3) the condition in which, in the absence of other heat-producing material, proteid is necessarily employed for heat production, in larger quantity than can be advantageously disposed of by the organism.

These three cases are stated in the following Tables:- 


\section{TABLE I. * \\ Exchanse of Material on Adequate Diet.}

INCOME.

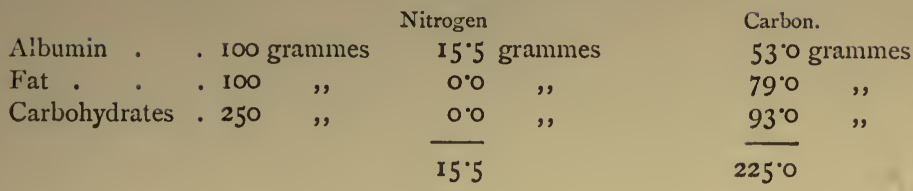

\section{EXPENDITURE.}

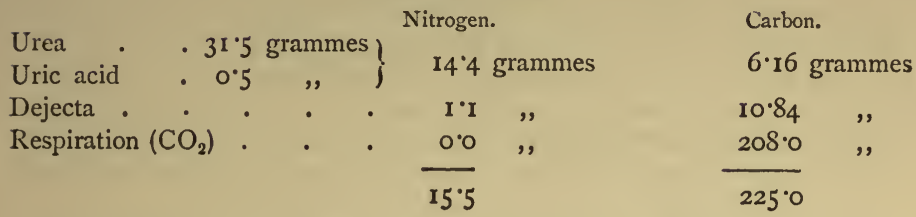

The quantities of albumin, fat, and carbohydrates in the Table represent a diet consisting chiefly of meat and bread, with the addition of smaller quantities of potato, butter, and eggs. It is seen that in man the discharge of $\mathrm{N}$ per kilo. of body-weight is 0.21 grammes, and of carbon 3.03 grammes, the quotient $\frac{\mathrm{C}}{\mathrm{N}}$ being $14^{\circ} 5$. In the carnivorous animal, which, according to Bidder and Schmidt, uses $\mathrm{I}_{4} 4$ of $\mathrm{N}$, and 6.2 of $\mathrm{C}$ per kilo. per diem, the $\frac{\mathrm{C}}{\mathrm{N}}$ quotient is 4.4 . In the human being on a flesh diet, the exchange of $\mathrm{N}$ amounts to 0.83 per kilo. per diem, and the $\frac{C}{N}$ quotient is 5.2 . Thus the exchange of material of the human organism, when fed on flesh, is intermediate in character between the normal exchange and that of the carnivorous animal.

\section{TABLE II.}

Exchange of Material on an exclusively Albuminous Diet.

INCOME.

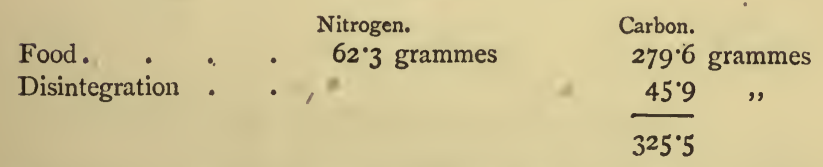

- The data on which Tables I., II., and III. have been constructed have been derived for the most part from the observations of Prof. Ranke on himself. 


\section{Outсоме.}

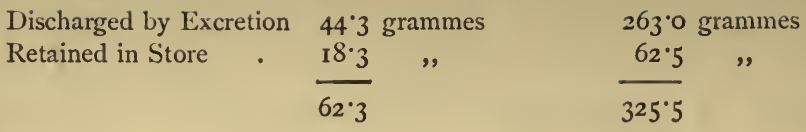

In the experiment referred to in this Table 1832 grammes of meat consumed as food yielded 3.4 per cent. of Nitrogen, i.e., 62.3 grammes, and 12.5 per cent. of Carbon, i.e., 229.3 grammes. Seventy grammes of fat also consumed as food yielded 72 per cent. of Carbon, i.e., 50.3 grammes: $229^{\circ} 3+5^{\circ} 3=279^{\circ} 6$. During the same period $86^{\circ} 3$ grammes of Urea were discharged daily, containing $46^{\circ} 6$ per cent. of Nitrogen, i.e., $40^{\circ} 4$ grammes, and 20 per cent. of Carbon, i.e., 17.3 grammes, to which must be added two grammes of Uric Acid, containing 33 per cent. of Nitrogen, i.e., o.66 gramme, and 35 per cent. of Carbon, i.e., $0 \% 7$ gramme. Further, $2{ }^{\circ} 9$ grammes of Nitrogen and I4 grammes of Carbon were discharged in the fæces, and 23I grammes of Carbon were expired as $\mathrm{CO}_{2}$. Hence the total discharge of Nitrogen $\left(40^{\circ} 4+0^{\circ} 66+2.9\right)$ was $43^{\circ} 96$ grammes, and may therefore be stated as 44 : and the total discharge of Carbon $(17 \cdot 3+0.7+14+231)$ as 263 grammes. Deducting the quantity of Nitrogen discharged from that taken in, 18.3 grammes must have been retained in 108 grammes of Albumin, and consequently 53 per cent. of that weight of Carbon, i.e., $62 \cdot 5$ grammes.

Comparing the quantity of Carbon disposed of in the 24 hours with the quantity introduced as food, we find that the latter is in excess by $45^{\circ} 9$ grammes, which must have been derived from the disintegration of the fat of the body.

TABLE III.

Exchange of Material in Inanition.

Disintegration of Tissue.

\begin{tabular}{|c|c|c|c|c|c|c|}
\hline \multirow{2}{*}{$\begin{array}{l}\text { Albumin } \\
\text { Fat }\end{array}$} & \multirow{2}{*}{$\dot{.}$} & \multirow{2}{*}{$\begin{array}{cc}\text {. } & 50 \\
\text {. } 199^{\circ} 6\end{array}$} & rammes & \multirow[t]{2}{*}{$\begin{array}{l}\text { Nitrogen. } \\
7 \cdot 8 \text { grammes }\end{array}$} & \multicolumn{2}{|c|}{$\begin{array}{l}\text { Carbon. } \\
26.5 \text { grammes }\end{array}$} \\
\hline & & & , & & 157.5 & , \\
\hline & & & & & $184^{\circ} \mathrm{O}$ & a \\
\hline
\end{tabular}

Discharge of Nitrogen and Carbon.

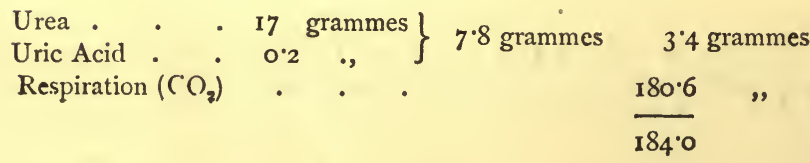


This Table represents the exchange for a twenty-four hours' period, commencing twenty-four hours after the last meal, and relating to the same person as Table I. The discharge of $\mathrm{N}$ per kilo. of body-weight was reduced to $0.1, \frac{\mathrm{C}}{\mathrm{N}}$ being 23.5 . In the carnivorous animal, in prolonged inanition, the discharge of $N$ per kilo. is 0.9 per diem per kilo. and $\frac{C}{N}=6 \cdot 6$.

In fever the exchange of material resembles that of inanition, but the disintegration of proteid is more rapid.

\section{TABLE IV. *}

Exchange of Material in Fever.

Disintegration of Tissue.

\begin{tabular}{|c|c|c|c|c|}
\hline Albumin & . 120 & grammes & $\begin{array}{l}\text { Nitrogen. } \\
18.6 \text { grammes }\end{array}$ & $\begin{array}{l}\text { Carbon. } \\
63^{\circ} 6 \text { grammes }\end{array}$ \\
\hline Fat . & . $205^{\circ}$ & $7 \quad$ & & $\underline{157^{\circ} 4} \quad$ \\
\hline
\end{tabular}

Discharge of Nitrogen and Carbon.

Urea and Uric Acid 40 grammes 18.6 grammes Respiration $\left(\mathrm{CO}_{3}\right) 780 \quad$,"

$8 \cdot 3$ grammes $212 \cdot 7 \quad$, $22 \mathrm{I}^{\circ} \mathrm{O}$

\section{Production of Heat.}

Animal heat, like mechanical work, is a result of the chemical process of the conversion of food into water, $\mathrm{CO}_{2}$, urea, and other excreted products.

An approach to an experimental proof of this is obtained by comparing the quantity of heat produced by a man or an animal in a given time, with the quantity and physiological "heat-value" of the different kinds of food consumed during the same period.

Of these investigations the first is accomplished calorimetrically; the second by determining the quantity of

* The data for this Table are to be found in a paper in the Practitioner for April, May, and June, 1876. 
heat produced by each substance used as food when completely burnt. The physiological heat-value of any substance is the quantity of heat produced by the chemical disintegration which it actually undergoes in the animal organism. Those substances which yield in the living body the same quantity of heat as by complete combustion in the laboratory, have the same physiological as physical heat-value; but as regards substances containing nitrogen, the result must be corrected by deducting from it the heat produced by the combustion of the equivalent weight of urea. Thus, albumin, which by complete combustion yields 4998 units of heat, has a physiological heat-value of only $42 \sigma_{3}$ units. The results so obtained, although only approximately correct in application, are correct in principle; for, however various may be the chemical processes of animal life, their value as regards the quantities of heat and work produced must be estimated by the end-products.

Of the heat produced in the body, it is estimated by Helmholtz that about 7 per cent. is represented by external mechanical work, and that of the remainder about four-fifths is discharged by radiation and evaporation from the surface, and one-fifth by the lungs and excreta.

The following Table exhibits the relation between the production and discharge of heat in twenty-four hours in the human organism at rest, estimated in kilogramme units or calories :-

TABLE V.

Production of Heat.

Consumption of Albumin . (100 grms.) $\cdot 100 \times 4^{\circ} 263=426$ Cals. " "Fat . . (100 grms.) $.100 \times 9069=907 \quad$ ",

" " Carbohydrates $\quad(223$ grms. $) \cdot 223 \times 230=1167 "$,$$
\text { ' Carbohydrates }
$$
2500 Cals. 


\section{Discharge of Heat.}

(I) Warming Water in Food.

(2) Air .

(3) Evaporation in Lungs

(4) Radiation and Evaporation at Surface . 2.6 kilo. $\times 25^{\circ}=65^{\circ}$ Cals. 16 kilo. $\times 25^{\circ} \times 0.26=104$,

$$
\begin{gathered}
.630 \text { at } 582=367 ", \\
. \quad . \quad \cdot=\frac{1964}{2500} \text { Cals. }
\end{gathered}
$$

The mean temperature of the body is remarkably constant, but is higher in the central than in the superficial parts. The uniformity of temperature is dependent on the constant equilibrium of the two processes by which severally heat is produced and discharged. 


\section{PRACTICAL EXERCISES}

RELATING TO THE

\section{FOOD STUFFS AND ANIMAL LIQUIDS.}

I.-Starch, Dextrin, Dextrose, Fat.

1. Starch is insoluble in cold water.

2. It dissolves imperfectly in hot water ; the liquid so obtained is opalescent.

3. It gives a blue colour with iodine, which vanishes when the liquid is heated, but returns on cooling, if the heating has not been prolonged.

4. Dextrin is soluble in water.

5. The solution gives a red brown colour with iodine, which vanishes on heating.

6. Dextrose (Grape-sugar) is crystalline and very soluble in water.

7. It reduces many metallic oxides.

8. The copper test. To a small quantity of ten per cent. solution of cupric sulphate add about 5 c.c. of the liquid to be tested; then solution of caustic potash drop by drop until the solution is clear, and heat gradually. If dextrose is present, the blue colour vanishes and a yellow precipitate appears of cuprous hydrate, or a red precipitate of cuprous oxide.

9. Conversion of starch into dextrose. Boil about 50 c.c. of starch solution in a flask with a drop of 25 per cent. sulphuric acid for five minutes. The liquid becomes limpid. It contains in addition to dextrose much unconverted soluble starch.

I0. Fat. Lard is insoluble in water. By boiling with potash it yields a solution of soap.

I I. Decompose the solution by adding a few drops of dilute sulphuric acid. On heating, a layer of fatty acid collects on the surface.

12. Microscopical preparations. Starch grains; their disintegration by hot water; action of iodine on them. Crystalline forms of fatty acids.

$$
\text { II.-Milk, Flour, Bread. }
$$

I. Milk has (in London) usually an acid reaction, and a specific gravity of from 1025 to 1030. After removal of the cream, the specific gravity is higher. 
2. Milk contains fat, sugar, and proteids.

a. Proteids. Heat about 50 c.c. of milk in a flask to $50^{\circ}$, C., add two to six drops of dilute sulphuric acid (25 per cent.) and shake ; the milk curdles ; strain off the coagulated casein (curd) through muslin.

b. When milk is filtered under pressure through a porous disk, its casein, being particulate, remains behind. The clear filtrate contains lactose (milk-sugar) and salts.

c. The strained liquid from $a$ (whey) contains lactose, which, like dextrose, reduces metallic oxides. Apply the copper test (\$ i, 8).

d. The coagulated casein contains much fat (butter) which can be extracted by ether. The ether extract when evaporated on paper leaves a greasy stain.

e. Butter. Repeat $\S \mathrm{i}$, Io and II. Butter yields a small percentage of volatile acid.

3. Flour. Wash about a dessert-spoonful of sound flour in a muslin bag.

a. A milky liquid passes through containing much starch $(\S \mathrm{i}, 3)$ but no sugar (§i, 8).

b. After washing for some minutes, a sticky and tenacious material remains on the muslin, which can be collected; this after further washing forms an elastic mass (gluten) which can be drawn out into threads, and on burning gives off the smell of burnt feathers characteristic of a proteid.

4. Bread. Digest with warm water. The extract contains starch $(\S \mathrm{i}, 3)$ and dextrose $(\S \mathrm{i}, 8)$. The residue consists principally of starch and gluten.

\section{III.-Albumin and its Acid and Alkaline Modifications.}

I. Albumin. White of egg (albumen) when diluted with water, strained and filtered, yields a faintly opalescent liquid. This liquid contains a proteid body, albumin, which diffuses through an animal membrane with great difficulty $(\S \mathrm{ix}, 8)$.

2. Such a liquid, containing five per cent. of albumen, is to be used in the following experiments. It coagulates on heating at about $70^{\circ} \mathrm{C}$. if neutral.

3. To some of the liquid add a few drops of 0.1 per cent. solution of caustic potash, and warm gently for two or three minutes. Boil. The liquid will no longer coagulate, the albumin having been transformed into the alkaline modification (alkali-albumin or casein).

4. In a similar way treat another portion with a few drops of very dilute sulphuric acid (O.I per cent.). Warm very gently for not less than five minutes. On boiling no coagulation occurs, the albumin having passed into its acid modification (acid-albumin, syntonin).

5. Cool some of the liquid obtained in 3. Colour it with litmus solution, and add carefully very dilute acid. A precipitate falls on neutralization which is soluble in excess of acid.

6. Make a similar experiment with the liquid obtained in 4, substituting weak solution of potash for weak acid. A similar precipitate occurs on neutralization, which is soluble in excess.

7. Take three portions, of 5 c.c. each, of the original liquid in three testtubes, and colour them with litmus. Dilute the $0^{\cdot} \mathrm{I}$ per cent. acid about 5 
times, and add a drop of it to one of the portions; to another add a drop of potash solution similarly diluted. Heat all three tubes gradually, and note the temperature at which each coagulates.

8. Make alkali-albumin solution as in 3 . Divide it into two equal parts. To one add two or three drops of ten per cent. solution of sodic phosphate. Colour both with litmus and neutralize with weak acid. The portion without sodic phosphate is precipitated. The other portion is not precipitated until enough acid has been added to convert the sodic phosphate present into acid sodic phosphate.

\section{IV.-Characteristics of Proteids. Peptic Digestion.}

r. Tests for proteid bodies in solution.

a. To some of the albuminous liquid referred to in $\$$ iii, 2, add strong nitric acid. The precipitate obtained turns yellow on boiling.

$b$. Cool the liquid in $a$ and add strong ammonia. The precipitate assumes an orange tint (Xanthoprotein reaction).

c. To another portion add IMillon's reagent. (Mercury is dissolved in its own weight of strong nitric acid. The solution so obtained is diluted with twice its volume of water. The decanted clear liquid is Millon's reagent.) A precipitate is formed which turns dull red on boiling.

$d$. To a third portion add solution of potassic ferrocyanide, and a drop of acetic acid. A white precipitate appears.

e. Introduce a fourth portion of the liquid into a test-tube containing one drop of ten per cent. solution of cupric sulphate. On adding solution of potash, a violet colour is obtained (compare $\S \mathrm{v}, 2, b$ ).

2. Paraglobulin (Fibrino-plastin).

a. Dilute five c.c. of serum with about seventy-five c.c. of water. Neutralize carefully with a few drops of $0^{\circ} \mathbf{I}$ per cent. sulphuric acid, and allow the precipitate to settle.

This precipitate is soluble in excess.

b. Repeat $a$, passing a stream of $\mathrm{CO}_{2}$ through the liquid, instead of neutralizing it with weak acid.

c. Repeat $a$ and $b$ without dilution. No precipitate is produced.

3. Peptic Digestion.

$a$. Introduce some fibrin into a test-tube and just cover it with $0 * 2$ per cent. solution of $\mathrm{HCl}$. Allow it to stand for forty-five minutes in a water-bath at from $35^{\circ}$ to $38^{\circ} \mathrm{C}$. At the end of this time the fibrin is swollen and transparent, but has not dissolved.

$b$. Repeat $a$, using, instead of hydrochloric acid, water to which a drop of glycerine extract of pepsin has been added.

The fibrin remains unaltered.

c. Repeat $a$, adding a drop of the same extract to the acid liquid. The fibrin dissolves gradually.

$d$. Colour with litmus the liquid obtained in $c$. Neutralize carefully with weak solution of caustic potash ( $\$$ iii, 6). The acid albumin formed during the first stage of digestion is precipitated. 
V.-Pancreatic Digestion. Amylolytic Ferments. Gycogen.

\section{Pancreatic Digestion.}

$a$. Introduce five c.c. of one per cent. solution of sodium carbonate, to which a couple of drops of glycerine extract of pancreas have been added, into each of two test-tubes. Boil one of them and allow it to cool. Add some boiled fibrin to each, and place them both in the water-bath at $35^{\circ} \mathrm{C}$. Compare the changes produced with those observed in peptic digestion ( $\$ \mathrm{iv}, 3, c$ ).

b. Examine the liquid product of a pancreatic digestion, previously prepared by digesting albumin as in $a$. It is alkaline, and may have a characteristic and offensive odour.

c. Boil some of this liquid after acidulating slightly. Albumin is coagulated.

d. Colour another portion with litmus, and neutralize carefully $(\S \mathrm{iii}, 5)$; alkali-albumin is precipitated.

e. In a liquid obtained by concentrating the product above referred to, after having separated the greater part of the proteids contained in it, test for Tyrosin by adding Millon's reagent and boiling. The presence of Tyrosin is indicated by the reddish colour assumed by the liquid.

$f$. The liquid contains Leucin in a crystalline form.

2. Peptones. A solution obtained either by pancreatic or peptic digestion can be used.

$a$. The solution yields no precipitate either by boiling or by neutralization.

$b$. When treated as in $\S$ iv, $\mathrm{I}, e$, it gives a red instead of a violet colour.

The liquid product of the slow putrefaction of proteids resembles in most respects that of pancreatic digestion. To the latter, the presence of septic organisms is not essential.

3. Amylolytic Ferments. Prepare some starch solution and ascertain that it contains no dextrose, $\$ \mathrm{i}, 2$ and 8 . To another portion add saliva, and place the tube containing the mixture in a water-bath at from $35^{\circ}$ to $38^{\circ} \mathrm{C}$. After a short time, the product will be found to contain dextrose.

\section{Glycogen.}

$a$. To an extract of liver (prepared by extracting the perfectly fresh organ with boiling water after washing) add a solution of iodine in potassic iodide. The liquid assumes a red colour identical with that yielded under similar circumstances by dextrine (see $\S \mathrm{i}, 5)$.

$b$. On treating a slice of washed liver, hardened in alcohol, with iodine solution, a similar colour is seen.

c. Repeat 3, substituting extract of liver for starch paste, using the same precautions.

$$
\text { VI.-Bile. }
$$

I. Observe colour and reaction. The bile of camivora is brownish-red, that of herbivora green. Neutralize and boil in a test-tube. Bile does not contain albumin.

2. Acidify bile with acetic acid; mucin is precipitated 
3. Prepare a solution of syntonin $(\$ \mathrm{iii}, 4)$ by digesting albumin in water containing 0.2 per cent. of hydrochloric acid. On the addition of a drop of bile, the mixture curdles en masse. If a large quantity of bile be added, little or no precipitate may be formed, the liquid being rendered alkaline.

4. Boil bile with twice its bulk of strong hydrochloric acid for five minutes. The bile is decomposed into bile-resin (cholic acid with colouring matter) and glycin and taurin, the two last-mentioned substances remaining in solution.

5. Pettenkofer's Test for Cholic acid. Spread a drop of bile in a thin film on a white porcelain capsule. Mix with a drop of strong solution of cane-sugar. Add concentrated sulphuric acid drop by drop, and, if necessary, warm. A deep purplish-red colour appears.

6. Repeat the test with an alcoholic solution of bilin. The same colour is produced.

7. Gmelin's Test for the colouring matter. Spread a drop of bile in a thin film on a white porcelain capsule. Allow a drop of strong nitric acid to fall into the middle of the film and observe the effect. The drop becomes surrounded by rings of green, blue, red, and yellow, in the order in which they have been named. Consequently the green, which is first formed, is eventually farthest from the drop of acid. If, instead of allowing the liquid to remain undisturbed, the acid be mixed with the bile, the liquid passes through the same tints in the same order.

8. Warm a little nitric acid in a test-tube. Incline the tube and pour bile down the side, so as to form a layer over the acid. The colours appear as in 7 , at the line of contact of the two liquids.

9. Cholesterin. Extract gall-stones with ether. The extract yields, on evaporation, crystals of cholesterin, which, when dropped into warm sulphuric acid, dissolve with a red colour. The residue, insoluble in ether, consists of colouring matter and mucin.

ro. Acidify ro c.c. of bile in a flask with hydrochloric acid and add zinc. Nearly close the flask with a cork to which acetate of lead paper is attached. The taurin of the bile is decomposed, $\mathrm{H}_{2} \mathrm{~S}$ being formed, which blackens the lead paper.

\section{VII.-Urine.}

1. Observe reaction and colour.

2. Determine the specific gravity, either by weighing or with the urinometer. Observe the effect of temperature.

3. Compare fresh with stale urine as regards appearance, smell, and reaction.

4. Sulphates. Add baric chloride after acidifying with hydrochloric acid. A white precipitate of baric sulphate is formed.

5. Chlorides. Add argentic nitrate after acidifying with nitric acid. A white curdy precipitate of argentic chloride is produced.

6. Phosphates. Add ammonic molybdate to urine which has been mixed with half its volume of nitric acid. Boil. A yellow crystalline precipitate falls. 
7. Urea. To urine evaporated to one-third, add a drop of nitric acid in a watch-glass. Glistening scales of urea nitrate are abundantly formed in the liquid.

8. Uric Acid. To a hundred c.c. of urine add 5 c.c. of strong hydrochloric acid. Allow the liquid to stand for forty-eight hours. Dark red crystals of uric acid separate from the liquid.

9. Urochrome. Precipitate about 50 c.c. with lead acetate and a drop of ammonia. Filter. The filtrate is colourless. Scrape the precipitate from the filter paper into a capsule. Mix with a few drops of strong sulphuric acid and add to the pasty mass a little alcohol. Filter. The yellow filtrate on boiling with excess of strong sulphuric acid turns black. Dilute the acid liquid with a large quantity of water. The uromelanine which separates in flocks is characterized by its extreme solubility in ammonia. It can be precipitated from its solution in ammonia by sulphuric acid.

Io. Indigo. To 500 c.c. of urine add 250 c.c. of pure hydrochloric acid. Allow the liquid to stand twenty-four hours. A coppery scum floats on the surface. Filter. Treat the filter first with ammonia to extract the uromelanine, secondly with cold alcohol, which acquires thereby a red colour. On boiling the residue in alcohol a blue solution is obtained, which exhibits the absorption spectrum of indigo-blue.

N.B.-In consequence of the large quantities which must be used, this experiment cannot be carried out by each student.

VIII.-I. Quantitative determination of Urea. Urea $\left(\mathrm{CO} \mathrm{N}_{2} \mathrm{H}_{4}\right.$ ) when decomposed by suitable oxidizing agents, yields $\mathrm{CO}_{2}, \mathrm{H}_{2} \mathrm{O}$ and N. The most convenient reagent for effecting this decomposition is an alkaline solution of sodic hypobromite. The $\mathrm{CO}_{2}$ is absorbed by caustic soda. The nitrogen which is disengaged is collected and measured in a suitable apparatus. Every $37^{\circ} 3$ c.c. of nitrogen, at ordinary pressure and temperature, corresponds to $0.1 \mathrm{grm}$. of urea. The hypobromite solution is prepared by adding 25 c.c. of bromine to 250 c.c. of a solution containing $100 \mathrm{grm}$. of caustic soda.

a. If Russell and West's apparatus is used, measure off in a pipette 5 c.c. of urine and introduce carefully into the bottom of the "reaction-tube." Rinse the sides of the tube with distilled water until the liquid reaches the constriction. Plug with the caoutchouc stopper, avoiding the introduction of air. Fill up the tube with the hypobromite solution and half fill the trough with water. Fill the measuring tube with water and invert it in the trough. Lift out the stopper, and, without loss of time, place the measuring tube over the reaction-tube. Warm the bulb of the latter until the liquid just boils, and read off the quantity of gas collected.

b. If Dupré's apparatus be used, introduce 25 c.c. of hypobromite into the flask $c$. Measure off 5 c.c. of urine into the test-tube, and close the flask with the caoutchouc stopper to which the test-tube is attached. Open the pinch-cock $d$ and lower the measuring tube $a$, until the surface of the water is at the zero point of the graduation. Close the pinch-cock and raise the measuring tube. If the apparatus be tight, mix the urine gradually with hypobromite solution by inclining the flask. Finally, tilt the flask so as to rinse out the test-tube with the solution, and shake well for a few seconds. Immerse 
the flask in a vessel containing water at the same temperature as that in the jar. At the same time lower the measuring tube. After two or three minutes, raise the measuring tube again until the surfaces of the liquids inside and out coincide. Read off the quantity of nitrogen which results from the decomposition of the 5 c.c. of urine.

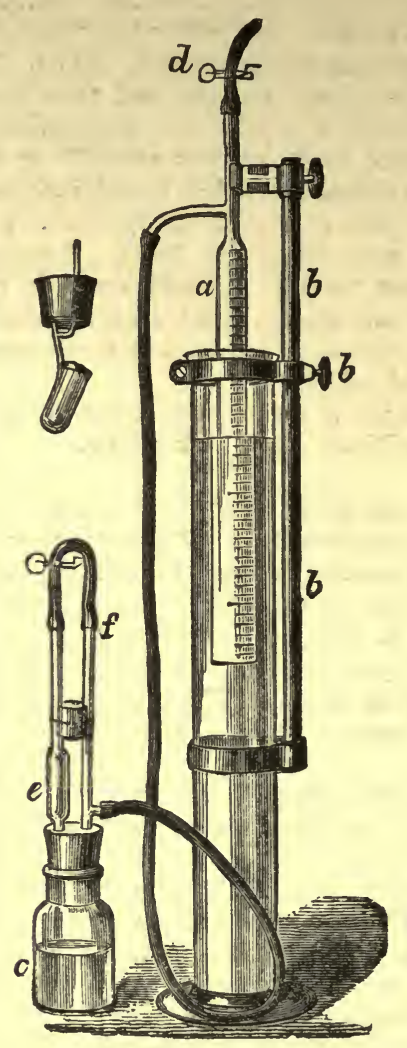

DUPRE'S UREA APPARATUS.

The stopper and test-tube represented in the upper left hand of the figure take the place of the stopper, pipette and tube $e f$. The woodcut has been kindly lent by Dr. Dupré.

Phosphates. When solution of uranic nitrate or acetate is added in successive quantities to a hot solution containing phosphates, previously acidified with acetic acid, the whole of the uranium is precipitated so long as any phosphate remains in solution as uranic phosphate. As soon as an excess 
of uranic salt is present, it can be detected by potassic ferrocyanide, which gives a brown colour with uranic salts.

The standard uranic nitrate solution contains $35^{\circ} 5$ grammes in a litre. One c.c. corresponds to 0.005 gramme $\mathrm{P}_{2} \mathrm{O}_{5}$.

To 50 c.c. of urine add 5 c.c. of a solution containing 100 grammes of sodic acetate in 900 c.c. of water, to which 100 c.c. of glacial acetic acid have been added. Heat the 55 c.c. to $80^{\circ} \mathrm{C}$. Add the uranic nitrate solution, until a drop of the mixture placed on a white porcelain slab gives a distinct brown colour, with a drop of potassic ferrocyanide. Note the quantity of solution used and calculate therefrom the percentage of $\mathrm{P}_{2} \mathrm{O}_{5}$ in the urine. *

\section{IX.-Blood-Plasma and Serum.}

\section{** The experments described in this section cannot be satisfactorily carried out in warm weather.}

I. Dilute about I c.c. of sodic sulphate plasma (obtained by collecting blood in one-third of its volume of saturated solution of sodic sulphate) with 20 times its volume of water and place in a water-bath warmed to about $35^{\circ} \mathrm{C}$. ; it will probably coagulate in about 20 to 30 minutes.

2. To a second similarly diluted liquid add a drop or two of solution of "blood-ferment" (prepared by precipitating serum with alcohol, collecting the precipitate, drying in vacuo and extracting with water). The addition of this solution promotes coagulation.

3. To 2-3 c.c. of pericardial fluid (from the horse) or hydrocele liquid add a little serum and place the mixture in a warm bath; it will coagulate.

4. Saturate about 5 c.c. of pericardial fluid with sodic chloride, by adding finely-powdered salt, and shaking; a proteid substance separates and forms a thick scum on the surface. Pour off the liquid, dissolve the scum in water, add a few drops of serum, and place in the warm bath; the mixture will coagulate.

5. Precipitate about 5 c.c. of sodic sulphate plasma as in 4, dissolve the sticky precipitate in water and place in the warm bath; the solution will coagulate.

6. Acidify 5-10 c.c. of serum with a drop of acetic acid and boil, filter off the albumin and evaporate the residue. Sodium chloride crystallizes in aggregations of cubes.

7. Dilute I part of serum with 15 parts of water, add a drop or two of dilute acid (O'I per cent.). Paraglobulin is precipitated (see $\S \mathrm{iv,} \mathrm{2,a).}$

* For details as to the hypobromite method, see Dupré's original paper in the Fournal of the Chemical Society, 1877, vol. i. p. 534 .

The method for the determination of $\mathrm{P}_{2} \mathrm{O}_{5}$ is practised in this class as an example of a volumetric process. For other methods relating to the urine consult Handbook for the Physiological Laboratory, pp. 545-558. It is important to remember, that in order to obtain trustworthy results, as scrupulous care must be taken in the measurement and collection of the urine passed during the period of observation as in the analytical procedures. 
52 COLOURING MATTER

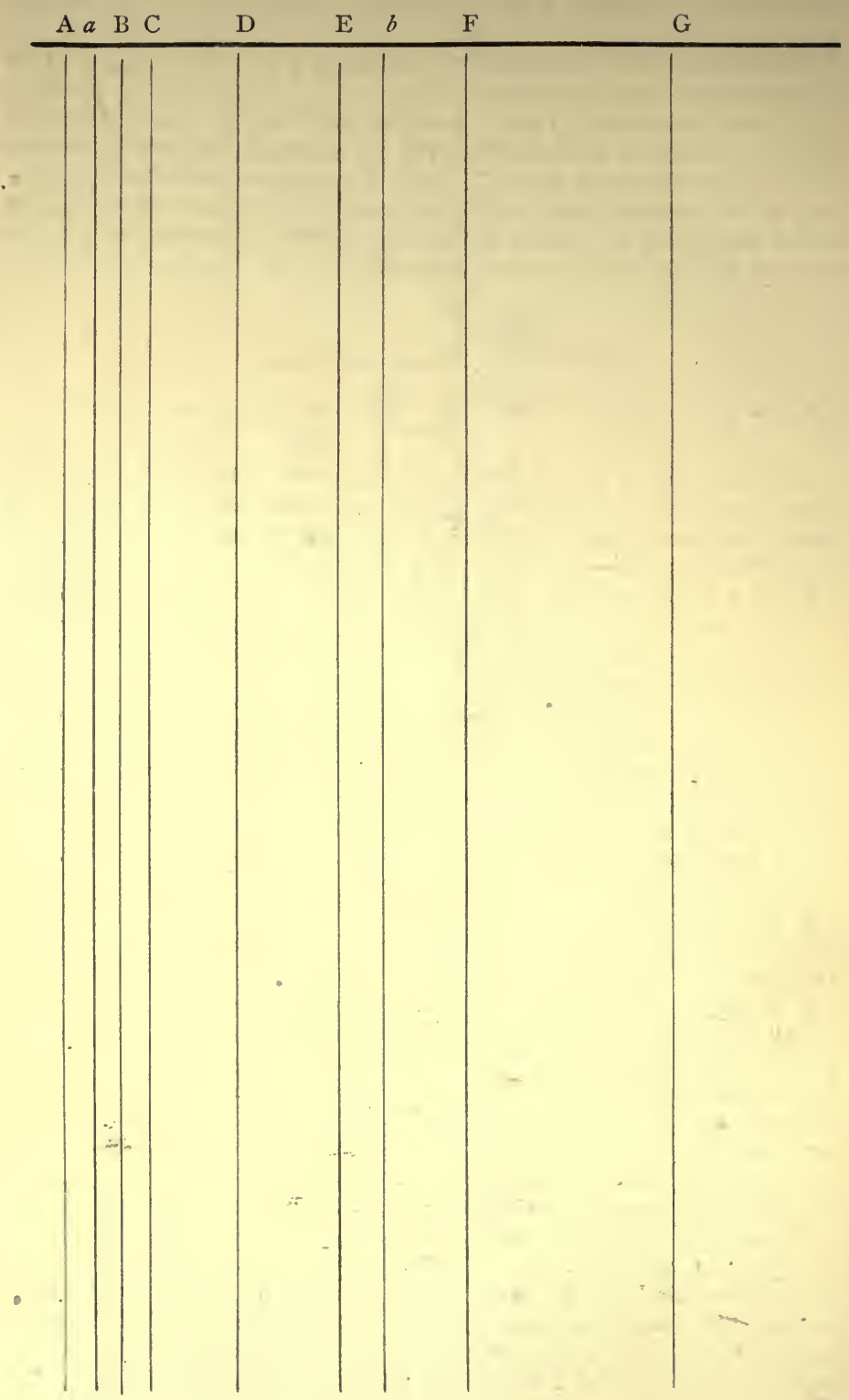


8. Tie up in a piece of bladder or other animal membrane some whipped blood, and place the bag containing the blood in a beaker of distilled water.

The colouring matter and proteids exhibit but a slight tendency to pass through the membrane; the soluble salts pass through readily, and their presence can be recognized in the water by the usual tests.

9. Pour over some fibrin contained in a watch-glass some solution of peroxide of hydrogen. Bubbles of oxygen are given off. If some tincture of guaiacum be added a blue colour is developed. Gluten, potato peelings, and many other substances develop a blue colour under the same conditions.

\section{X. - The Colouring Matter of the Blood.}

I. Observe the solar spectrum, noting the positions of the dark lines $\mathrm{D}, \mathrm{E}, b$ and $\mathrm{F}$, in relation to the colours. Compare it with the spectrum of a gas flame, which shows no dark lines.

2. Observe the spectrum of a flame coloured with sodic chloride, noting the position of the bright yellow line.

3. Oxy-hæmoglobin. Introduce defibrinated blood into a test-tube, and observe its opacity when undiluted.

a. Dilute by adding five to ten times its bulk of water. Place the test-tube in front of the slit of the spectroscope, direct it to a gas flame. The only light which passes through is that of the red end of the spectrum.

b. Add water until the green appears. Note the dark space (absorption band) between the red and green.

c. Dilute still further until the yellow-green light is distinguishable in the middle of the dark space, dividing the single broad band into two.

$d$. After a further addition of water, note that the band nearest the $\mathrm{D}$ line is somewhat more sharply defined than the other. The spectrum is still shortened by the absorption of its violet end.

e. On diluting, until the solution is almost colourless, two faint bands ar still visible.

$f$. Map on the diagram the appearances observed in $3, b$ and $d$.

4. Reduced Hæmoglobin. To some blood diluted as in 3 , $d$, add a drop of solution of ammonic sulphide, and warm gently. The colour becomes purplish. Place the tube in front of the slit as before, and observe the change which has occurred. A single absorption band, with ill-defined edges, takes the place of the two bands previously observed. Map its position on the diagram.

5. Alkaline Hæmatin. Add to solution of blood, rather stronger than the last, a drop of solution of caustic potash. Warm gently; the colour completely changes. An absorption band appears to the left of the line D, and much of the blue end of the spectrum is cut off.

6. Reduced Alkaline Hæmatin. To the solution obtained in $\mathbf{5}$ add a drop or two of ammonic sulphide and warm gently. Observe the change of colour. Dilute if necessary. A strongly marked band is seen to the right side of the line $\mathrm{D}$, and a second less defined, which nearly coincides with the line E. 
7. CO-hæmoglobin. Blood which has been acted upon by carbonic oxide has a peculiar cherry-red colour. The two absorption bands have nearly the same position as those of Oxy-hæmoglobin, but no change is produced when the liquid is treated with reducing agents, as in 4 . 
PART II.

\section{THE MECHANICAL PROCESSES.}

\section{Muscular Contraction.}

MUSCLE consists of parallel fibres, each of which is a tube containing contractile living substance. This living substance is of two kinds, which differ in their optical properties, and are arranged in layers alternating with each other. In contraction their absolute and relative volumes alter. So long as the tissue is living, the contractile substance can be squeezed out as juice (muscleplasma), but after death it solidifies and exhibits a tendency to split, transversely and longitudinally. Muscle is neutral when living, acid after death. Muscle-plasma coagulates spontaneously at all temperatures above that of freezing. At $40^{\circ} \mathrm{C}$. coagulation is instantaneous: the promptitude with which it occurs is the less, the lower the temperature. The coagulum is myosin (see p. 3I).

The chemical changes which constitute the life of muscle manifest themselves in the production of $\mathrm{CO}_{2}$ and $\mathrm{H}_{2} \mathrm{O}$, which are disengaged in the proportions in which they result from the combustion of carbohydrates. When the tissue is inactive, these are formed in very inconsiderable quantities ; but in muscular activity, the rate of discharge is increased in proportion to the work done.

Living muscle is elastic, contractile and transparent. As life ceases it stiffens, shortens, loses its contractility and transparency, and the contents of its fasciculi become solid. Death of muscle is promoted by defective blood supply, high temperature or injury. It is slow and 
gradual in the frog, rapid in man and mammalia. It is associated with chemical changes which resemble those which take place in contraction.

Partial rigor can be induced in living muscle by arrest, and removed by restitution, of the circulation. Muscle becomes rigid at about $45^{\circ} \mathrm{C}$. in 'frogs, $48^{\circ}$ to $50^{\circ}$ in mammals. Rigor occurs sooner after death in exhausted muscles than in others : all rigid muscles are acid.

In doing work muscle shortens and thickens. Its volume diminishes very slightly and it becomes more extensible. Every muscular contraction results from excitation either extrinsic or intrinsic. An instantaneous extrinsic excitation of a muscle by its nerve produces a single contraction, called a twitch. The contraction begins a certain time after the excitation (period of latent excitation of du Bois-Reymond); it rapidly increases to a maximum and then gradually subsides. After contraction has ceased the muscle is nearly as long as before, and soon quite as long.

By the myographic method (see Practical Exercises) a single contraction may be investigated with reference to the time after excitation at which it begins, to its duration and character, and to the modifications produced by changes in its physiological condition, or in its temperature. If two or more instantaneous excitations of a muscle through its nerve follow each other, the effect is augmented by each successive excitation; but the increment produced by any single excitation is always less than that produced by its predecessor. The effect of a series of equal excitations following each other at very short intervals of time, although apparently continuous, consists in reality of a succession of instantaneous contractions, of which the frequency is the same as that of the excitations. This condition is called, in physiological language, Tetanus. The number of single contractions per second of which a tetanic or voluntary contraction is constituted may be judged of by the "tone" heard in the contracting muscle. 
In ordinary voluntary contraction in man, the tone has a vibration rate of from 38 to 40 per second.

Under the influence of the arrow poison (curare), the end-organs of the muscular nerves become incapable of performing their function, so that the muscles of animals poisoned by this drug are virtually nerveless. The contraction produced by instantaneous excitation, at any point of a "curarized" and extended muscle, progresses from the point excited in the direction of the fibres. In fresh muscles the rate of progress of the contraction wave is from 3 to 4 metres per second; the duration of the contraction is about 0.07 second; hence the wave length of contraction is about a quarter of a metre. In exhausted muscles and in muscles under the influence of cold, the rate of progress is slower than in fresh muscle at the ordinary temperature.

The above statements refer to the effects of single induction shocks, or of successions of them. If a voltaic current is led for a moment through a curarized muscle, the tissue is excited at the negative pole (cathode) at the closure, and at the positive pole (anode) at the opening of the circuit. In this case, the muscle remains contracted during the whole period that the current is passing.

By the term "absolute force" is denoted the heaviest weight a muscle is able just to lift, when contracting to the utmost advantage under the influence of a sufficient excitation. The weight which a muscle is able to lift varies according to its extension, being greatest when it is most extended-consequently greater at the beginning of a tetanic or voluntary contraction than at the end. The maximum quantity of owork is done by a muscle when it is nearly loaded to the utmost throughout the whole contraction. In order that this may be the case, the load and the power of the muscle to lift it must diminish at the same rate. If the load to be lifted remains constant, the muscle acts most advantageously (i.e. does most work) when the 
weight is considerably less than the maximum weight which the muscle is able to lift. Muscle is elastic: a muscle extended by a load recovers its original length when the load is removed. When a loaded muscle is extended by successive additions of equal weights to its load, the increase of length, resulting from each addition, becomes less and less as the extension proceeds, until no further increase is observable. Of two muscles, of which one is in tetanus, the other at rest, the former is more extended by the same weight than the latter.

In contraction the temperature of muscle is slightly raised : the greater the effort, and the less the work done, the greater the rise.

In living muscles, differences of electrical tension are usually observed between different parts of the natural surface, which differences can be shown to be intimately associated with the vital properties of the tissue, and cease with the cessation of its life. The greatest differences (often amounting to several hundredths of a Volt) present themselves when a sound surface is compared with an injured one, the injured part being always negative to the sound. In a muscle which is at rest, all parts being in the same physiological condition, the surface is (according to Hermann) isoelectric or equipotential. Such a condition is rarely met with in the voluntary muscles, for the slightest exposure or injury produces electrical inequality, but is easily observed in the resting heart. In voluntary muscles, separated from the body, it is commonly observed that the end surfaces are negative to the lateral surfaces. During the state of excitation, which precedes contraction (period of latent excitation) the electrical state of (uninjured) muscular tissue undergoes a change which consists in its becoming negative to the unexcited parts. In tetanus this change precedes each single contraction (see p. 56). In nerveless (curarized) muscles, the excitatory state 
is propagated along the fibres at a rate which agrees with that of the propagation of the wave of contraction, so that the latter is preceded in its progress by the former. In nerved muscles, which are excited through their nerves, the excitatory waves are similarly propagated, but originate from nerve endings. In injured muscle the electrical difference between injured and uninjured surfaces is diminished during excitation. This excitatory effect was therefore called by du BoisReymond the "negative variation."

The excitatory disturbance is, in all cases, followed by other changes, which correspond in time to the contraction, but have not yet been fully investigated.

All of the phenomena above described are comprised by du Bois-Reymond in a theory, according to which every portion of living muscular fibre contains electromotive particles, each of which has ends (poles), which are directed towards the ends of the fibre, and are negative to the zonal surface, which corresponds to the surface of the fibre. The effect of excitation is to produce a momentary diminution of the electromotive force of these particles. The particles being called by du Bois-Reymond 'molecules,' the theory is known as the molecular theory of the muscle current.

In involuntary muscle the process of contraction is similar, but much slower. It is attended with electrical changes of the same nature as those observed in voluntary muscle.

\section{Circulation.}

The Arterial Circulation.-The arterial system is an elastic receptacle for blood, the form of which is dendritic. At the ends of the ramifications, blood flows by innumerable capillary channels into the venous system. Into the trunk, blood is injected at intervals by the heart, each injection lasting from three to four-tenths of a second. In the aorta the blood is squeezed by the arterial wall with pressures which probably vary from 
6 to 10 inches ( $=150$ to 250 millimeters) of mercury $=\frac{1}{3}$ to $\frac{1}{5}$ of an atmosphere $=3$ to $5 \mathrm{lbs}$. on the square inch. It is this pressure which is the cause of the circulation. Its maintenance is the function of the heart. The sum of the lumina of the capillaries is much greater than that of the aorta: the velocity of the capillary blood-stream is in the same proportion less. Arterial tissue recovers its length after stretching as perfectly as muscle: it is however more extensible. In the living body, its elastic properties are modified according to the degree of contraction of the muscular elements it contains.

The arterial blood-stream can be best understood by reference to the schemata described below.

Schema I. As regards the relation of pressure to progressive motion, the arterial system is represented by a tall cylindrical bottle from the bottom of which water flows through a horizontal tube of equal width throughout. In the arterial system, as in the schema, the lateral pressure (supposing the velocity of the blood-stream to be constant) is proportional to the sum of the resistances in front. If such a bottle, having an aperture equal to the lumen of the aorta, were substituted for the heart, the height to which it would be necessary to fill it with blood in order to carry on the circulation at the normal rate, would represent the force required for that purpose. That height multiplied by the weight of blood discharged per second in grammes, would give in gramme-meters the work done by the heart in the same time in maintaining the circulation.

Schema 2. As regards wave motion, or pulsation, it is represented by an elastic tube, $a b$, closed at both ends and moderately distended with liquid, into which water is suddenly and for a short time injected. The phenomena observed remain unaltered, if, instead of closing the tube at its ends, we imitate the conditions of the circulation by 
injecting liquid into it at short intervals at $a$, allowing it to flow out by a small opening at $b$. In the arterial system, just as in this schema, the momentary distension produced in the aorta by each injection of blood, is propagated to other parts of the system at a rate which is dependent on the previously existing pressure. Every such sudden distension is followed sooner or later by a second, which is called the second beat.

By virtue of the elasticity of the arteries, part of the motion which is communicated to the blood during each ventricular systole is stored as arterial distension, to reappear as progressive motion during the diastolic interval. If the arteries were not elastic, this motion would lose itself in the shock of the blood against the rigid arterial wall, whereby the arteries would be injuriously strained at each injection of blood, and the effect of the heart's action would be diminished.

Investigation of Arterial Pressure.-The hæmadynamometer is a mercurial manometer of which one limb can be connected with an artery by a tube containing solution of sodic bicarbonate. In order that the measurement may be accurate, it is necessary (I) that the mean level of the mercury surface in the proximal limb should be the same as that of the arterial aperture; and (2) that the tube should enter the artery at right angles to its axis.

Any instrument by which the arterial pressure can be measured, by inscribing its variations on a surface moving horizontally by clockwork at a uniform rate, is called a kymograph. A mercurial kymograph consists of three parts-the clockwork and recording cylinder; the manometer and writer; the tube and cannula by which the manometer is connected with the artery. Its uses are (I) to measure the mean arterial pressure and to record its variations; (2) to measure the duration of the pulsation intervals. Its chief defect arises from the "proper motion " of the mercurial column. The spring kymograph 
on Bourdon's principle is nearly free from "proper motion," and consequently enables us to measure the fine variations of arterial pressure in the course of each pulse interval.

The pulse as felt by the finger indicates the moment of greatest distension, i.e. that of greatest pressure in the artery. The distinctness with which it is felt is proportional to the shock communicated to the arteries by the heart. Pulses are classified according to frequency, hardness, duration and dicrotism. All of these characters may be appreciated by the finger, but are studied more accurately by the sphygmograph.

Three events may be distinguished in every pulse, viz., the beginning of the expansion, the collapse, and the beginning of the second beat. Of these the first occurs in the normal radial pulse about 0.15 second after the beginning of the effective part of the systole of the left ventricle. The second is synchronous with the end of the systole, and hence immediately precedes the closure of the sigmoid valves. The third is synchronous with, or immediately after, the closure of the valves.

The graphical characters of the arterial pulse, e.g. the radial, are determined by $(a)$ the character of the diastolic notch which, in the tracing, separates the first from the second ascent, and (b) the relative height of the second ascent. The notch is produced by the sudden cessation of the flow of blood from the ventricle into the aorta. It may be generally stated that the shorter the duration of the systole and the less the vascular resistance, the deeper is the notch.

The second beat is determined entirely by events which occur in the arteries and capillaries. When any part of an artery is suddenly distended, all parts of the arterial tree beyond pulsate after it; but each pulsates at a different moment, according to its distance from the $\mathrm{par}^{+}$primarily distended, and as each attains its maximum of distension, it sends back a return wave of expansion. The moment at which the strongest return waves, and the greatest number of them, arrive at the point of observation, is that at which the second beat occurs. 
Unnatural frequency of pulse depends either on functional disturbance of the cerebro-spinal centres or increased bodily temperature (pyrexia). Unnatural celerity of pulse, i.e. diminished duration of the period of expansion, is observed either in association with increased frequency, or in consequence of mechanical defect of the aortic valve. The opposite condition (tardiness of pulse) occurs in advanced age, and in collapse (e.g. in concussion), or under the influence of certain drugs, particularly of opium and digitalis.

Velocity of the Circulation.-The velocity of the bloodstream is dependent on the relation of the effort made by the heart to the resistance to be overcome in the vessels. This resistance varies according to the condition of the vascular nervous system.

It is believed that the velocity of the blood-stream in the aorta is about a foot in a second; in the capillaries about I-5oth of an inch; and that the circulation is accomplished in the time occupied by about thirty pulsations of the heart.

Of the instruments used for investigating the progressive movement of blood in the arteries, those by which the quantity conveyed in a given time can be estimated are called Dromometers (e.g. Volkmann's and Ludwig's), those by which the rate of movement only is determined, Tachometers. By the latter we learn that in the large arteries the second beat or expansion is attended by a cessation or even reversal of the blood-stream; by the former, that the rate at which blood is transmitted through an artery is subject to great and often sudden variations, and that these variations are independent of the rate at which blood is discharged into the arterial system by the heart.

Capillary Circulation.-In studying the circulation in the transparent parts of animals, we observe that the smallest arteries are subject to great variations of diameter, and often contract rhythmically; that the progressive move- 
ment in arterioles is more rapid than in veins of corresponding size; that in the veins the coloured corpuscles are carried along by the axial stream, the leucocytes tending towards the vascular wall; that when a tissue is injured the capillaries begin first to widen and then to leak, the plasma and leucocytes passing out in succession, and that more intense injury produces stasis and extravasation of the coloured disks.

Circulation in the Liver, Kidneys, and Spleen.-The difference between the pressure which exists in the trunk of the portal vein and that of the hepatic vein probably does not exceed half an inch. Consequently the blood-stream through the liver is extremely slow. In the kidneys, the blood enters the glomeruli at high pressure and with rapid motion; in the capillaries of the convoluted tubes the motion is slow, and the pressure that of the venous system. In the spleen, the quantity of blood contained in the organ at one time, and, consequently, its bulk are subject to very great variations; these are mainly due to the action of the muscular fibres contained in the capsule and framework.

Venous Circulation.-The capacity of the venous system much exceeds that of the arterial, and is sufficient for the reception of the whole of the circulating blood. The mean lateral pressure in the venous system, though much inferior to that which exists in the arteries, is dependent on it and varies with it. It is greater in the capillary veins than in the venous trunks: this difference is the chief cause of the venous blood-stream. It is greater during inspiration than during expiration. This difference is more marked in the intra-thoracic veins (where during inspiration the lateral pressure sinks below that of the atmosphere) than in others: it manifests itself in the respiratory movements of the brain, and other similar phenomena. The venous blood-stream is promoted by intermittent external pressure, hindered by continuous pressure. The venous pressure, and, conse- 
quently, the quantity of blood in a $\operatorname{limb}$, and the velocity of the venous blood-stream, are much influenced by position; but this does not affect the quantity of blood transmitted through the part in a given time. A slight diminution of the pressure in the veins nearest to the heart accompanies each pulsation: this is due to the diminution of the volume of the heart, which occurs at the moment of ventricular systole. When, from disease, the tricuspid valve is incompetent, the opposite effect is produced, and is called the venous pulse.

Veins are contractile, but there is no proof that their contractility is of physiological importance in man. In certain animals, the veins contract rhythmically.

The Lymph-Stream. - The progressive motion of the lymph is dependent on the difference between the pressure under which liquid exudes from the capillaries into the tissue interstices from which the lymphatics spring, and the pressure which exists in the lymphatic trunks. In all muscular parts it is promoted by the alternate tension and relaxation of the tendons and aponeuroses. In the visceral cavities it is similarly aided by the respiratory variations of external pressure to which the trunks are subjected, as well as by the circumstance that the mean pressure in the abdomen is greater than in the thorax. Solid particles, if of sufficient minuteness, whether introduced into the blood-stream or into the tissues, find their way into the lymphatics, which can usually be "injected" by the introduction of any particulate liquid into living tissue. It is probable that such particles are for the most part arrested in the lymph glands. The particulate constituents of chyme are forwarded from the intestinal cavity into that of the lacteals by the agency of the living protoplasm of the epithelium and mucosa. The further progress of the chyle in the mesentery is promoted by muscular action. 


\section{The HeART.}

The heart consists, in its simplest form, of a muscular dilatation provided with a valve or valves at either opening, and a venous antechamber or reservoir, which in the lower vertebrates is more perfect than in man and mammalia. In the osseous fishes another dilatation (the bulbus arteriosus) exists between the ventricle and the branchial arteries, the function of which is to store up energy during the ventricular systole, as the arteries do in mammals. In the cartilaginous fishes the bulb is a muscular organ in which energy originates, and it is often provided with valves. These complications in the structure of the central organ are rendered necessary by the simplicity of the circulation. In the batrachians the bulb is less required, for only part of the blood-stream passes through the respiratory apparatus, but the auricles are still provided with valves. In the mammalian heart, the mechanism of respiration renders the auricular valves unnecessary.

Motions of the Heart and phenomena which accompany them.-The form of the contracted human heart is that of a cone, of which the base is elliptical and the apex rounded off; in the relaxed state the heart assumes the form of the wedge-shaped space in which it is contained. It approaches the anterior wall of the chest in expiration, and recedes in inspiration. In systole the ventricles suddenly draw themselves together towards a part of the septum which is about two-thirds of the way from the auriculo-ventricular groove to the apex.

On grasping the contracting heart of an animal it is felt to widen and become harder. The impulse is due to these changes of form and consistency. It is felt most strongly between the fifth and sixth cartilages.

Each heart period is divided into two parts, the period 
of repose and that of action. The period of rest commences with the closure of the sigmoid valve. Its duration varies according to the frequency of the contractions. During the whole of it, the cavities fill with blood. The period of action, of which the duration in man is rather more than four-tenths of a second, commences with the auricular systole. About one-tenth of a second later, the ventricular systole begins: thereupon the auriculo-ventricular valves close and the blood is suddenly ejected into the aorta and pulmonary artery. At the end of the ventricular systole, which lasts about three and a half tenths of a second, the ventricle suddenly relaxes.

The lateral pressure in the auricles is about equal to that of the atmosphere. It rises, however, slightly in auricular systole, attaining its maximum at the commencement of ventricular systole. In the ventricles the pressure sinks below that of the atmosphere immediately after the sigmoid valves close; at the moment of systole it rises above the pressure in the aorta.

Each action of the heart is accompanied by two sounds. The first is produced by two causes, the muscular contraction and the sudden tightening of the heart. The second sound is due to the tightening of the aorta and sigmoid valves.

The filling of the right ventricle may, in the normal state, be attributed to the influence of the elasticity of the lungs, and in its absence to the pressure in the systemic venous system. The filling of the left ventricle is mainly due to the pressure in the pulmonary veins, and to the "aspirating power" of the ventricle itself. It is supposed by Brücke to be aided by the distension of the coronary arteries.

It is probable that about 195 grammes of blood are discharged by the left ventricle at each contraction. If the lateral pressure in the aorta were equal to that of 
a column of blood two metres in height, the work done by the left ventricle in each systole would amount to about four-tenths of a kilogramme-meter, without counting any work done within the heart itself.

\section{RESPIRATION.}

The alternating in-flow and out-flow of air, which constitute respiration, result from the action of muscles which, by changing the capacity of the chest, produce corresponding, though not necessarily proportional, variations of the capacity of the thoracic air cavity. In the state of rest, that is when the chest is not acted on by contracting muscles, its capacity is determined by the opposed tractions of elastic structures in a state of tension-namely, that of the lungs, which tends to diminish it, and those of the ribs and cartilages, intercostal muscles, and diaphragm, which tend to enlarge it. The capacity which the chest possesses under this condition is called the capacity of equilibrium. In ordinary tranquil breathing the chest is expanded beyond its equilibrium capacity in inspiration, but returns to it in expiration. The muscles by which this is effected are the diaphragm and the scaleni, which act by increasing the vertical diameter of the chest, and the external intercostals, levatores, and intercartilaginous internal intercostals, which increase its girth. When a larger exchange of air is required by the organism than can be thus secured, other inspiratory muscles come into play, which, by their combined action, aid in the expansion of the chest in inspiration, while in expiration the whole visceral cavity is constricted by the action of the muscles of the abdominal wall, of the lower internal intercostals, of the serrati postici inferiores, and of the sacro-lumbales-in consequence of which action the chest acquires in expiration a capacity less than that of equilibrium. 
In tranquil breathing the glottis is motionless, but in the more active modes of respiration, the cords diverge in inspiration, resuming their normal position in expiration. In extreme dyspnoa, inspiration is accompanied by dilatation of the nostrils.

The lungs, mechanically considered, may be regarded as a collection of elastic and very distensible bags, all of which communicate freely with each other as well as with the atmosphere. The volume of each lung, when removed from the chest, is much smaller than that of the cavity in which it is contained, and which, in its normal state of expansion, it completely fills ; consequently, when a pleural cavity is opened, the lung collapses. When the closed pleura is brought into communication with a mercurial manometer, the column in the open limb falls, so that the pressure to which any fluid in this cavity is exposed is less than that of the atmosphere. As measured when the chest is in the condition of equilibrium, the difference can be shown to be about $\frac{1}{\mathbf{1}} \overline{0}$ of an atmosphere $(7$ millimeters mercury). In natural inspiration it increases to 8 or 9 millimeters, and in full inspiration it may be increased to 30 millimeters. It is increased by any cause which destroys the expansibility of any part of the lung.

As the organs contained in the chest are under the same pressure as the fluid in the pleura, the flow of blood towards the heart is aided by the elasticity of the lungs. The same condition is also favourable to the diastolic filling of the heart, which contracts with more effect after each inspiration, so that the arterial pressure rises.

An adult male inspires from 25 to 30 cubic inches at a time, and about 20 times per minute; consequently, from 500 to 600 cubic inches per minute. The greatest volume of air which an individual is able to exchange in a breath is called the "vital capacity." The mean "vital capacity" of a man of ordinary height and build (5 feet 7 inches, and 32 inches in girth) is 2 IO cubic 
inches $=3480$ cubic centimeters. A woman 5 feet 5 inches in height and of average girth, has a vital capacity of not more than 160 cubic inches. From observations made on a large number of male adults of ordinary heights, it has been found that on the whole the vital capacity varies according to the height of the individual, in such a way that a difference of $I$ inch in height makes a difference of 150 centimeters, i.e. about 9 cubic inches in vital capacity; and further, that between two men of the same height, but different girth, there will be a difference of about the same amount, viz., 9 cubic inches for every inch difference in girth. Similar laws have been found to hold good as regards female adults. In individual instances this result is much affected by the flexibility of the chest, the muscularity of the individual, and other circumstances, the influence of which it is difficult to estimate. After the most complete expiration possible, a quantity of air remains in the thorax, which is sometimes called "residual," and amounts to about 90 cubic inches. In the equilibrium position the chest contains about 190 cubic inches; when fully expanded, about 300 , of which 2 Io can be expelled.

Two sounds are heard in listening to the normal chest, viz., the vesicular inspiration sound, and the bronchial sound, which is chiefly expiratory. The former has its seat in the infundibula, the latter in the rima glottidis. In each case the production of the sound is dependent on the sudden widening of the channel along which the air flows.

\section{BODILY Motion.}

Action of Voluntary Muscles on the Skeleton.-With the exception of those cases in which voluntary muscles act peristaltically, the effect of muscular contraction in producing motions of the whole body, or of parts of it, is always 
dependent on approximation of the ends of the muscles concerned. The direction and extent of these motions are regulated by the forms of the movable bones, and of the symphyses or of the joints by which they are connected with the rest of the skeleton. The term symphysis is applicable to the connection of two bones by a perfectly elastic material, in such a way that, after having been bent or twisted on each other, they tend to recover their relative normal position. The only example of this in the human skeleton is that of the bodies of the vertebræ. The essential difference between the joint and the symphysis consists in this-that in the former the bones have no normal relation to each other, but assume with equal readiness any among the infinite number of relative positions which the structure of the joint allows.

Joints are divisible into those which have a single axis of rotation (hinge joints) and those which have several axes (ball-and-socket joints). It is essential to the efficient working of a joint of either kind (I) that the two surfaces should be kept in apposition; and (2) that the movements of the bones on each other should be restrained within duc limits ; accordingly contrivances exist in all joints for these two purposes.

The efficiency of the action of a muscle in producing motion about a joint depends on the mode of its attachment to the bones. In all cases the effect produced is to the force exerted, as the distance of the nearest point of the straight line which connects the origin with the insertion of the contracting muscle from the axis of rotation of the joint is to the distance from the joint to the insertion of the muscle.

The maintenance of the erect posture is dependent on constant muscular exertion, for the line of gravity of the head falls far in front of the condyles of the occipital bone, that of the head and trunk together behind the line which joins the hip joints, that of the whole body, in front of the 
ankle joint. As regards each of these parts, excepting the head, the supporting muscles are aided by the forms of the joints and the arrangement of the ligaments. In sitting, the body if unsupported in front or behind is balanced on the tubera ischii.

- In walking, the position of the advancing or acting limb at the beginning of each step, is represented by the vertical side, the following limb by the hypothenuse of a rightangled triangle, of which the base is a step or pace, and the apex is in the position of the hip-joint: at the same moment the knee and ankle joints are flexed. Towards the end of each step, both joints become strongly extended. During each step the pressure of the foot upon the ground increases towards the end: the pelvis oscillates once from side to side and twice up and down, for every two paces, i.e. in each period of progression. In walking there is no interval during which the weight of the body is unsupported: in running an interval exists, the relative length of which increases as the pace quickens.

\section{VOICE AND SPEECH.}

The movements of the thyroid and arytenoid cartilages by which the form of the glottis and the tension of the cords are modified, are, (I) rotation of the thyroid on its horizontal axis; (2) rotation of each arytenoid on its vertical axis; and (3) rotation of each arytenoid on its horizontal axis. The first produces tightening or relaxation of the cords, the second, opening or closure of the vocal glottis. By the third, the arytenoid cartilages are approximated to or withdrawn from each other so as to vary the width of the space between them.

It is the principal function of the glottis to produce those "compound musical tones" to which in physiology we apply the term "voice." These, when modified by the 
mouth so as to become articulate, constitute "speech." Articulation consists in the production of certain sounds in the mouth and pharynx which are either associated with voice (as in speaking aloud), or constitute all that is heard (as in whispering). These sounds are distinguished as vowels and consonants. Vowel sounds differ from consonant sounds in possessing the characters of musical tones, and may accordingly be distinguished by the relative vibration rates of the tones which constitute them. Each vowel has its own pitch or tone. To produce any vowel sound, such form must be given to the cavity of the mouth and pharynx as to render it a "resonator" for the tone which is characteristic of the vowel to be produced. Consonants are modifications of the voice or whisper caused by the passage of air through constricted or valvular parts of the mouth or fauces. They derive their characters from the duration and order of succession of the sounds which constitute them. They are produced by the soft palate, tongue or lips. They are divisible into four groups, viz. (I) valve sounds, (2) blowing sounds, (3) nasal sounds, (4) vibrating sounds. Of these groups each of the sounds belonging to the first and second, presents itself in a soft and a hard modification, of which the former cannot be adequately produced in a whisper. This classification does not include the aspirate $\mathrm{H}$, which consists in the production of an expiratory sound in the larynx, immediately preceding that of the vowel sound aspirated. 


\section{PART III.}

\section{FUNCTIONS OF THE NERVOUS SYSTEM.}

\section{NERVES.}

THE organs of the nervous system of which the functions are known are (I) Reflex centres; (2) End-organs; and (3) Conducting organs. The most important conducting organs are nerves. A nerve is made up of fibres, each of which consists of axis cylinder, medullary sheath and nucleated sheath. The medullary sheath is divided into lengths by septa at equal intervals, but the axis cylinder is continuous. The axis cylinder consists chiefly of proteid, the medullary sheath of material for the most part soluble in ether.

Living nerve exhibits in itself three properties which appear to be characteristic-(I) that when injured so as to produce solution of continuity of its fibres, the injured part is electrically negative to the uninjured, (2) that when a nerve is excited, this electrical property is modified, the modification thus produced characterising the state of excitation, and (3) that this state can be propagated along the fibre in both directions. With reference to the state of excitation, two inferences are allowable, viz., (I) that the electrical change exists in uninjured nerves, although it is imperceptible, and (2) that it is associated with a chemical change.

The state of excitation is capable of being propagated from the nerve originally excited to excitable end-organs, namely, in the case of efferent nerves, to muscle or gland, and in the case of afferent nerves to centres. In this way 
it manifests itself outside of the nerve, either in the production of motions, secretions, reflexes, or states of consciousness. The excitability of a nerve admits of being measured by ascertaining the minimum excitation by which the signs of the excitatory state can be evoked. For this purpose the exciting agent used must be measurable. In the case of nerves of voluntary muscles, the excitability can also be judged of by measuring the degree of shortening of the muscle produced.

When the circulation ceases in a nerve or in the whole body, its vital properties alter. Its excitability at first increases, then gradually declines, until it is extinguished. These changes take place in the same order in all nerves, but occur earlier in parts nearest the centres (Ritter and Valli); thus the intra-muscular parts of motor nerves survive longest. Injury of a nerve produces increase of excitability in the neighbourhood. The extinction of excitability of a living nerve consequent on cessation of circulation, is immediately followed by structural changes affecting chiefly its medullary sheath.

In a similar manner loss of excitability and consequent change of structure, are produced by severance of a nerve from the cerebro-spinal centres. It is believed that they may also result from want of exercise. Nerve is more excitable and more vulnerable than muscle, but is less affected by want of blood supply and less readily exhausted by repeated excitation. The two last facts indicate that its exchange of material is much less active.

Influence of the voltaic current on excitability.-(I.) Under the influence of a constant current flowing along a nerve, its excitability is increased near the negative pole (cathode), decreased near the positive pole (anode), but the nerve is, as a rule, not excited so long as the intensity does not vary. (2.) Every variation of intensity of a current so directed excites the nerve. Other things being equal, the degree 
of effect produced is the greater, the shorter the time occupied in the variation. No effect is produced if the current is transverse. (3.) If the current is of moderate intensity, the excitation occurs at make and break whatever its direction-the make excitation starting from the cathode, the break from the anode. (4.) If the current is strong, the make excitation is suppressed when the current is from the muscle; the break excitation when it is towards the muscle. (5.) If the current is weak, there is no excitation excepting at make. The propositions 3,4 , and 5 constitute the so-called "Law of contraction." (Pflüger.) If the current lasts long and is of great intensity, reversed after effects manifest themselves on its cessation. Thus there is increased excitability at the anode which may lead to excitation and manifest itself in contraction (Ritter's Tetanus). This contraction is increased by reclosing the current in the opposite direction-annulled by reclosing it in the same direction.

The above experimental facts constitute the basis of the doctrine of Electrotonus. The contrast between the two opposite states (called Cathelectrotonus and Anelectrotonus) referred to in ( $\mathrm{r}$ ), is most easily observed in the parts of the nerve which are immediately beyond the limits of the part through which the current passes; but it can also be studied in the intrapolar part. Here it is found that the cathelectrotonic effect diminishes in extent, and that the anelectrotonic increases as the current becomes stronger. The statement (4) is satisfactorily explained on the ground that the propagation of the make excitation which originates at the cathode, is hindered by the anelectrotonus which exists at the anode, and that in like manner the break excitation is interrupted in consequence of the after effect at the cathode. The fact recorded in (5) which occurs invariably, simply means that the cathodic excitation is stronger than the anodic.

\section{Methods and Processes of Excitation.-(I) A motor} nerve may be excited by the closing or opening of a voltaic current flowing along it; (2) by any change in the intensity of such a current ; (3) by the passage along it of an induction current; (4) by the passage of a succession of induction currents in alternately opposite directions (Faradization) ; (5) mechanically-either by a single per- 
cussion or by a rapid succession of percussions (Heidenhain); (6) by chemical agents which either deprive the nerve of water or disintegrate it.

In all measurable modes of excitation, the muscular effect increases with the stimulus up to a certain limit, beyond which there is no further augment. Excitations just sufficient to produce the maximum effect are called "maximal"; others "over maximal" or "minimal" as the case may be. The effect of a minimal excitation is increased when the seat of excitation is in cathelectrotonos; the effect of a maximal is diminished when it is in anelectrotonos.

Excitation of one or more of the constituent fibres of a nerve is without effect on the others: it is incapable of propagation from the excited fibre to any other structure excepting the end-organ in which it terminates.

The phenomena known as the "paradoxical twitch" and the "secondary twitch from the nerve," which are apparent exceptions to the above statement, are due to electrotonic variation.

If by the myograph or otherwise the time is measured which elapses between an instantaneous excitation of a motor nerve and the beginning of the contraction of the muscle which it supplies, first with the seat of excitation close to the muscle, and then with the seat of excitation at 2.6 centims. distant, it is found that there is a slight difference amounting to about one-thousandth of a second between the two measurements.

Living nerve is electromotive. The phenomena closely agree with those of muscle. In an undivided nerve no electrical differences manifest themselves either in the normal state or during excitation. In a severed nerve, the cut surface is found to be negative to the sound surface; the difference is, however, much less than in muscle. An instantaneous excitation of any part of a severed nerve produces a momentary diminution of the relative 
negativity of the cut surfaces (negative variation). The time at which this happens depends on the distance between the seat of excitation and the section. The rate of propagation of the negative variation as measured by the "rheotome" (Bernstein), agrees with that of the transmission of the excitatory state in a motor nerve, as measured by the myograph.

Electrotonic zariation of the nerve current.-If during the passage of the voltaic current through the central part of a length of nerve, the extra-polar parts are investigated, electrical differences show themselves which have the same direction as those which are produced by the current in the inter-polar tract.

\section{Functions OF NERVE-CENTRES.}

By the term "centre" are designated certain parts of the Brain or Spinal Cord, respecting each of which it is known that it is concerned in the regulation or control of some one of the chemical or mechanical processes of the living organism. Our knowledge of the limits and topographical relations of these parts, and of the channels by which they mutually influence each other, and the organs over which they preside, is derived almost exclusively from experiments on living animals.

Nerve centres are excitable organs which owe their physiological endowments to the nerve cells and reticulum of which they consist, and to the connection of these structures with afferent and efferent nerves. The excitatory state originates in them for the most part by propagation from afferent nerves, or from other centres, and is propagated by them to other centres or to efferent nerves.

This process is designated "reflex action ;" a term which is applied to any case in which the function of a mus- 
cular, glandular, or other organ is called into activity or arrested in consequence of the excitation of an afferent nerve.

The most important reflex actions are muscular. These are of two kinds, which may be called normal and abnormal. Normal reflex processes spring from the excitation of one or more peripheral sense-organs, by usually feeble stimuli. They are characterized by the fact that excitations of the same kind, originating from the same end-organs always lead to the same results, that is, occasion the same combinations or series of co-ordinated muscular actions. This fact justifies the hypothesis that in the centres there are channels of propagation, by which the excitatory process is guided, notwithstanding that our present knowledge of anatomy affords no clues by which they may be traced. All normal reflex processes are adapted to the accomplishment of useful purposes in the animal economy.

Abnormal, incoordinate, or convulsive reflex processes, do not occur in the healthy body, excepting in consequence of injury. The excitatory state which here as in the other case is communicated to the centre by an afferent nerve, spreads from it to other centres by mere continuity of structure, irrespectively of channels of propagation. Consequently those centres which are nearest, are as a rule first affected, and in their turn the motor nerves which spring from them and the muscles to which such nerves are distributed, without distinction of function. In the abnormal state, whether induced by loss of blood, by interference with respiration, by disease, or by poisons, incoordinate reflexes may be excited by the action of ordinary stimuli on sensory end-organs, but much more readily by injuries of nerve trunks.

The time occupied by normal reflexes varies according to their complexity, and to the remoteness of the centres concerned, from a twentieth to a tenth of a second, or even 
more. Of this time, all but about a hundredth of a second is occupied in the central process.

It is often observed that the muscular effect produced by the excitation of one afferent nerve is hindered or delayed by excitation of another. This phenomenon is called inhibition. This may be attributed either to the counteraction of two centres, or to the counteraction of two excitations in the same centre.

Our knowledge of both kinds of reflex action is largely derived from the observation of the phenomena exhibited by the body of the frog after the animal has been killed by removing the brain. In preparations of this kind it is seen (I) that definite series or groups of muscular actions adapted to purposes, occur in response to excitation of particular spots of the cutaneous surface ; (2) that slight excitations so applied, act by summation, i.e., do not produce any effect until they have lasted for some time ; $(3)$ that the excitation of the central ends of nerve trunks produces irregular or convulsive reflexes, the extent of which varies according to the intensity of the excitation ; (4) that under the influence of strychnine, similar effects are produced, by ordinary cutaneous stimuli ; (5) that by acting directly on the "convulsive centre" in the medulla oblongata, or by faradization of the whole cord, general convulsion is produced, similar to the partial effects above described (see Practical Exercises).

\section{Functions of the Roots of the spinal nerves and of their Ganglia.}

It was discovered by Charles Bell, in I 8 I I, that mechanical irritation of the anterior roots of the spinal nerves, produced convulsive movements of the muscles to which they were distributed. More than ten years later, Magendie discovered that excitation of the posterior roots produced pain, and occasioned reflex contractions of the muscles, and that these were prevented by section of the anterior roots: subsequently he discovered that in mammals after severance of an anterior root, excitation of the peripheral end influences the cord through the trunk and posterior root of the same nerve. In the frog the anterior roots are exclusively afferent.

Of the function of the ganglia of the posterior roots 
nothing is known, excepting that severance of a ganglion from the nerve trunks to which it belongs, produces loss of excitability and structural changes in afferent fibres of the nerve. (Waller.)

\section{Functions of the white columns of the Spinal Cord.}

The most important anatomical facts relating to the channels by which excitation is transmitted in the spinal cord, are (I) that the fibres of the spinal nerves are not continued to the brain, but communicate with ganglionic cells; (2) that in the anterior roots this communication is direct, mediate in the posterior, i.e. through the reticulum; (3) that the anterior roots may be traced through the anterior horns, to the anterior columns of the other side by the white commissure, as well as to the anterior and lateral columns of the same side ; $(4)$ that the fibres of the posterior roots divide into two sets, of which the smaller at once lose themselves in the substantia gelatinosa, the larger division tending inwards towards the posterior columns, in which some of the fibres appear to acquire a vertical direction; (5) the sectional area of the lateral columns of the spinal cord is, as measured at any part of its course, proportional to the sum of the sectional areas of the nerves which enter it below the section; (6) the sectional area of the grey substance is proportional to the sum of the sectional areas of the nerves which enter the cord in the neighbourhood of the section.

The most important results of experimental investigation as to the channels of propagation in the cord may be stated as follows:-(I.) The fibres of the lateral columns are the only channels of influence between the intra-cranial centres and the lower limbs. (2.) The afferent fibres by which excitation of either lower extremity influences the intracranial centres, are contained in the lateral columns of the opposite side. (3.) The fibres by which the intra-cranial centres influence the muscles of either inferior extremity are contained for the most part in the lateral column of the same side. (4.) It is probable that the fibres of the anterior and posterior columns serve as channels of communication between neighbouring parts of the cord. There is reason, however, for believing that in the lumbar region, the posterior columns contain fibres by which sensory impressions are transmitted upwards. 
The spinal cord is entirely insensible to mechanical stimulation excepting in the immediate neighbourhood of its motor roots. Its grey substance seems to be also wholly insusceptible of electrical stimulation, but its fibres. can be excited either by single induction shocks or by faradization.

\section{Centres of the Medulla Oblongata.}

The central canal of the cord opens out into the rhomboidal space, or fourth ventricle, the two grey columns (horns) thus becoming superficial, and assuming such a position that what was before posterior lies outside. In the stratum of grey substance thus exposed, are contained the regulatory centres which preside over the most important functions of the body, namely those of the heart, of the arteries, of the respiratory organs, of the organs of digestion, of speech, of taste, and of locomotion. The origins of the nerves concerned in the functions of these centres are in close relation with each other, but nothing precise is known of their anatomical relations.

The regulatory centre for the heart is represented by two tracts of grey substance on either side of the spinal canal, but nearer to the posterior surface. At the cal. script. these diverge and become continuous with the vagal tracts (ale cinerea) which are separated from each other by the nuclei of the hypoglossal nerve. Each vagal tract is in relation at its upper end with the nucleus of the glossopharyngeal nerve, which is close to the auditory striæ. Outside of each vagal tract are the internal and external nuclei of the auditory nerve, which are respectively continued downwards into the grey tubercle of Rolando and the restiform nucleus. Higher up, the internal auditory nucleus becomes continuous with the origin of the sensory division of the trigeminus, the motor division of which springs from the grey substance nearer the middle line. The hypoglossal nucleus is continuous with those of the abducens and facial, which lie underneath the eminentia teres of each side, and is in relation externally with the origin of the motor root of the trigeminus. The same motor tract is continuous upwards with the grey substance underneath the floor of the aqueduct, from which the oculomotorius and trochlearis spring.

Influence of the Nervous System on respiration.-The respiratory nervous system consists of $(a)$ the regulatory centre (vagal tracts) ; (b) the afferent fibres of the vagus; (c) motor fibres contained in the facial and recurrent, as well as in the phrenic, intercostal, and other spinal nerves. (I.) Destruction of the vagal tracts produces instant death in mammalia; destruction of the upper part only, arrests 
those respiratory movements which are dependent on the facial nerve: destruction of the lower part only, arrests the thoracic movements. (2.) The respiratory centre acts automatically, i.e., is self-acting, but (3) its activity is affected by the condition of the circulating blood, in such a way that the more abundantly it is supplied with arterial blood the less active are the respiratory movements, and the fewer muscles take part in them. Accordingly saturation of the hæmoglobin of the blood with oxygen produces apnœa, i.e., suspension of respiratory effort, while defective arterialization produces increased activity of both centres, i.e., hyperpnœa, which, if prolonged and excessive (dyspnœa) results in exhaustion. (See Asphyxia, p. 90.) (4.) The centre receives through the vagus trunk two sets of nerve fibres which act upon it antagonistically to each other. Of these, one set are chiefly contained in the superior laryngeal, the other probably exclusively in nerves distributed to the bronchial tubes and lungs, of which some of the fibres are also inhibitory. The influence of these fibres may be understood by supposing either that the respiratory centre consists of two parts, of which one is inspiratory, theother expiratory, and that the second of these acts antagonistically to the first, i.e. exercises an inhibitory influence over it, or that there is one centre of which the action is affected in opposite ways, according as one or the other set of fibres is excited. (5.) The condition which produces hyperpnœa is not excess of $\mathrm{CO}_{2}$ but defect of oxygen. (6.) The influence of increase of the temperature of the blood on the respiratory movements resembles that of defect of oxygen.

Experimental Proofs. - I. Destruction of the vagal tracts produces sudden cessation of respiratory movements, without convulsion; but severance of the fascic. teretes above the strix stops only the respiratory movements of the face, the laryngeal and thoracic movements continuing. 2. After section of both vagi and of the cord above the third cervical vertebra, the animal dies of asphyxia, but the respiratory movements of the facial muscles and those of the sternomastoids continue. 3. Section of both vagi below the sup. laryng. produces diminished frequency, increased amplitude and altered rhythm of thoracic respiratory movements, with prolongation of each inspiratory act. 
4. In artificial respiration the rhythmical action of the laryngeal and facial muscles continues, and follows the rhythm of the artificial respirations, each injection of air being followed by expiratory movements of the nares and glottis. 5. Excitation of the central end of the divided sup. laryng. nerve always produces transitory cessation of respiratory movements with relaxed diaphragm. The same effect is produced by injection of air impregnated with $\mathrm{NH}_{3}$ gas into the larynx from below. 6. Excitation of the central end of the divided vagus produces sometimes continuous or interrupted contraction of the diaphragm, sometimes the effects described in 5. 7. Respiration of an atmosphere containing excess of $\mathrm{CO}_{2}(20 \%$ or more) does not produce dyspnœa if as much as $20 \%$ of $\mathrm{O}$ be present. 8. Dyspnœea is produced by warming the blood which is supplied to the medulla oblongata, whether the general temperature of the body be raised or not.

Reflex respiratory movements.-Co-ordinated respiratory movements adapted for the exclusion or expulsion of irritating substances from the respiratory cavities, are determined either by mechanical or chemical excitation of the nares (sneeze), of the mucous membrane below and on either side of the epiglottis (closure of the glottis), or of the vocal cords (cough), or of the bronchial mucous membrane (paroxysm of cough by summation). In coughing and sneezing, each reflex effect consists of three acts, viz., a short inspiration, followed by a violent expulsive burst of air through a previously closed air-way, in the production of which all the expiratory muscles, both the constrictors of the abdominal cavity, and the depressors of the lower ribs, take part. The closure, which is the second phase in the process, takes place in cough at the glottis, in the sneeze at the fauces. The afferent channels concerned in these reflexes are contained in the middle division of the trigeminus and the vagus. The muscles are those of respiration and of the fauces and soft palate.

The various abnormal modes of respiration which occur in disease, may be referred either to altered rhythm of the centre (Cheyne Stokes breathing), to excessive proneness to the production of reflex expiratory action (spasmodic cough), to suspension of vagus action (true asthma), \&c.

Influence of the Nervous System on the Heart.-I. The 
regulatory nervous system of the heart consists of $(a)$ the intra-cranial heart-centre (spinal accessory nuclei); $(b)$ the fibres of the spinal accessory and vagus, which are distributed to the heart, and $(c)$ the accelerator nerves. 2. It was discovered by E. H. Weber in $\mathrm{I} 842$ that through the vagus the brain exercises an inhibitory influence on the heart, i.e., that excitation of the cardiac fibres of the vagus either arrests the heart in diastole, or, if less intense, diminishes the frequency of its beats by prolonging each diastolic interval, and thus diminishes the arterial pressure, while it increases the amplitude of the arterial pulsation. Between the excitation and the effect, a delay takes place which (in the rabbit) amounts to $\frac{1}{6}$ second. 3 . The effect above described is produced reflexly by excitation of various afferent nerves, e.g., in the mammal by inhalation of irritant substances, in the frog by excitation of the "rami mesenterici." 4. It is also produced by direct excitation of the intra-cranial centre, by compression of the brain, by increase of arterial pressure in the brain, or by the circulation in that organ of venous blood. 5. In most mammalia, particularly those in which, as in the dog, the influence of the vagus centre on the heart is constant, each inspiratory act is followed by increased frequency of pulse. This may, with much probability, be attributed to the inhibitory influence of the respiratory centre on that of the heart.

In all of these instances, the experimental proof that the vagus is the channel by which the heart is acted on, is obtained by observing that the effect is no longer produced after both vagi have been divided.

6. In the frog, section of both vagi is almost without effect on the rhythm of the heart, but in the dog, it is followed by great increase of frequency and of arterial pressure. Neither of these effects is obvious in the rabbit.

7. Accelerator Nerves.-The increased frequency of the heart-beats, which, in all animals, is produced along with 
increased arterial pressure by excitation of the cervical part of the spinal cord, is attributable to direct excitation of the accelerator fibres it contains. Accelerator nerves, i.e., nerves of which the excitation induces increased frequency of action without in any other way affecting the circulation, reach the heart from the spinal cord through the sympathetic system. In the rabbit, they approach the heart through the inferior cervical ganglion; in the dog they are derived chiefly from the dorsal ganglia, from the Ist to the 5 th. In all cases there is a delay of several seconds between the excitation and the effect. When the inhibitory and accelerator nerves of the heart are excited simultaneously, the effects balance each other.

Intra-cardiac Ganglia and Nerves of the Heart.-The nervous system of the heart of the frog consists of (I) a plexus, which is situated in the septum between the auricles, close to the opening by which the right auricle communicates with the simus venosus. This is connected by nerve filaments with (2) smaller groups of ganglion cells (Bidder's ganglia) in the neighbourhood of the auriculo-ventricular furrow. Collections of ganglion cells exist in other parts of the heart, but their arrangement is imperfectly known. The phenomena relating to the functions of the intra-cardiac ganglia may be studied in the heart after its removal from the body, either in the empty state or when supplied with blood or other nutrient liquid in such a way as to enable it to fill and discharge itself under natural conditions. The liquid used must contain the salts of the blood, and a trace of proteid, but need not contain hæmoglobin. Mechanical or electrical excitation of the dorsal surface of the right auricle (inhibitory centre) arrests the heart in diastole. Accordingly, if a tight ligature is placed round the heart in this position, it loses the power of rhythmical contraction. If, thereupon, the auricles are cut off from the 
ventricle, the rhythmical action is resumed, provided that the middle part of the base of the ventricle remains intact. So soon as this part is cut off or destroyed, the rhythmical contractions cease; it is therefore believed to contain the motor centre for the rhythmical motion of the ventricle. After its removal, the ventricle responds to each single or mechanical excitation by a single contraction, determined by the direct action of the excitant on the muscular fibre. Similar motor centres are inferred to exist in the sinus, auricles, and bulb. Application to the beating heart of a trace of solution of the alkaloid muscarine, stops it in diastole. The effect is promptly counteracted by the application of solution of atropine in similar manner and quantity. A heart so 'atropinized' cannot be stopped in diastole, either by mechanical or electrical excitation of its inhibitory centre.

Ganglia exist in the hearts of the higher animals, but nothing is known of their functions.

Influence of the Nervous System on the blood vessels (Vascular Nervous System). - The principal vaso-constrictor centre is situated in the upper part of the floor of the fourth ventricle; subordinate centres exist in the spinal cord, both in mammalia (Stricker) and in the frog. The channels of the influence of these centres on the arteries are contained in the lateral columns of the spinal cord, from which they extend by the anterior roots and rami communicantes to the ganglia and prævertebral plexuses of the sympathetic system, whence vaso constrictor nerves are distributed to the arteries.

The constrictor centres are in constant action; their activity varies with the $\mathrm{CO}_{2}$ tension of the blood, and is consequently augmented by arrest of the circulation in the brain. The centres are also influenced by excitation of sensory nerves, of which the ordinary effect is to increase their activity. But in the case of the afferent fibres which reach the vagus from the heart (Depressor fibres), the 
opposite effect is produced (see below). It cannot be stated whether in this case the constrictor centres are acted upon directly, or with the intervention of other centres. I. Section of the spinal cord in the neck causes in all animals vascular dilatation and consequent diminution of the arterial pressure, and of the velocity of the circulation. As the dilatation affects the vessels of the viscera much more than those of the skin and of the muscles, the distribution of the blood is altered. 2. Excitation of any external sensory nerve produces contraction of the blood vessels of the viscera, but dilatation of those distributed to the muscles and skin (Heidenhain, Bernstein). In the normal animal the effect of these vascular changes is to increase the velocity of the circulation and the arterial pressure. In those animals in which the depressor forms a separate nerve, excitation of the central end of that nerve produces dilatation of the visceral blood vessels, and consequent diminution of arterial pressure. 3. Severance of the constrictor nerves distributed to external parts, or of spinal nerves, produces relaxation of the arteries to which they are distributed, but after a time the arterial tonus (see below) is restored, no:withstanding that the communication between the arteries and the central nervous system continues to be interrupted. Excitation of the same nerves (peripheral ends after section) determines, under normal conditions vascular constriction, pallor, and diminished temperature, in the parts to which they are distributed, and diminishes the flow of blood in the veins which lead from those parts. If, however, the nerves subjected to excitation are in a state of partial degeneration, consequent on previous severance, it often happens that the opposite effects are produced. Again, if the temperature of the part is already lower than the normal, the vessels dilate in response to the excitation instead of contracting, even though the nerve excited may have been divided imme- 
diately before. 4. Excitation of the nerves distributed to the abdominal viscera produces, under all circumstances, vascular constriction. Section of the same nerves produces as invariably vascular dilatation. 5. In some instances excitation of a cutaneous sensory nerve leads, by reflex action, to vascular changes, limited to the area of its distribution. These reflex effects vary according to the mode of excitation. 6. Any nerve of which the excitation (peripheral end after section) leads to vascular dilatation and hyperæmia in the parts to which it is distributed, is called a vaso-inhibitory nerve. Fibres of this kind are contained in the. lingual nerve, some of which are distributed to the submaxillary gland, others to the mucous membrane of the tongue. All erectile organs are provided with vaso-inhibitory nerves, which are distributed to their arterioles. On excitation of these nerves, whether reflex or direct, the arterioles expand, in consequence of which the venous system of the tissue becomes distended with blood. 7. The normal state of contraction of the arteries of a healthy part is called Tonus. The arterial tonus is maintained by the constant activity of the vasoconstrictor centres; it is also influenced by conditions which act independently of the vascular nervous system, particularly by the temperature of the part (Mosso), by the pressure under which blood flows into it (Heidenhain), by changes in the structure of the blood vessels (Cohnheim), \&c. It is subject to fluctuations which recur at irregular intervals, and may either be limited to particular arteries or may affect so large a number simultaneously as to produce variations of the volume of the organs supplied by them (Mosso), or fluctuations of arterial pressure (Traube, Hering).

The regulation of the Circulation of the blood, i.e., the maintenance of such a relation between the activity of the heart and the resistance of the blood vessels as is most advantageous, is effected by the combined action of the 
cardiac and vascular centres. Overaction of the heart is prevented by the influence of the resulting augmentation of intra-cranial pressure on the heart centre in the medulla oblongata; over-constriction of the vessels by the influence of the resulting increase of endocardial pressure through the depressor fibres of the vagus on the vaso-motor centre.

Death by Asphyxia.-When respiration is suddenly prevented, either by complete occlusion of the air passages or by submersion, the circulation of unarterialized blood in the brain gives rise to disturbances of the actions of the respiratory, cardiac, and vascular centres, which in a few minutes bring respiration and circulation to an end. The process is divisible into two stages. The first stage is characterized by rapidly increasing hyperpnœa, contraction of the arteries, increased arterial pressure, and acceleration of the circulation; towards its close the expiratory movements become more forcible than the inspiratory, and as insensibility approaches, pass into "expiratory convulsions" of short duration. In the second stage the animal is entirely unconscious; the pupils are first contracted, then dilated, while the convulsive expirations give place to violent inspiratory gasps. After these have ceased the heart continues to beat, at first slowly, then with increased frequency but diminished effect, until at last the arterial pressure has sunk to zero, and the whole of the blood has collected in the venous system and in the cavities of the heart. The duration of the process is mainly dependent on the quantity of air contained in the respiratory cavity at the moment of occlusion of the air passages, on the relative quantity of blood which the animal possesses, on its age, and on the activity of its chemical processes.

Influence of the nervous system on the Tempcrature of the body.-The influence of the nervous system on the heatproducing processes, by which the constancy of the temperature of the body is maintained, is as yet unknown. 
The discharge of heat is, in man, chiefly dependent on the circulation of the blood in the skin and subcutaneous tissues, and on the secretion of sweat. Both of these processes are presided over by nervous mechanisms of such a nature that their activity varies with the surface temperature of the body. In animals (particularly in the dog) the increased activity of the respiratory movements, which is produced by increase of bodily temperature (see Influence of Nervous system on respiration), also serves as an efficient means of regulation.

The Reflex process of Swallowing.-In the accomplishment of the act by which food is conveyed from the fauces into the stomach, the following changes take place:-

The larynx is drawn upwards under the tongue and nearer to the hyoid bone, the epiglottis applying its upper surface to the base of the tongue, and its under surface to the larynx; the glottis is closed; the palato-pharyngeal arches tighten and approach each other, without quite meeting. The soft palate with the uvula is drawn backwards (by the combined action of the levatores and palatopharyngei), while the posterior wall of the pharynx advances to meet it, and thus completely shuts off the nares from the pharynx. The morsel as it glides downwards between the nearly even surfaces offered by the tongue, epiglottis and cricoid cartilages in front, and the palato-pharyngeal arches behind, is at once seized by the constrictors and carried onwards by their successive contractions into the œsophagus. By a mode of action which is called "peristaltic," and which resembles that of the intestine and other muscular tubes, the food is conveyed as far as the closed sphincter of the stomach. As soon as this happens, the sphincter opens to allow of its entrance into the stomach, closing again immediately.

The centre which presides over this reflex process has its seat in the medulla oblongata. It derives its most important afferent influences from the mucous membrane of the 
fauces. After section of the vagus, near its origin (vagoaccessorius), the muscles of the pharynx, as well as those of the larynx and the œsophagus, are inactive, and the reflex act of deglutition is prevented. The effect of rernoval of the accessorius roots is scarcely different. After section of both vagi in the neck, the first part of the process is possible, but it cannot be completed. Food collects in the relaxed œesophagus, being prevented from entering the stomach by the permanently closed cardia; the glottis being inactive, portions of food are apt to enter the trachea. The peristaltic action of the osophagus differs from that of the intestine in being much more dependent on the intra-cranial centre which governs it.

Regulation of the peristaltic action of the Stomach and Intestine.-Throughout the alimentary canal the motions of its contents are produced by temporary constrictions of its wall, which progress in the direction of its length. In the intestine all that is observed is that the constriction follows the mass in its progress and that, as a rule, every peristaltic act begins at the pylorus and advances onwards. In the stomach, the action is similar, but in consequence of the form of the cavity, the effect is different; for the contents, instead of advancing, circulate along the smaller curvature from pylorus to cardia, and along the larger, in the opposite direction. In the inactive state, the stomach is contracted and the pylorus closed, whereas the intestine is (apparently) relaxed. When food is introduced into the stomach its wall begins to relax and contract alternately, each change beginning at the cardia. These movements, at first feeble, become more and more active towards the close of the process of gastric digestion, the pylorus opening more and more at each relaxation, so as to allow of the gradual escape of chyme into the duodenum.

The motions of the stomach are in large measure influenced by the vagus, for after section of both vagi the 
stomach is almost inactive, but can be brought into action by exciting the nerve. In the frog, after section of both vagi, the stomach is contracted. The function of the vagus in relation to the stomach is therefore regarded as inhibitory.

The peristaltic motion of the intestine is increased in dyspnœa, arrested in apnœa. Arrest of the circulation usually increases its activity, but the effect varies according to the previous state of the intestine. The splanchnic nerves are the channels by which the influence of the cerebro-spinal centres is conveyed to the intestines, but nothing can be certainly stated as to the nature of that influence. Inasmuch as the peristaltic motion can be always suspended, if previously active, by excitation of these nerves, an inhibitory function, like that of the vagus in relation to the stomach, is attributed to them.

The Reflex of Vomiting.-Vomiting consists of three acts, viz. (I) Descent of the diaphragm, (2) Relaxation of the cardia and contraction of the longitudinal fibres of the cardiac end of the œsophagus, (3) Closure of the glottis and compression of the stomach between the abdominal muscles and the still contracted diaphragm, and discharge of its contents by a mode of action of the muscles of the œsophagus and pharynx, which resembles that of swallowing but is in reversed order. Usually the process is preceded by increased secretion of saliva, which is immediately swallowed. At the moment of the discharge of the contents of the stomach the muscles of the pharynx are brought into action, so as to give to that cavity the same form as in swallowing, and prevent the passage of vomited matters into the larynx or nares: the neck is also extended. The centre for vomiting is in the medulla oblongata, and is in close relation with those which preside over the reflexes of coughing and swallowing. It may be induced either reflexly or by direct action on the centre. In the latter case, retching 
may occur even after section of both vagi, but effectual vomiting is impossible.

The Reflex of Defrecation.-As defæcation is possible after severance of the spinal cord in the dorsal region, provided that the lumbar part of the cord is in a normal state, it must be essentially a reflex process, governed by a spinal centre. When accomplished under these conditions, it consists of two acts, namely, peristaltic contraction of the rectum and relaxation of the sphincter externus. The mode of action of the latter, although it consists of striped fibres, resembles, when not controlled by the will, that of the cardia and pylorus : in its ordinary state it is contracted, but it is excited to rhythmical relaxation by the presence of fæcal matter in the neighbouring part of the rectum.

The Reflex of Micturition.-The retention and discharge of urine are also reflex acts, not necessarily dependent on the will. The mechanism of micturition resembles, so far as the bladder is concerned, that of defæcation, urine being discharged after severance of the spinal cord, at long intervals, by the simultaneous contraction of the muscular wall of the bladder and relaxation of the sphincter, this primary act being accompanied by other auxiliary movements accomplished by striped muscles acting under the direction of the same centre. In the normal animal, the anal and vesical sphincters are so far under the control of the will that their relaxation can be inhibited by voluntary effort.

Influence of the nervous system on the processes of Secretion.-The processes of secretion which have been hitherto investigated, are those of the salivary glands, the pancreas, the gastric glands, the liver and the kidney.

The salivary glands are normally inactive, excepting when excited by the presence of sapid substances in the mouth. Hence the process is a reflex one. The centre which governs it is in the medulla oblongata, and transmits its influence to the submaxillary gland by the chorda 
tympani, and to the parotid by a nerve which springs directly from the auriculo-temporal, ultimately, like the chorda, from the facial. The submaxillary may be excited to normal action by direct faradization of the chorda, in which case it pours out its secretion in abundance, and with such force, that if its duct is occluded, its internal surface is exposed to a pressure which may exceed the arterial. In addition to this, excitation of the chorda produces dilatation of the arteries of the gland, in consequence of which its supply of blood is largely increased. It can, however, be shown that each of these two effects is independent of the other. During excitation, the temperature of the gland rises and the secreting cells undergo important changes (in the dog, disappearance of the "mucous cells" or discharge of their contents, multiplication or regeneration of the "protoplasm-cells"). The submaxillary gland can also be made to secrete by excitation of the vaso-constrictor nerves which accompany its arteries; the product so obtained is of high specific gravity and contains much mucus. Severance of all the nerves of the gland produces a continuous discharge of watery liquid which continues for some time.

The pancreas. During the intervals of digestion the pancreas is inactive. It begins to secrete immediately after food is taken and attains its greatest activity towards the end of gastric digestion. At this time it is red and turgid, and is richest in the material to which its secretion owes its digestive activity; its cells are larger than before and contain a granular material, which as secretion goes on disappears, but is subsequently regenerated. Nothing is known as to the channels by which the nervous system influences the process.-The gastric glands are normally brought into activity by the presence of food or of saliva in the stomach. Their secretion ceases when the stomach is empty, but can be readily excited by mechanical and chemical stimuli, particularly by alkaline liquids. It is 
not dependent on integrity of the vagus nerves. Its activity is associated with increased circulation of blood in the mucous membrane, and with changes in the secreting cells, comparable with those already described in other glands. Nothing can, however, as yet be stated with certainty as to the relation of these changes with the process.

The liver.-The secretion of bile cannot be directly excited by any mode of acting on the nervous system. Excitation of the spinal cord, which at first increases the discharge of bile, by producing constriction of the bileducts, eventually diminishes it. The secretion of bile is arrested by even very slight increase of pressure in the bile ducts; whenever this happens bilin and colouring matter exist in the circulating blood (jaundice). The power of the liver cells to store glycogen is annulled by destruction either of the centre which controls its bloodvessels or of the channels by which that control is exercised; in either case the urine becomes saccharine (glycosuria). A similar effect is produced by curare, carbonic oxide and some other poisons, as well as by central excitation of the vagus.

The kidneys possess no secreting nerves: the renal nerves have no other function excepting that of constrictors of the arteries. The rate of secretion of urine is directly influenced by the state of the circulation: thus, it can be increased in animals by augmentation, and diminished by reduction, of the pressure under which blood enters the glomeruli. It can be diminished or even arrested by increasing the pressure in the renal veins. By destruction of the renal vascular centre in the floor of the fourth ventricle, or of the renal nerves, the vascular tone of the kidneys is annulled, in consequence of which the urine flows abundantly (polyuria) and often contains albumin (albuminuria), but is not necessarily saccharine. Similar effects are observed after severance of the renal 
nerves; excitation of the renal nerves arrests the secretion.

Regulation of Locomotion (Maintenance of Balance).The motions of the body in walking and other modes of progression, although under the influence of the will, are regulated by centres which act in obedience to impressions of which the will takes no cognizance, received from the retinæ, from the semi-circular canals, and other sensory end-organs. These impressions have to do chiefly either with the relation of the head to the plummet line, or to changes of speed or direction in the motions of the head or body. With reference to impressions of the latter class, it is to be noted, that all felt motions give rise, on their cessation, to a subjective sensation of motion in the opposite direction.

After injury of either of the crura-cerebri, animals have a tendency to rotation of the body round an axis, which usually lies on the side of the body opposite to that injured. This tendency, when strong, manifests itself in rolling; when weaker, in manége motion. Similar effects follow injury of the cerebellum, but in this case the axis of rotation is often on the same side of the body as the injury. After injury, or irritation of the semi-circular canals, birds walk as if they had lost their balance, and the head oscillates. The oscillation varies in direction according as. the vertical or horizontal canals are interfered with: if the former, the head moves backwards and forwards; if the latter, it is rotated from side to side. At the same time, the head assumes an unnatural attitude, and the body tends to fall backward or to the side. The sensation of vertigo, in which the body of the affected person seems to rotate round its vertical axis, is produced by passive rotation in the opposite direction: when intense, it expresses itself in actual rotation, the direction of which is always opposed to that of the subjective motion. Vertigo may be also produced by the passage 
of a voltaic current through the brain (cerebellum?), in which case the direction of the subjective rotation is determined by that of the current. Both kinds of vertigo are accompanied by nystagmus. In the frog, after removal of the hemispheres, locomotion is as perfect as in the normal animal, provided that the optic lobes and cerebellum are present. A frog which possesses its cerebellum, but has no optic lobes, jumps normally, but fails in maintaining its balance. In mammalia (the dog), loss of the cerebellum is followed by disorders and perverted action of the muscles of the trunk and limbs, in consequence of which, neither voluntary nor reflex acts can be accomplished in a manner adapted to their purpose.

All of these phenomena may be understood on the supposition that centres exist (in the cerebellum ?) of of which it is the function (I) to receive impressions as to the direction of the passive and active motions of the body and of its parts; and (2) to direct and regulate the actions of the muscles of the trunk and limbs (independently of consciousness) in obedience to those impressions.

Regulation of the Motions of the Eyeballs and the Actions of the Iris and Tensor of the Choroid.-These actions are governed by centres which have their seat in the floor of the aqueduct of Sylvius, and of the 3 rd and $4^{\text {th }}$ ventricles, the influence of which is conveyed to the muscular structures, over which they preside, by the $3 \mathrm{rd}$,

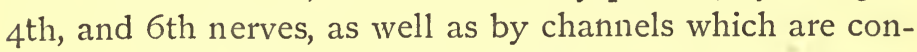
tained in the cervical portion of the spinal cord, and in the corresponding part of the sympathetic system. They have been localized by experiment as follows:-Excitation of the floor of the aqueduct at its entrance into the third ventricle, produces convergence of the visual axis, and contraction of the pupil; excitation of the anterior tubercles of the corpora quadrigemina, or of the optic 
thalami, occasions divergence and dilatation; on excitation of the outer part of either anterior tubercle, both eyeballs are rotated to the opposite side.

The iris receives, in addition to sensory and vascular nerves, constrictor nerves, which are distributed to the sphincter pupillæ, and dilatator fibres, which are believed to terminate in muscular structures of corresponding function. Every excitation of the retina by light is followed, after an interval of about half a second, by contraction of the pupils. Both pupils respond to excitation of one retina. In the frog, the iris continues to respond to excitation of the retina, even after the eye has been removed from the body. In accommodation for near vision, the contraction of the tensor choroideæ is normally associated with convergence of the visual axes and narrowing of the pupil. The dilatator nerves of the iris are derived immediately from the trigeminus, ultimately from the sympathetic system, for excitation of the upper cervical ganglion produces dilatation, and destruction of it narrowing of the pupil. Dilatation is also produced reflexly by excitation of any sensory nerve : in all cases it is associated with vascular contraction (see Vascular Nervous System), proptosis, widely-opened eyelids, and retraction of the membrana nictitans. These effects are weakened, but not annulled, by extirpation of the upper ganglion of the sympathetic. Corresponding phenomena are observed in dyspnca and during violent muscular efforts. In deep sleep, the visual axes converge, and the pupil is contracted. Certain alkaloids (called mydriatics) produce lasting dilatation of the pupil, associated with complete relaxation of the tensor of the choroid. Others (called myotics) have the opposite effect; in the former case, the action is known to have its seat in the eyeball itself. Convergence of the visual axes, and narrowing of the pupil are so associated, that one of them cannot be normally accomplished without the other. Accordingly, 
accommodation for near vision is always accompanied by contraction of the irides.

Regulation of the Movements of Expression.-On this subject, information is derived from the observation of disease. When the muscles of one side of the face are rendered temporarily or permanently inactive by compression or destruction of the portio dura in the Fallopian canal, the affected side loses its expression, and is drawn to the opposite side. The affected cheek is flabby, and the eyelids cannot be closed (lagophthalmus paralyticus), in consequence of which, tears flow over the cheek, while the exposed eyeball is rotated upwards. If the lesion is on the central side of the genu, these phenomena are accompanied by asymmetry of the posterior arch of the fauces, consequent on inactivity of the levator palati, as well as by loss or impairment of hearing; moreover, the salivary glands of the affected side cannot be excited to reflex secretion.

The Functions of the Brain-comprising those of the Cortical Convolutions, Corpora Striata, and Optic Thalami.-A frog which has been deprived of its hemispheres, acts in all respects as a normal frog, excepting that it is incapable either of interpreting its sensations, or of initiating voluntary acts. The condition of the brainless mammalian animal is analogous. It is subject to emotion, and acts in such a way as to show that it is influenced both by impressions received through the nerves of common sensation and through those of sight and hearing, but it is incapable of understanding, remembering, or willing. All of its acts are of the kind described on p. 78. Any direct interference with the brain as, e.g., by compression of its substance, or by arrest, or great diminution of its circulation (as in syncope), annuls consciousness.-Although at first sight the development of the hemispheres seems in animals to exhibit only a very general relation to that of the mental faculties, it can be shown that the relation between 
the weight of the brain and intelligence is a very close one, provided that the weight of the mesencephalon be taken as the standard of comparison, not that of the whole body.

The inference that is suggested by the anatomical relations of the corpora striata, viz., that they serve to bring into connection the cortex of the hemispheres, particularly of the "motor region," with the reflex motor centres of the mid-brain, is supported by clinical observations, for the almost constant result of lesions of these organs is loss of voluntary control over the muscles of the opposite side of the body (hemiplegia), a condition which is not, as a rule, permanent. By experiment, we learn that the part of the corpus striatum on which this effect depends, is the mucleus lenticularis, for while destruction of this part produces as complete hemiplegia as if the whole hemisphere were removed, interference with the mucleus caudatus is almost without effect.

There is, at present, no evidence either that the corpora striata contain motor centres, or the contrary. As regards the functions of the optic thalamus, no general statement can at present be made.

The Convolutions.-It was formerly believed that all parts of the cortex of the hemispheres have the same function. It is now known that in certain regions each part has physiological relations which are peculiar to itself. The proof that this is so, lies in the observation of two classes of phenomena, viz., (I) the effects of electrical excitation of particular parts of the surface of the hemispheres, and (2) the results of ablation of certain parts.

As regards the effects of excitation, the best ascertained facts are those which relate to the excitation of the præ-frontal, post-frontal, and super-sylvian convolutions of the dog; corresponding in position to the convolutions which surround the fissure of Rolando in the human 
brain. These excitations severally induce co-ordinated motions (varying in their character according to the precise part excited) of the head and neck, of the extremities, and of the muscles of the face, on the side of the body opposite that on which the cerebral surface is excited. After removal or destruction of any of these parts of the cortex, excitation of the white substance subjacent to it produces the same effect as excitation of the part of the cortex with which its fibres were previously in relation, so that the cortical substance is not essential. In all cases, a perceptible interval of time intervenes between the excitation and the muscular action which results from it.

The effects of ablation can only be studied after the animal has entirely recovered from the immediate pathological effects of the injury. From observations so made, we learn (I) that absence of parts of the cortex, by the excitation of which particular groups of muscles are brought into action, is not associated with any impairment of the function of the muscles, but only with loss or impairment of the power of the animal to employ them $\mathrm{n}$ the performance of certain combined motions ; (2) that destruction of the whole or the greater part of the cortex is attended with impairment of memory and perception. If the lesion is on one side only, this impairment manifests itself chiefly in relation to impressions received from the opposite side of the body. According to recent observations of Prof. H. Munk, visual perception is localized in the occipital lobe. Thus (in the dog) ablation of the posterior extremity of this lobe on one side, produces blindness of the middle and inner part of the retina of the opposite side, and of the outer part of the retina of the same side. In the ape, the same lesion produces blindness of the inner half of the opposite retina, and of the outer half of the retina of the same side.-It has been long known clinically, that destruction (by disease) 
of the lower end of the ascending frontal convolution in man (Broca's convolution), is associated with aphasia, a condition in which the patient, though able to articulate, and possessing the power of forming adequate conceptions which he remembers, is unable to word them. In the vast majority of the cases in which this happens, the lesion is on the left side of the brain.

Common and Special Sensation.

\section{(Functions of Sensory end-organs.)}

Sensations and Perceptions in general.-By the word Sensation is meant in physiology the felt effect of an excitation either of a sensory end-organ, or of a sensory nerve. Sensations which originate from end-organs are divided into those of common sensation, vision, hearing, taste, \&c., according to the end-organ affected. Sensations which spring from direct irritation of sensory nerves, are usually painful. Very feeble excitation of an end-organ is not felt. As regards those excitations which from their nature admit of measurement, it was found by $\mathrm{E} . \mathrm{H}$. Weber that the degree of intensity which must be attained by any excitation in order to be felt-the limen (Reizschwelle) is constant in the same individual. As regards all excitations of which the intensity exceeds the limen, it is found that the "sensible increment" (i.e. the smallest additional excitation that can be felt), is proportional to the previous excitation. Hence, the sensation produced by any given excitation varies inversely as the intensity of the previous excitation. The ratio of the "sensible increment" to the "previous excitation" differs in different cases. Thus as regards light, it is as I : I0O, or thereabouts; as regards sound as $\mathrm{I}: 3$, and so on. 
Between an excitation of any end-organ and a voluntary motion prompted by it, a time elapses, usually called the "personal time," which is made up of the time required for recognizing the sensation (perception) and the time required for transforming it into muscular action (intention). In the simplest possible case, that in which the person under observation signifies his recognition of an expected excitation by a preconcerted signal, the personal time is about one-sixth of a second for sound, light, and touch. By increasing the intensity of the excitation the time may be somewhat diminished. If the sensation is of such a character as to require interpretation or discrimination before it is acted upon, the time is longer.

\section{Tactile Sensation.}

Tactile sensation is regarded as the function of the so-called "tactile corpuscles" of the skin, and of analogous end-organs which exist in the exposed mucous membranes. According to the mode in which the end-organs are affected, tactile sensation is divisible into that of Pressure, that of Temperature, and that of Locality. As regards pressure, Weber found that an increment of pressure on the hand must amount to at least one-thirtieth of the previous pressure to be felt. As regards temperature, the degree of excitation is estimated by the difference between the temperature of the object applied, and the actual temperature of the skin. A difference of about one-eighth of a degree can be felt. The sensation of locality may be tested either by "'interrogation," or by measuring the distance at which two points of excitation must be apart in order that they may be felt as two. In relation to the latter method, any area on the surface of the skin within which two such points cannot be distinguished, is called a "sensation area." The widths of sensation areas for 
different regions are, in millimeters, as follows :-Tongue I ; finger-tip 2 ; lip 4 ; neck 20 ; back 60.

\section{Muscular Sensation.}

Muscular exertion is attended with a "sensation of effort," the relation of which to the work done (e.g. the weight lifted), according to Weber's experiments, is such, that no difference less than a fortieth between two weights lifted in succession can be appreciated. The sensation of effort is therefore more delicate than the sensation of pressure. The existence of sensory nerve-endings in the sartorius muscle of the frog has lately been demonstrated ; with this exception, channels of muscular sensation have not hitherto been recognized.

\section{Vision.}

The Eye as an optical instrument.-To understand the paths of luminous rays through the eye to the retina, it is necessary to know the form of its three principal refracting surfaces, and the refractive indices of its transparent media. Of the normal eye the radii of curvature, indices of refraction, and dimensions are approximately as follows : -Radius of the corneal surface, 8 millimeters, radius of the anterior surface of lens, Io millimeters, of posterior surface, 6 millimeters, these surfaces being severally 4 millimeters apart in the axis of the eye ; the distance from the posterior surface to the retina is 13 millimeters. The index of refraction of the aqueous or vitreous humour is $I \cdot 35$, that of water being $I^{\prime} 336$. The refraction-index of the lens varies from $\mathrm{I} 405$ at the surface to $\mathrm{I} 454$ in the centre.

An eye supposed to be constructed according to these measurements is denoted by the term "schematic eye," 
which represents what the normal eye would be, if its refracting surfaces were spherical, their centres in the same axis, and its transparent media homogeneous.

The lensless or reduced Eye.-If it were not necessary that the eye should be capable of being adjusted for the distinct vision of objects of different distances, the lens would not be required; for an eye which consists of but one medium, and has but one refracting surface, answers the dioptrical purposes of the real eye in every respect, excepting that it cannot be "accommodated." A schema of this kind is called a "reduced eye." In such an eye, if the radius of curvature of the cornea is 5.12 , and the index of refraction about I. 35 , the conditions approach pretty closely to those of the normal eye. In the reduced eye the straight line which passes through the centre of the cornea and the centre of its sphere of curvature is the axis. Rays which are in the same line with a radius of the refracting surface are not refracted : such rays are called principal rays. As they all pass through the centre of the sphere of curvature of the cornea, that centre is called the "crossing point." In the normal eye this point lies immediately in front of the posterior surface of the lens. Any number of rays reaching the cornea from a luminous point (object) at sufficient distance in the axis, are so refracted at the surface that they converge to a point (image) on the other side. Rays which emanate from a luminous point in a plane including the first, which is vertical to the axis (objectplane) converge to a point in the same vertical plane with the image of the first point (image-plane). It thus happens that (as regards flat surfaces of small extent which face the cornea) every point of the object-plane is focussed in the image-plane, forming there an inverted image. The further the object-plane is from the refracting surface, the nearer must be the image-plane. The point to which the almost parallel rays which emanate from any very distant point in the axis converge, is called the principal 
focus. In the unaccommodated eye this point is in the retina.*

The Lens.-When the tensor of the choroid is inactive, the principal focus of the normal (emmetropic) eye lies in the retina; consequently those objects only are seen distinctly from which the eye receives parallel rays. The process by which it is adjusted for vision of near objects, is called "accommodation." Its accomplishment is the purpose or function of the lens, and of the muscular and fibrous structures by which its form is regulated, the tensor of the choroid and the zonule of $\mathrm{Zinn}$. The tensor of the choroid consists, in man, of fibres of two kinds, viz., of annular fibres which encircle the border of the lens, and of much more numerous meridional fibres which draw the choroid towards the cornea. When (in the dog) this muscle is thrown into action by excitation of the short root of the lenticular ganglion, the anterior surface of the lens becomes more convex and approaches to a shorter distance from the posterior surface of the cornea.

The increase of convexity is due to the relaxation of the zonule, by virtue of which the lens is left to its own elasticity, and assumes a form approaching that which it possesses after removal from the body. Under the influence of atropin the tensor is completely paralysed; in consequence, the convexity of the lens is diminished; for, in the ordinary condition of the eye, the muscular fibres are not entirely relaxed. The degree of accommodation of which the eye is capable varies in different individuals at different ages. Thus, in the normal emmetropic eye, which, when entirely relaxed, sees distant objects distinctly, the lens can in childhood be rendered convex enough to give well-defined images of objects at a distance of 3 inches. As age advances,

* The statement above is simplified to the utmost by the substitution of the hypothetical lensless eye for the schematic eye. All that has been said is applicable to the real eye, but much is omitted. Those who desire to understand in what way the formation of the image is modified by the presence of the lens, will find it clearly explained in Hermann's Physiology, pp. 377-384. 
this distance (the "near limit" of vision) at first slowly, then more rapidly lengthens, until at 50, nothing nearer than 12 inches; at 60 , nothing nearer then 24 inches can be defined. Whence it results that, inasmuch as the form of the lens when unaccommodated remains nearly the same, the range of adjustment in advanced life is exceedingly small. The term myopia is applied to the condition in which the lens is too convex for parallel rays, even when the eye is atropinized; hypermetropia, to that in which it does not become convex enough for parallel rays, even when the tensor is in full action. In the former case the defect must be compensated by concave, in the latter by convex lenses.

The methods used for measuring the limit of near vision, are founded on an experiment known as Scheiner's. A diaphragm having two minute apertures at a distance less than that of the width of the pupil, is placed immediately in front of the cornea, while the eye is kept fixed on an object-point, at a sufficient distance to be distinctly defined. If now the object is gradually brought nearer, it is observed, that as soon as the "near limit" is passed, it is seen double. The instrument used for making this experiment with exactitude is called an optometer.

For all investigations relating to accommodation, it is of importance to be able to determine in the living eye the convexity of the anterior surface of the lens, under different conditions. This is done by measuring the apparent diameter of an object seen reflected in it. The instrument used is called an ophthalmometer.

When the eye is contemplated by an observer so placed that the direction in which he looks at it makes an angle of about $20^{\circ}$ with the axis of the observed eye, the image of any luminous object also placed in front of the eye, rays from which form the same angle with the axis but on the opposite side, is seen reflected in the middle of the cornea, and therefore, apparently, close to the far border of the pupil. On the near side of this image a second appears similar to it, but larger, feebler, and indistinct. When the observed eye is accommodated, this image becomes smaller and a little more sharply defined. 
Astigmatism.-This term is applied to a condition of the eyes in which the curvature of the cornea is somewhat less in the vertical than in the horizontal meridian. If such an eye is so accommodated that rays which lie in the vertical meridian converge to the retina, while those in the horizontal meridian converge beyond it, the point is seen as a horizontal bar.

Chromatism.- If the eye is fixed on a luminous point at a great distance, it often appears as if it had a sharply defined red centre, surrounded by a luminous fringe. This happens when the accommodation is such that the less refrangible rays converge to the retina, the more refrangible in front of it. "In the contrary case, i.e. when the distance of the luminous point is less than that for which the eye is accommodated, the centre is blue.

Entommatic vision.-Shadows of objects floating in the media of the eye are distinguished by the retina, when the eye is illuminated from a point which is so near the cornea that the rays in entering the eye become parallel. As thus seen, objects behind the pupil may be distinguished from objects in front of it, by the observation that they appear to move in the direction opposite to that in which the source of light is moved.

Reflection of light in the Eyeball.-Light which reaches the retina is partly absorbed, partly reflected. Every reflected ray returns approximately in the path of its incidence. Consequently, although the cavity of the globe appears under ordinary circumstances dark, it can be made to appear luminous if illuminated by light which reaches it as if it came from the eye of the observer. Thus, if a plate of glass be so placed between the observing and the observed eye that light emanating from a luminous source is reflected by it into the observed eye, as if it came from the other, the former appears bright ; and if it were possible for both eyes to remain relaxed, that is accommodated for extreme distance, a distinct image of the retina would be seen by the observing eye. In the ophthalmoscope as originally invented by Helmholtz, this is done by the interposition of a concave correcting lens between the observing eye and the mirror.

The Retina.-The retina is a sensory end-organ excited by light. Its excitability has its exclusive seat in the bacillary layer.

If a strong light is suddenly thrown, by a lens, on the outside of the eyeball of a person in a dark room, an appearance of branching blood-vessels is seen by him, of which the explanation is that the side light throws shadows of the 
retinal vessels on parts of the bacillary membrane, which are not accustomed to receive them. If the source of light moves, the sharlows move with it, and in the same apparent direction. The motion of the retinal image (I) can be measured; that of the light (2) can also be measured, and the distance (3) of the vessels from the bacillary membrane is known. If from 2 and 3 , I be calculated, it will be found to agree with the measurement.

The fovea centralis is more perfect structurally and functionally than any other part of the retina. Accordingly, as it lies approximately in the axis of the eyeball, objects which lie in the prolongation of this axis (the visual line) i.e. those on which the eye is fixed, are seen more distinctly than any others. Thus, two objects so near together that the straight lines leading from them to the crossing point of the eye, meet each other at an angle of 60" or $70^{\prime \prime}$ (and of which consequently the retinal images are at most 0.005 millimeter from each other), can be distinguished as two. If the images fall on the retina outside of the fovea, they must be at least a millimeter apart, in order to be distinguished. If the rays from two objects at the same apparent height meet at $15^{\circ}$, and the eye is fixed on the one nearest the middle plane of the body, the other (provided that its retinal image does not measure more than $I^{\circ} 5$ millimeter) is not seen, for its image falls on the entrance of the optic nerve, the so called "blind spot."

Retinal Purple. - The external layer of the bacillary membrane (outer joints of the rods and cones) is infiltrated with a red colouring matter, which in the eye removed from the body, remains unaltered so long as the retina is in the dark, or is exposed only to yellow light. On exposure to ordinary or blue light it disappears, but can be restored even after the cessation of the circulation, by contact in the dark with the pigment epithelium. During life it is alternately destroyed and reproduced according as the eye is exposed, or not to light.

Excitability of the retina.-Process of excitation in the retina. As with respect to other excitable structures, so in the case of the retina, we may best distinguish between the excitation and the physiological effect which it occasions (sensation of light), by studying their time-relations. We learn by observation,(I) that the sensation of light produced 
byan instantaneous excitation (say of $\frac{1}{100}{ }^{\prime \prime}$ ) at first increases, culminates about $\frac{1^{\prime \prime}}{6}$ after the excitation and then rapidly diminishes; (2) that of a succession of such excitations following each other without intermission, all are at first (during the first tenth of a second) equally effective, so that the sensation occasioned by the series is equal to the sum of the sensations which would have been produced by all of the excitations had they occurred separately; but afterwards the excitations become less and less effective. Hence it results, first, that in the case of illuminations of the unexhausted retina of about $\frac{1}{10}$ " duration or less, the sensation of light is proportional to the product of the intensity and duration of the illumination; and secondly, that when the illumination is continued, the sensation of light at first increases, then gradually diminishes. This diminution of the excitability of the retina by previous excitation is called "exhaustion." In consequence of it, when we contemplate a bright object and then look elsewhere, we see a dark image (called an after-image) of it.

When the retina is excited by homogeneous rays, i.e., by rays of which all are of the same refrangibility, the effects follow each other in the same order, but it is found that the colour-sensations occasioned by rays of equal intensity, but different refrangibility, culminate at different rates. The exhaustion produced by monochromatic light affects the excitability of the retina only in respect of light of the same kind. Consequently, the after-images of coloured objects are themselves coloured.

Colour sensations are said to be "blended" when the rays which occasion them affect the retina, either simultaneously or in such rapid succession that their action is simultaneous. If two kinds of light act simultaneously on both retinæ, they may also give rise to a blended sensation.

Classification of colour-sensations:-The sensations occasioned by monochromatic rays of different kinds admit 
of being placed in linear series, in the order of the refrangibility of the rays which produce them. Those occasioned by the simultaneous action of rays of different refrangibilities are much more various, and cannot be arranged in line. If, however, on a plane surface a central position is assigned to the sensation "white," the other sensations may be arranged round it in such a way, that the sensation which results from the "blending" of any two or more others has its place between them, at distances from each which express their relative preponderances. In this arrangement (called the colour circle) spectral colour sensations form an incomplete ring round white, between the red and violet ends of which is placed purple. The relations of colour sensations exhibited in the colour circle can be most simply explained on the following hypothesis. (Young, Helmholtz.) There are three fundamental colour-sensations, viz. : red, green and indigo, from which all others are derived by blending. Every element of the retina (every cone) contains three terminal elements, one of which is most excited by the less refrangible rays (red element), one by the most refrangible (blue element), the other by those of medium refrangibility (green element), but all more or less by all.

The theory that red, green, and indigo, are the fundamental sensations is supported by the following observations, among others:-I. If the spectrum is contemplated while its colours are gradually weakened, until they cease to be visible, the colours named are the last to disappear. (Brücke.) 2. If a white surface is contemplated by a retina of which the excitability for a particular kind of homogeneous light has been weakened by excitation, it appears to be coloured; the colour sensation produced occupies a place in the colour circle exactly opposite to that immediately occasioned by the excitation, and is therefore said to be "complementary" to it. In like manner, if a coloured surface is contemplated by a retina partially dulled by the same mode of excitation, its hue is-provided that its colour is a blended one-altered, by the weakening of one of its constituent sensations. But if after dulling the excitability of the retina for red, an indigo surface is contemplated, its hue remains unchanged, for inasmuch as, according to the theory, indigo rays scarcely affect the red elements, the quality of the sensation is not affected by their not taking part in its production; if the experiment is repeated with a 
violet surface, the result is no longer the same. To the retina dulled for red it appears bluer. Similar observations may be made as regards the other primary colours. 3. The image seen in the dark after the eye has been directed to the sun is at first bright, then fades away and becomes red. If while the red image is observed white light is admitted, it becomes green. The excitation of the red elements is more persistent than of the others, and their consequent exhaustion more prolonged.

Colour-blindness.-In some persons (in consequence, it may be supposed, of defective excitability of the green or red elements of the cones), red, in others green is mistaken for grey. About two in every hundred railway officials examined by Donders, were found to present one or other of these conditions.

Motions (Rotations) of the Eyeballs.-I. The straight line which connects the apex of the cornea with the foved centralis retince is called the "visual axis." The plane in which the visual axes of both eyes lie is the "visual plane." When the visual axes of both eyes are directed to the horizon and are parallel to the middle plane of the body, the eyes are in the "position of rest" (primary position). 2. The vertical plane in which the visual axis lies when the eyes are in the position of rest, is called the "vertical meridian" and the horizontal plane at right angles to it, the "horizontal meridian" 3. All rotations of the eyeballs take place round axes (called "axes of rotation") which cut the visual axis at right angles, about $\mathrm{r}^{\prime} \mathrm{7}$ millim. behind its mid-point. (Listing and Donders.) 4. Any position into which the eyeballs can be brought by rotating them from the position of rest directly upwards (i.e., round horizontal and coincident axes of rotation), or directly to the right or left (i.e., round vertical axes of rotation), is called a secondary position. 5. In the position of rest and in every secondary position, the horizontal meridians of both eyes are in the visual plane. All other positions are called "tertiary." In every tertiary position, the horizontal meridians intersect the visual plane, at an angle which is called the "angle of rotation." (See Exercises.) 
The muscles of the eyeball are divisible in respect of their action, into two groups, of which one comprises the rectus internus and $r$. externus; the other, the obliquns inferior, and o. superior, which act in concert with the rectus superior and $r$. inferior. The axis round which any muscle rotates the eyeball is called its proper axis of rotation. Those of the internal and external recti nearly coincide with the vertical axis of the eyeball. Consequently these muscles, acting antagonistically, rotate the eyes directly to right or left (secondary positions). The combined axis of the oblique muscles (the axes of the two being approximately identical) is horizontal, but cuts the equator of the eye at an angle of $60^{\circ}$. The combined axis of the superior and inferior recti is neither horizontal nor transverse, but has its inner end lower, as well as further forwards than the outer. If, however, the rectus sup. acts with the obliquus inf., they together rotate the eye round an axis which lies between their own axes, and nearly coincides with the horizontal axis of the eyeball: the obliquus superior acts similarly in conjunction with the rectus inferior. Thus rotations of the eyeball from the rest position into secondary positions are performed, if to right or left, by the internal and external recti, if upwards and downwards, by the combined action of the other four muscles.

When the eyes are so fixed on any point that it lies in the visual axis of both of them, the point so contemplated is seen singly and perfectly; and all other points are seen singly, but not perfectly, which are received by corre sponding points of the two retinæ-that is by points which would exactly cover each other if it were possible for both eyes to occupy the same position, the vertical and horizontal meridians respectively coinciding.

Mental Interpretations or Fudgments of Visual Sensations.-I. Binocular blending of colours. When rays of two colours enter the two retinæ simultaneously, the sensation 
is not always the same. Sometimes the two colours are blended as completely as if both affected one retina: at others there is a contest between the two, first one, then the other predominating in the blending. 2. Judgment of distance. We judge of the distance of any object, chiefly by the degree of convergence of the visual axes, which we find necessary in order to fix both eyes upon it. Consequently, if one eye is shut and two or more objects of the same form but of different sizes are placed before the other at such distances that their retinal images cover equal areas, their respective distances cannot be distinguished. If both eyes are used a correct judgment can be formed without difficulty. 3. Judgment of solidity. By exploring an object with the eyes, i.e., by fixing them successively on different points of its visible surface, we are able to judge of the relative distances of these points, as well as of their directions. It can, however, be shown that this process is not ordinarily employed in judging of the form and solidity of objects, but that the mind accomplishes this instantaneously, by the blending of the two dissimilar images which are received by the two retinæ, whenever both eyes are fixed on some point in a solid object at a short distance from them. The point so contemplated is of course seen single, others are for the most part seen double : notwithstanding this, we are not conscious of any confusion of images.

\section{Hearing.}

The process of hearing consists (I) in the production of vibratory movements of the membrana tympani, which are synchronous with the sound-vibrations of air in the meatus; (2) in the communication of these vibrations to the liquid contained in the labyrinth; and (3) in the production of vibrations in all those parts of the lamina 
spiralis of which the vibration-rate agrees with those of vibrations existing in the liquid.

Sensations of sound are divided, according to the character (form) of the air-vibrations which occasion them, into non-musical sounds or noises, and musical sounds or "tones." Of tones, simple and compound are distinguished. The former are heard when the air molecules at the external surface of the membrana tympani are in simple pendular vibration; the latter when the vibrations are compounded of vibrations of different rates of frequency, of which the relations to each other may be $I: 2$, $I: 3, I: 4, I: 5$, and so on in the same order. The tones which correspond to each of these simple constituent vibrations, are called "partial tones." According to the number, relative strength and relative frequency of the simple tones into which they can be resolved, compound tones differ in timbre or quality. Tones whether simple or compound differ also in pitch: the pitch of a simple tone is expressed by the number of its vibrations in a second: that of a compound tone by the vibration-number of its predominant partial-tone.

The middle ear.-The cavity of the tympanum across which sonorous vibrations are transmitted by the ear bones, communicates with the pharynx by the Eustachian tube: the pharyngeal end of this tube is, however, usually closed and can only be opened by bringing into action the muscles of deglutition. The external wall of the cavity is formed by the membrana tympani, which, by the arrangement of the radiating and annular fibres which compose its two layers, by the conical form of its internal surface, and by the mode of attachment of the handle of the malleus, is fitted for its function-the passive reception of the motions communicated to it by the vibrating air particles at its surface. In the communication of the movements of the membrana tympani to the foramen ovale, the malleus and incus act as one piece; for, so long as the mem- 
brana tympani is tense, the tooth of the incus is kept locked against the notch of the malleus. When in this condition, the two bones rotate on an axis of which one extremity is at the tip of the short process of the incus, the other corresponding approximately to the attachment of the ligamentum anterius of the malleus: hence the axis of rotation nearly coincides with the upper border of the tympanic ring. The two bones may be compared when in action to a bell-crank lever of which one limb, representing the handle of the malleus, is approximately half as long again as the other (the long process of the incus), and forms with it an acute angle. Consequently every motion of the tympanic membrane which is transmitted to the stapes is diminished by about a third. When the membrana tympani is relaxed, the distance between the tip of the long process of the incus and the handle of the malleus slightly increases. Nothing can be certainly stated as to the uses of the muscles of the middle ear.

The internal ear.-The essential part of the organ of hearing is the cochlea and particularly the organ of Corti. The organ of Corti consists of a series of arches, about 3,000 in number, of extreme minuteness, the span of which increases gradually from the base of the cochlea to the helicotrema, and of epithelial elements (the hair-cells) in relation with these arches, which are intimately connected with the terminations of the cochlear nerve. These structures rest upon a ribbon-shaped fibrous membrane (the lamina spiralis membranacea or membrana basilaris) which is wide at the helicotrema, narrow at the base of the cochlea. It is attached by its edges to bone, and consists chiefly of fibres which run transversely to its length, and are believed to be tense. Corti's organ is contained in a spiral tube, triangular in section, the duct of the cochlea, one side of which is formed by the membrana basilaris, the other by the membrane of Reissner. 
With reference to the transmission of sound, the cavity of the vestibule and cochlea may be regarded as divided into two, that of the vestibule and scala vestibuli which communicates with the lymph space surrounding the vestibular sacs, and that of the scala tympani, which is closed by the membrane of the fenestra ovalis. Although these two cavities communicate by a small opening, they may be regarded as in so far separate that any motion of the membrane of the foramen ovale must be communicated to the membrane of Reissner, then to the membrana basilaris and thereby to the organ of Corti. From the structure of the organ of Corti it was inferred by Helmholtz that it must be an organ for the perception and discrimination of tones, and that the elements (nerveendings, Corti's arches and adjoining cells) serve in the discrimination of the sonorous vibrations of the liquid in which they are immersed-a function which is analogous to that of the hypothetical red, blue, and green elements of the retinal cones in regard to luminous vibrations. Tones can be readily discriminated by the human ear of which the vibration-rates range from 40 to 7,000 per second. A skilled musical ear can distinguish more than 6,000 different tones within the range of these seven and a half octaves; consequently, as there are only 3,000 arches of Corti, each must be capable of being excited by several gradations of tone.

In the case of the elements of the cones of the retina we can form no conception of the modes in which they are acted upon by light, but the action of tones on the organ of Corti can be satisfactorily explained by comparing that organ to a system of resonators. By a resonator is meant anything which, by virtue of its form and structure, is capable of being thrown into musical vibration. Every resonator produces when thus acted upon, a tone which is peculiar to itself-its " proper tone," and is readily excited by tones of the same vibration-rate when. 
communicated to it either through the air or otherwise. Many resonators can be excited to vibration not only by their "proper tones," but also by vibrations of approximately the same frequency, in a degree proportional to the approximation. As there is reason to believe that the resonators of the organ of Corti have this property, it enables us to understand how it happens that the number of distinguishable tones exceeds that of the elements which serve to appreciate them. For a tone affects not one, but two or more resonators, each in proportion to its proximity to the tone by which it is excited, so that just as every perception of colour is founded on impressions received through at least three elements, every perception of tone is occasioned by the simultaneous vibration of several elements of the organ of Corti. The power of distinguishing two tones which follow each other at very short intervals of time, is known to vary with their rate of vibration. Thus, whatever be the tone, it has been found that the time intervening between one excitation and its successor must be sufficient for about twenty-two vibrations in order that they may be heard as two. Helmholtz explains this on the principle that the resonators of the organ of Corti are very readily thrown into vibration, and continue to vibrate only a short time after the excitation has ceased.

Nothing can be stated with certainty as to the functions of the end-organs of the vestibular sacs; from their analogy with the auditory vesicles of invertebrate animals without cochleæ it may be inferred that they have similar functions. (With reference to the ampullæ, see p. 97).

\section{Taste.}

Sensations of taste are occasioned by the access of sapid substances to the tongue, either in the neighbourhood of the papillæ vallatæ, or of the papilla foliata of 
either side, or to its upper surface close to the tip. Almost all unmixed sensations of taste may be referred to one of four fundamental kinds, viz., bitter, sweet, salty, and acid. Those which cannot be so classified result for the most part from the "blending" of gustatory with tactile or olfactory impressions. Of the four fundamental tastes, all can be appreciated by the papillæ vallatæ and the papillæ foliatæ. The tasting power of the tip is imperfect, and in some persons wanting. When present, it is in most persons confined to the appreciation of acid, sweet and salty tastes. Taste sensations can be excited by the passage of voltaic currents through the base of the tongue, particularly when the anode is applied to the neighbourhood of the papillæ vallatæ, or to the papilla foliata of either side. Taste is believed to be dependent on the excitation of certain end-organs, the so-called taste buds, which are to be found in the structures above mentioned. As, after section of the glossopharyngeal nerve in animals, these organs degenerate and finally disappear, there can be little doubt that they contain the gustatory terminations of that nerve. In judging of their function it must remembered that they are met with beyond the limits of the gustatory region, as, e.g., on the under surface of the epiglottis, in the larynx and in the papillæ fungiformes of parts of the tongue which are not endowed with taste.

The taste region at the base of the tongue is supplied by the glossopharyngeal nerve. The tip of the tongue receives its supplies from the lingual, and has been found in several instances in man to lose its tasting power after. destruction of that nerve. There is, however, reason for believing that the gustatory fibres of the lingual are ultimately derived from the glossopharyngeal nerve, through the tympanic plexus. In animals, after section of the glossopharyngeal nerves, near their origin, taste appears to be entirely absent. 


\section{Smell.}

Sensations of smell are occasioned when air containing odorous substances in the state of vapour or gas is inspired through the nostrils, but not when the cavity of the nares is filled with their solution.

Smell is limited to the upper part of the septum, the upper turbinated bone, and the upper part of the middle turbinated bone. This region is characterized by its yellow colour, by its slender columnar epithelial elements, and by the existence among them of the peculiar spindle-shaped elements, which are believed to be the endorgans of the nerve of smell. In inspiration, a large proportion of the air inspired passes through the olfactory region; but, in consequence of the form of the channel through which it passes, the expiratory current is almost entirely diverted, so that odours of intrinsic origin are but little perceived. The varieties of smell are more numerous than those of taste, and appear to have little relation to the chemical constitution of the gases or vapours which occasion them. 



\title{
PRACTICAL EXERCISES!
}

\author{
RELATING TO THE PHYSIOLOGICAL PROPERTIES OF THE
}

\section{CONTRACTILE AND EXCITABLE TISSUES.}

\section{I.-Modes of Excitation.}

Electrical Excitation.-The requirements for the purpose are Batteries (Grove's or Daniell's), an Induction coil, wires, two keys, and suitable Electrodes. The Induction apparatus used is that of Prof. du Bois-Reymond. (See "Handbook," p. 35r, fig. 298.) The key ordinarily used is also that of du Bois-Reymond. The Electrodes are made as follows:-Cement with sealing-wax two copper wires, each about three inches long and pointed at one end, into two pieces of glass tube two inches long, just large enough to contain the wires. The ends of the wires must project about half an inch from the glass tubes, and must be coated on all sides, excepting one, with sealing-wax. Bind the two glass tubes together with strong thread and solder fine copper wires to the blunt ends of the electrodes.

r. Use of the Induction Coil.- $a$. For single induction shocks.Connect a Daniell cell by copper wires with the two upper screws which are directly connected with the ends of the primary coil, interposing a key in the circuit. Insert the wires from the electrodes in the binding screws of the secondary coil, and place the points of the electrodes against the tongue. Withdraw the secondary coil from the primary and then gradually bring it nearer, opening and closing the key after each approximation. The "break shock" is first felt, and is throughout perceptibly stronger than the "make shock." b. For faradization.-Connect the battery wires with the screws at the bases of the brass pillars ( $\mathrm{C}$ and $\mathrm{A}$ in fig. 293). If the platinum-pointed screw $(f)$ is properly adjusted, the hammer begins to vibrate on closing the key, and a series, consisting alternately of "make" and "break" shocks, is felt, which, as the secondary coil begins to cover the primary, becomes unbearable. For many purposes it is desirable to avoid the great disparity which in the ordinary arrangement exists between the opening and closing shocks. This is accomplished by a contrivance known as Helmholtz' modification (see " Handbook," fig. 294) :-A side wire connects the outer pillar with the top screw of 
the same side. The upper platinum-tipped screw is withdrawn and the under platinum tip brought into contact with the vibrating hammer, at the moment that it is drawn down by the temporary magnet. Compare the effects with those previously felt, particularly when the primary coil is covered by the secondary. It is convenient in all cases to interpose a key in the primary circuit.

2. The Single Induction Shock.-Connect the primary coil of the Induction apparatus with a Daniell cell, interposing a key. Arrange a rheoscopic preparation of the lower limbs of a pithed frog, by placing two slender glass rods under the sacral plexuses, having first opened the visceral cavity and removed the viscera. Connect the electrodes with the terminals of the secondary coil, and place them underneath the nerves thus separated from other structures. The preparation should be supported in the vertical position by a clamp. Remove the secondary from the primary coil until no response occurs on closing or opening the key. Then bring the secondary coil gradually nearer and observe that at a certain distance the preparation responds only to the "break" shock, afterwards to both "make" and "break," but more strongly to the latter, and finally with equal vigour to both.

3. The Extra Current.-To demonstrate Faraday's "extra current" physiologically, introduce the exciting electrodes into the primary circuit of the induction apparatus, removing the secondary coil. Connect the electrodes by a couple of copper wires whose ends are united by a key, so that when the key is closed the electrodes are in metallic connection by the wires and key as well as by the coil and battery. Place the electrodes under the sacral plexus in the preparation used in the previous experiment; and observe that when the key is opened the rheoscopic limbs respond strongly; this is clue to the extra current, that is, to the induction current which is produced in the primary coil in the same direction with the battery current, immediately after the sudden diminution produced by the opening of the key.

4. Unipolar Excitation,-Connect one electrode with one terminal of the induction coil and place it under the sacral nerves of the same preparation, which for this purpose must be on a glass plate. No response takes place either on making or breaking. Touch the preparation or otherwise connect it with the earth, and it will be observed that it responds at break.

5. Faradization.-Arrange the coil for faradization and place the electrodes under the sacral plexus in a similar preparation. The limbs are extended and the muscles rigid. The spasm so produced persists, though with gradually diminishing intensity, so long as the primary circuit remains closed. This condition of tonic contraction is designated Tetanus.

6. Galvani's Experiment.-Take a clean bit of zinc wire, and coil round one end of it a copper wire of the same length, so as to make a fork. Pith a frog and lay it on its belly. Remove the skin from the back of the thigh, separate with the finder and remove the narrow biceps femoris. Separate the sciatic nerve which is thus brought into view, from the surrounding structures, and touch the nerve first with the copper wire, then with the zinc. It will be observed that on closing the circuit thus formed, the gastrocnemizes muscle contracts and the foot is extended. If it is moderately excitable, the same thing happens also on opening it. 


\section{Excitation by Interruption of the Direct or Battery} Current.-For this purpose it is necessary to arrange the circuit so that its intensity can be varied at will. This might be accomplished by the interposition of large resistances, but such a method would be so inconvenient as to be impracticable. The method always used is to connect the poles of the battery by a side wire, whose resistance can be varied at pleasure. As the resistance of nerve and muscle is very high, the strength of the current in the circuit varies approximately inversely as the resistance of the side wire. A graduated side wire suitable for this purpose is called a rheochord. The rheochord commonly used is that of du Bois-Reymond ("Handbook," fig. 298). Connect the two terminal binding screws of the rheochord with the battery (a single Daniell's cell) interposing a key ; connect with the same binding screws the two end screws of the reverser ("Handbook," figs. 299, 506), and finally insert the wires from the electrodes in the two central screws (I \& 2). Prepare the sacral plexus and rheoscopic limbs as before, and arrange the electrodes. Diminish the resistance of the rheochord to the utmost, and observe that on opening and closing the circuit, no contraction takes place. Then gradually increase the resistance. At first the muscles respond only to closure, subsequently to "make" and "break," whatever the direction of the current. On continuing the observation, particularly with stronger currents, it will be observed that the "make" and " break" effects are in no instance equal, and that the nature of the inequality is influenced by the direction of the current. The results are further modified by exhaustion or injury of the nerve.

\section{Excitation of a Motor Nerve by contact with a Con-} tracting Muscle. The Secondary Twitch.-After preparing the sciatic nerve as above directed, expose the gastrocnemius as directed in 6 . Seize its tendon with the forceps and separate it from its attachments. Cut off the tibia and femur, close to the knee on either side, along with the muscles and other soft parts, taking care not to injure the nerve. A gastrocnemius with its nerve as described, constitute a "nerve muscle preparation." Two such preparations are required.

Place one of them, b, on a glass plate, and fix the other, a, along the edge of a small piece of board. Then place the board on the glass plate in such a position that the nerve of $b$ can can be readily laid on the muscle of $a$. Excite by a single induction shock passed through its nerve. At the same moment that a contracts, $\mathrm{b}$ will contract. Then repeat the experiment, but instead of passing single induction shocks, faradize the nerve. Tetanus is produced in $\mathrm{b}$, which lasts so long as $\mathrm{a}$ is tetanized. Ascertain that the effect is not due to escape of current, by ligaturing the nerve and repeating the experiment.

9. Mechanical Excitation.-Mechanical Tetanus. Connect a Grove cell with the "Tetanometor," introducing a key into the circuit. The wire from the zinc terminal of the battery must be inserted in the binding screw marked Z, that from the platinum in $\mathrm{K}$. Adjust the apparatus so that on closing the key the ivory hammer vibrates so as to excite, without destroying, a nerve placed on the ivory groove. The effect produced is identical with tetanus by faradization. 
I0. Chemical Excitation.-Make a nerve-muscle preparation. Place it on a card, having a hole in the middle just large enough to allow the nerve to pass. Place the card, with the nerve hanging from it, over a beaker containing ammonia. The muscle does not contract. Then cut off the nerve and expose the muscle to the gas. It contracts. Glycerine, on the other hand, excites nerve readily, but scarcely acts on muscle.

Ii. Action of the Arrow Poison (Curare) on Muscle and Nerve.-In a preparation of which the hemispheres have been destroyed, pass a ligature under the sciatic nerve above one knee and tighten it so as completely to arrest the circulation beyond. Inject a drop of a solution containing $O \cdot I$ per cent of curare under the skin and leave the preparation in a moist chamber for an hour. Then test the condition of the muscles by direct excitation and excite both sciatic nerves, comparing the effects. Although both have been equally acted upon, it is on the ligatured side only that the excitation is responded to. The experiment shows that the arrow poison acts neither on nerve trunks nor on muscular tissue but only on the muscular nerve-endings.

\section{II.-The Myograph.}

Any instrument by which a curve can be drawn which truly represents the contraction of a muscle is called a myograph.

I. The most simple myograph is that of Marey, the construction of which is as follows :-A pillar, supported by the horizontal triangular bar of the recording apparatus (kymograph), carries a board seven inches long by two and a half in width, which with the aid of a rack-and-pinion and adjusting screw, can be moved either vertically or horizontally. At one end of the board is a vertical pillar on which a writing lever is supported; the point of the lever can be brought into such a position as to inscribe its movements on the revolving cylinder. The lever is centred on a horizontal axis, its motion being resisted by a delicate spring. The upper surface of the board is covered to within a short distance from the lever, with a thick plate of cork. (See "Handbook," fig. 270 bis.)

Various muscles of the frog are used for myographic purposes; the one most easily prepared is the gastrocnemius. All that is required is to divide the skin so as to expose the tendon, and to attach the latter to a strong ligature thread. A strong needle must now be thrust through the end of the femur without injuring other parts, so as to fix the femoral attachment of the muscle to the cork plate in such a position that the ligature may be advantageously fastened to the lever.

Arrange the apparatus for single induction shocks as directed in Section I., 2, interposing in the primary circuit an additional key, which is so placed as to be opened by the recording cylinder on arriving at a certain part of its revolution.

Cover the cylinder smoothly and tightly with glazed paper, taking care that the edge of the crease does not catch the writing style. Smoke the surface uniformly with a paraffin lamp and put the cylinder on the middle axis.

Place the electrodes on the tongue and set the clock in motion, so as to ascertain that the electrical apparatus is working properly. 
2. The Curve of a Single Contraction, or Twitch.-Pith a frog and place it on its belly on the myograph plate. After preparing and attaching the muscle as above directed, expose the sciatic nerve, and place the electrodes under it. Adjust the style of the lever so as to touch the smoked surface. Open the key of the primary circuit and set the clock in motion. A line is drawn by the style-the abscissa of the future curve. As soon as the fly has attained its maximum expansion, close both keys of the primary circuit. At the moment the cylinder comes into contact with its key and opens it, a curve is insqribed. Stop the clock and prepare for a second observation by giving a single or half turn to the pinion, and draw a second curve similar to the first, and so on, until a series of parallel and similar curves has been drawn. To observe the effect of exbaustion arrange the apparatus so that, while the muscle is excited at each revolution, every tenth curve only is recorded.

3. Influence of Veratrin.-Inject a drop of O'I per cent. solution of Veratrin into the lymph sac of a brainless frog. After twenty minutes, destroy the spinal cord and inscribe one or more muscle curves, and compare hem with those previously obtained.

If in this, and in the preceding experiment, it be desired to employ the "nervemuscle preparation" rather than the entire pithed frog, the apparatus described below may be substituted; it can be made with simple materials, such as can be procured anywhere. A thick brass wire is bent twice at right angles, in the same plane. The middle part measures four inches, and each of the ends two inches. On the middle part slides a cork bearing two centres, in which an axis works. This axis bears a light lever about five inches long, which moves in the plane of the two ends. The femur of the muscle-nerve preparation is attached by a wire to the upper end of the brass wire (called the stretcher), and the tendon to the lever. A spiral spring, connecting the lower end of the stretcher with the lever, serves to extend the muscle and opposes its contraction. The nerve is enclosed in a tube provided with platinum electrodes, which serves to protect it from evaporation. The whole apparatus is supported as before (II, I), on an adjustable pillar, which is fixed to the recording apparatus.

4. Influence of Temperature on the Form of the Curve of Single Contraction.-For studying this subject, the simple myograph just described may be used. A spiral tube of metal of suitable form, must be prepared and fixed to the stretcher so as to surround the muscle during the observation. One end of the coil is connected by a flexible tube with a small reservoir of water at a higher level, the other with a waste pipe. Make a muscle-nerve preparation, pierce the femur with a fine awl, and pass a fine wire through the hole and attach it to the upper arm of the stretcher. Secure the tendon by a ligature to the lever and adjust the spiral spring, so that the lever is parallel to the arms of the stretcher. With the aid of a fine silk thread tied to its end, introduce the nerve with great care into the electrode tube and close the latter with its cork. Adjust the writing lever.

Having made the same arrangement as in the last exercise, pass a stream of water through the coil at the ordinary temperature and inscribe a succession of curves. Then repeat the observation, passing water through at various temperatures from $5^{\circ} \mathrm{C}$. to $30^{\circ} \mathrm{C}$., observing the successive alterations in the form of the contraction curve. 
5. The Curve of Tetanus.-Arrange the apparatus (as directed in Section I. 2) for single induction shocks. Introduce into the primary circuit a reed which automatically makes and breaks the circuit twenty times in a second. Prepare and fix the muscle according to either of the methods described above. On closing the key of the primary circuit for ten seconds, the muscle is tetanized and the curve inscribed on the cylinder (see p. 56).

Arrange the induction apparatus for faradization (see Section I. I, b), and repeat the preceding observation.

\section{The Time-Relations of a Muscular Contraction.-}

r. By noting the time required for a sufficient number of revolutions of the recording cylinder and accurately measuring its circumference, the rate of movement of the recording surface may be determined, and thereby the time-value of the records known. 2. A more direct method is to write simultaneously under the tracing the oscillations of a tuning-fork of which the vibration-rate is known. For this purpose the tuning-fork may be made to inscribe its vibrations directly, or (more conveniently) it may be introduced into a battery circuit, so as to interrupt it at each vibration. An electromagnetic writer (chronograph) is introduced into the same circuit ; it vibrates synchronously with the fork, and reproduces its motions on the cylinder. Record a curve of single contraction, using the "stretcher," and fix the recording cylinder on the quick axis. Mark the point of excitation by bringing the trigger of the cylinder very slowly into contact with the lever of the key. Measure the distances from the point, -(I) to the beginning of the curve, (2) to its maximum, and (3) to its close, and determine their value by either of the methods given above.

7. Measurement of the Period of Latent Stimulation and of the Rate of Propagation in Nerve, by the Pendulum Myograph.Preparation of the Apparatus. Cover the glass plate smoothly with paper, smoke its surface as before, and fix it to the pendulum. Arrange the "trigger" and the "catch" so that the pendulum when detached from the former just catches on the latter. Test the instrument by taking tracings with a tuning-fork vibrating 100 times a second, on the smoked paper, when the pendulum is moving at several different velocities (the velocity varying with the positions of the trigger and catch). Arrange the electrical apparatus for single shocks as in Sect. I. 2, including in the primary circuit one of the keys of the myograph. Prepare the gastrocnemius as in Sect. II, I. Fix the femur firmly to the cork table, pass the ligature round the pulley and attach it to the lever, adjusting the spiral spring to a suitable strength. Take great care that no part of the apparatus touches the glass plate, as the pendulum swings. Arrange the lever very carefully, so that when it is brought into position by the rotating handle it writes on the smoked surface. Observe that the glass plate is so adjusted that the lever at first touches it lightly, but presses more strongly as the plate swings past. Catch the pendulum with the trigger, see that everything is in order-the keys closed, the lever in its position, the electrodes under the nerve, etc. On liberating the pendulum, a muscle curve is inscribed on the smoked surface. Withdraw the lever from its writing position, bring the pendulum back past the key, close the latter, keeping it closed by firm pressure of the finger, allow the pendulum to rest against it, bring the lever into the writing position, and make a mark on the 
surface, which indicates the moment of excitation. Take three or four similar curves, depressing the table an equal distance after each observation ( $\frac{1}{4}$ or $\frac{1}{2}$ turn) by the handle. Remove the muscle lever and take a tracing with a tuningfork, vibrating 100 times a second, carefully arranging the style of the fork in the position previously occupied by the writing end of the muscle lever. Remove the paper, varnish and measure the tracings. From the mean result of the measurements, the latent stimulation may be computed.

8. Rate of Propagation.-I. Prepare the muscle as in the last exercise. Expose the sciatic nerve throughout its length. Place one pair of electrodes under the nerve close to the muscle, and a second pair under the nerve near its origin. Connect these two pairs of electrodes with a switch. To the middle screws of the switch attach the wires from the secondary coil, so that by turning over the bridge of the switch, the near and the distant portion of the nerve can be excited alternately without loss of time. The nerve should be prepared with great care, and each exposed part should be protected by a flap of muscle, except at the moment that it is being excited. Take tracings of muscle curves in pairs, alternately exciting the near and distant portions of the nerve. Take a tuning-fork tracing, varnish, measure the length of nerve: from one pair of electrodes to the other, and therefrom determine the rate of propagation in the nerve (see p. 77).

\section{III.-The Frog Heart.}

1. Rhythmical Motions. - In a curarized preparation of which the hemispheres have been destroyed, expose the sternum and cut across the episternal cartilage. Then sever the sternum from its connections by a cut on either side, and turn it down over the belly. The heart is seen still covered by the pericardium. Expose the heart by carefully dividing the pericardium. Note the condition of each of its cavities and the mode of its rhythmical action.

2. The Inhibitory Centre.-For the purpose of observing the effect of passing series of induction shocks through the inhibitory centre of the heart, a fine ligature is attached to the frænum (the thread-like ligament which stretches from the dorsal aspect of the ventricle towards the lower part of the pericardium). By means of the ligature the heart is raised out of its place and turned upwards. The inhibitory centre is recognized by the whitish crescent-shaped line which marks the junction of the wall of the sinus with that of the right auricle. Faradize this spot for a second or less, placing the points of the electrodes on the line, a couple of millims. distant from each other. Observe the mode and order in which the cavities of the heart resume their rhythmical action.

3. Destroy the spinal cord by pithing, and observe the changes thereby produced in the state of the circulation, and particularly in the mode of action of the heart.

4. The Cardiac Vagus of the Frog.- $a$. Preliminary Dissection.Expose the trunk of the vagus nerve as it escapes from the cranium as follows :Remove the integument so as to bring into view the muscles of the back of 
the neck on one side, avoiding injury to the cutaneous vessels. Then expose the scapula, and sever with the scissors the cartilaginous from the bony scapula ; remove the former, dividing the muscles attached to it, then expose the sterno-mastoid muscle which connects the outer part of the petrous bone and the posterior border of the cartilaginous ring of the membrana tympani with the concave anterior border of the scapula. Remove or draw aside the sterno-mastoid so as to expose the slender muscles (petrohyodei) which run from the petrous bone to the posterior horn of the hyoid bone, embracing the cavity of the pharynx. Parallel with these muscles, and in close relation with them, are seen the carotid artery and several nerves, of which the two nearest the cranium are the glosso-pharyngeal and the vagus.

b. Expose the vagus in a pithed preparation. Expose the heart as in III. $\mathbf{r}$, and introduce a small test tube into the gullet. Fix the preparation in such a position on a cork, that the electrodes can be conveniently applied to the nerve, at the same time that the motion of the heart can be observed.

5. The Stannius Heart.-Prepare a frog heart with frænum ligature as before. Then pass a thick ligature under the bifurcation of the aorta between it and the venæ cavæ superiores. Then, seizing the frænum ligature with the forceps, turn the heart up. Carefully observe the position of the "crescent," and loop the ends of the ligature so that when it is tightened it may embrace the crescent. On tightening, the heart will stop in diastole.

In the heart so prepared, sever the ligatured parts from the rest of the preparation with sharp scissors. The auricles and ventricle resume their normal rhythmical action.

Cut off in a preparation which has been so treated, the remainder of the auricles and the bulb, leaving the ventricle and auriculo-ventricular septum. The heart continues to beat normally, or, if the beats cease, they are renewed by a pinch, by an induction shock, or by bringing a hot wire into the neighbourhood of the cut surface.

6. Localization of the IMotor Centres.-In one of two such preparations (called ventricle preparations) which beat rhythmically, cut off the whole of the auriculo-ventricular furrow with sharp scissors. The preparation so obtained (the ventricle apex) does not contract spontaneously, but responds to a single excitation, whether mechanical or electrical, by a single contraction, the duration of which is dependent on the temperature. In the other preparation, divide the ventricle by two parallel cuts into a middle and two lateral thirds. The middle third includes the ventricular border of the interauricular septum, the right lateral third contains the root of the bulb. The middle third beats rhythmically, the lateral thirds respond to excitations by single contractions, but do not beat of themselves.

7. Action of Muscarin and Atropin.-In an entire heart (a heart removed by severing the vessels, for which purpose the organ should be lifted out of the pericardium by a ligature tied to the frænum), stop rhythmical action by applying to it a drop of serum containing a trace of muscarin. Observe the relaxed and motionless condition of the ventricle. After a few minutes apply (in serum) a drop of 0.2 per cent. solution of atropin. Observe the gradual restoration of rhythmical action in the atropinized heart. Observe that faradization of the inhibitory centre is without effect. 


\section{Action of the Constant Current on the Contractile} Substance of the Heart.-For this purpose prepare electrodes as directed in Exercise I. Fix a cork vertically on a sheet of lead about an inch and a half square; cover the top of the cork with wax mass, the upper surface of which should be somewhat concave. Place the support on a sheet of wet filtering paper and cover it with a beaker. Attach a fine ligature to the frænum, and remove the heart after severing the principal vessels. Collect some blood and dilute it with as much 0.75 per cent. salt solution, and place a few drops of it on the wax surface.

Make a "ventricle-apex preparation," as directed in 6. Having ascertained that it does not beat rhythmically of itself, fix it in its place by the aid of fine glass pins and replace the beaker.

Prepare and arrange two Grove's cells in circuit, interpose a key and a pair of electrodes. Fix the electrodes, so that their points are in contact with the apex and base respectively of the preparation. The passage through the ventricle apex of a voltaic current in the direction of its axis produces rhythmical action, which lasts as long as the current passes.

9. Study of the Ventricular Systole by the Graphical Method.-Prepare a writing lever consisting of a glass rod about $\frac{1}{40}$ inch in thickness and five inches long, having at one end a knob of glass, and at the other a writing point. This is thrust through a square bit of cork, which is then pushed up to the knob. A fine steel needle passes through the cork at right angles to the rod. The rod also bears, close to the needle, a vertical arm of cork, by means of which it rests on the ventricle. The preparation lies on a metal plate, which forms the upper end of a cylindrical brass box, through which water, at any desired temperature, can be passed. This plate is furnished with bearings in which the steel axis of the lever works. The metal box is fixed to one of the adjustable supports of the recording apparatus.

$a$. The rhythmically contracting heart.

Expose the heart as before. Raise it from the pericardiun by a ligature attached to the severed frænum, and cut through the vessels. Place the heart on the plate, adding a few drops of dilute serum, and arrange the lever so that the cork arm rests on the ventricle, and the writing end inscribes its movements on the blackened surface of the cylinder. The rate of motion should be about 20 inches per minute.

Allow water at $12^{\circ} \mathrm{C}$. to pass through the cylindrical box and record the rhythmical contractions of the ventricle. Repeat the experiment, substituting water at $\mathrm{I} 7^{\circ}$ and at $22^{\circ}$, and compare the tracings.

$b$. The curve of a single ventricular contraction.

Prepare finely pointed electrodes as in I. I, arranging for single induction shocks. Fix the electrodes to an adjustable support, so that they can be brought with precision into contact with the preparation. Prepare a Stannius' heart and arrange it for recording as in $a$. Adjust the electrodes, taking care not to interfere with the lever. Place the secondary coil at about ro centimeters distance from the primary, or nearer, if on trial it is found necessary to do so, Then bring the point of the lever into contact with the blackened paper, so as to write a base line or abscissa, and open the key. The rate of motion of the recording surface should be about $2 \frac{1}{2}$ inches per second. 
In order to obtain series of tracings which can be conveniently compared, introduce into the primary circuit the self-acting key described in II. I. In this way a number of curves may be drawn on the same abscissa, or on parallel abscissæ at convenient distances from each other. Having practised one or other of these methods, proceed to make the following observations :-

(I.) When a succession of ventricular curves are drawn at temperatures. varying from $12^{\circ}$ to $I 8^{\circ}$, it is found that the duration of the systole is increased. by about $\mathrm{O}^{\prime \prime} \cdot \mathrm{I}$ for every degree of temperature.

(2.) When the ventricle is excited by single induction shocks, following each other at about $10^{\prime \prime}$ intervals, each curve is observed to exceed its predecessor in amplitude, the augments gradually diminishing from the beginning to the end of the series.

(3.) In the muscular tissue of the heart, the period of latent stimulation is much longer than in voluntary muscle. Its duration is about $\mathrm{O}^{\prime \prime} \cdot 15$. To measure it, a vertical line must be drawn on the recording surface, indicating the position of the writing point at the moment that the trigger of the cylinder comes into contact with the lever of the self-acting key (see II. I).

\section{IV.-Functions of the Spinal and other Reflex Centres of the Fror.}

I. The preparation to be used in the following experiments is obtained by severing the spinal cord immediately behind the medulla oblongata and introducing, by the opening made for this purpose, a wooden plug into the cranial cavity, so as to destroy its contents. This having been done, it is placed on a sheet of moist filter-paper, resting on its ventral surface with the hind limbs extended, and covered with a bell jar. For a time it remains motionless, but eventually assumes a position which differs but little from that of a living frog. Observe the differences.

2. Prepare half-a-dozen pieces of filter-paper, each an eighth of an inch square, and some strong acetic acid. Turn the preparation over, and after observing that the natural position is not resumed, apply one of the squares, after moistening it with acetic acid and drawing off excess by touching with dry filter-paper, to the inside of the right thigh, and observe the result. Repeat the experiment, holding the right foot. Next, attach the preparation to a suitable holder in such a way that the trunk may be steadily supported and the limbs may hang freely, and apply the squares in succession to different parts of the surface, as e.g., to the slin on either side of the tendo Achillis, or to either flank. Olserve in each case that the muscular response which results from excitation of the same part of the surface of the body is always the same.

3. Arrange a second preparation as last described, using a holder so constructed that the limbs may be suspended at any desired height above the table. Prepare several beakers of water acidulated respectively with $\mathbf{I}, 2,3$, 4 and 5 per thousand of sulphuric acid, and place some of each mixture in a saucer. Beginning with the weakest of the acid liquids, bring down the preparation with the rack and pinion, until the tip of the longest toe is 
immersed. Repeat the experiment at intervals of three minutes with the stronger liquids in order, carefully washing the foot after each excitation, by dipping it into a beaker of water. Measure the time which intervenes between the beginning of the excitation and the muscular response in each case, with the aid of a metronome.

4. Observe carefully the attitude of a brainless frog when left to itself, and its behaviour when placed on its back, on an inclined surface, or in water, as well as when excited by cutaneous stimuli, comparing the phenomena observed with those which exhibit themselves in the spinal cord preparation.

5. Proceed as in $\dot{I}$, substituting a preparation in which, after destruction of the brain, a couple of drops of $0^{\circ} \mathrm{x}$ per cent. solution of sulphate of strychnia have been injected under the skin of the back. Observe that instead of co-ordinate muscular responses, cutaneous excitation produces under the influence of strychnia, paroxysms of convulsion, in which the body and limbs assume a characteristic attitude.

\section{V.-Sensation and Perception.}

\section{Time Occupied in the Simplest IMental Processes} (see p. 104).- - To measure the time required for responding to a signal (reaction time or personal time), the simplest plan is to arrange a battery circuit in such a way that it is closed by the same act by which the observer makes the signal, and that it is opened by the response of the observed person. Whatever be the nature of the signal, the requirements are: (I) Two Grove's cells arranged in circuit; (2) a break key (a lever resembling in shape a pianoforte key, which when touched breaks a mercurial contact); (3) a du Bois' key; (4) an electro-magnet with a light lever attached to its armature ; (5) a chronograph ; (6) a recording surface, of which the rate of motion is not less than I foot per second. The battery, two keys, electro-magnet and chronograph, are arranged in circuit, and in such positions that the electromagnet lever may be in the neighbourhood of the observed person, and the du Bois' key, cylinder and chronograph, in reach of the observer. On closing the circuit, the lever is drawn towards the magnet and gives the signal. The signal may be an induction shock through the tip of the tongue (in which case an induction coil must be in circuit in addition to the instruments above-mentioned), a touch on the hand given by the lever, a sound or a visible signal, such as a white disk, letter or number, suddenly brought into view.

2. Tactile and Muscular Sensation,-In all the following experiments two persons must take part : one of whom must vary the conditions without the knowledge of the other, and note the results. In the experiments relating to the sensations of pressure, locality, and muscular exertion, the observed person must have his eyes shut.

The appreciation of Temperature must be tested by immersing the same surface successively in water of slightly different temperatures. The smallest differences can be detected when the temperatures of the liquids compared approximate $30^{\circ} \mathrm{C}$.

To test the sensation of Pressure, the hand or other part to be investi- 
gated must be entirely at rest, and supported on a horizontal surface. The weights used must be moderate-from a pound to four or five pounds; in which case it will be found that a difference between two weights of onethirtieth can be detected.

For testing the sensation of locality in any part of the surface of the body, a pair of compasses is used, of which the points are provided with cork sheaths, having smooth blunt ends. The points being at first at such a distance that when both touch the skin or mucous membrane of the tongue, they are distinctly felt as two, they are gradually brought nearer until the two impressions blend into one. The smaller the distance at which this happens, the finer is the sensation of locality in the region investigated. Another method is that of interrogation. The observer touches the skin, and asks the observed person to designate the locality touched.

The sensation of muscular Exertion is tested by experiments, each of which consists in lifting in succession two weights, of which one is heavier than the other by a small but perceptible difference; this difference is diminished at each trial until it can nolonger be appreciated. As it is essential that sensation of pressure should be excluded, the weight to be estimated must in each trial be enclosed in a handkerchief, of which the corners must be held in the hand.

For the investigation of the sensation of taste and of the limits of the gustatory region, four test liquids should be prepared, viz., saturated solution of sulphate of quinine, Io per cent. solution of common salt, 3 per cent. solution of sugar, and $O^{\prime} I$ per cent. solution of citric acid. These liquids represent the four fundamental sensations, each of which may be tested separately, or two alternately. In each experiment a camel hair pencil is dipped in the liquid, drained by touching it with filter paper, and applied for a moment to the surface. To secure freedom from bias on the part of the observed person, trials should be made in which tasteless liquids, or liquids of different tastes are alternated in various orders, care being taken to irrigate the surface between each trial and the following one, with water.

The voltaic sensations of taste are experienced when two zinc plates, which form the terminals of a Grove's element, are applied respectively to the upper and under surface of the tongue as far back as possible. As the effect differs according to the direction of the current, a reversing key must be introduced into the circuit.

\section{VI.-Vision. *}

I. The application of Scheiner's experiment to the limitation of the range of accommodation can be best understood if it is made as follows:Stretch a white thread from end to end along the blackened surface of a narrow black board about a yard long. Fix at one end of the board a vertical screen

* The experiments and observations described under this heading are arranged in the order in which the subjects they are intended to illustrate happen to be referred to in the lectures. 
or diaphragm, having two vertical and parallel slits, about three millims. apart, taking care that the slits are opposite the thread. When the thread is contemplated through the slits, by a normal or myopic eye accommodated for near vision, two white lines are seen, which converge towards the spot in the thread, for the distinct vision of which the eye is accommodated, and, after crossing, diverge. If the eye were hypermetropic, the lines would not converge even if accommodated to the utmost.

2. Sanson's or Purkinje's images.-The relative positions of the observed and observing eye, and of the luminous object, which are most advantageous for the observation of the image reflected by the anterior surface of the lens, are stated on page ro8. The experiment must be made in a dark room. It is advantageous to substitute two lights, one above the other, for the single luminous object referred to in the text.

3. Chromatism.-In order to see the effects described in the text (p. 109) it is advantageous to place before the eye a purple glass, which, by cutting off the rays of medium refrangibility, facilitates the perception of the red and blue rays.

4. Reflection of light from the Retina (see p. rog).-To see the eye of another person luminous, the simplest way is to interpose between the observed and the observing eye a reflector, consisting of several glass plates applied to each other by their surfaces, in such a position that the light of a lamp placed on one side of the observed eye may be seen by it. The moment that this is the case, the retina is illuminated; and if the observed eye is accommodated for distinct vision of the lamp flame, and a suitable concave lens placed in front of the observing eye, a distinct image of the flame is seen on the observed retina, the whole interior of the globe appearing at the same time luminous.

5. The Fovea Centralis (see p. Iro).-(a) Fix a black board horizontally at a level a little below that of the eyes. Mark a point $a$ at one edge of the board, and bring the right eye up to it, closing the other, and plant a pin having a white bead for its head in the board at any distance at which it can be distinctly defined. Draw on the board a semicircle having the point $a$ for its centre and passing through the pin, and plant along the circle a number of similar pins, at an angular distance from each other of 5 degrees. If the eye is fixed on any of these pins, it will be seen that its next neighbours only are seen distinctly.

(b) Draw two parallel lines in white, on a black ground, each $\frac{1}{2}$ millimetre wide, and separated by an interval of the same width. Place the board against a wall, and fix one eye on it at a distance of five feet ( $1 \frac{1}{2}$ metre, and consequently 100 times as far from the crossing point as the surface of the retina). In a normal eye the two lines can be distinguished at that distance : if not, lessen the distance until this is the case. If the eye is myopic, a correcting lens must be used.

In those of the following experiments which depend on the blending of retinal excitations which occurs when these follow each other in rapid succession, a circular brass plate which revolves on a central axis is used. It is furnished with an arrangement by which its rate of revolution at any desired moment can be measured. 
6. Duration and culmination of light sensations.-On a black card draw two concentric circles, of which the respective diameters are 6 and 1o inches. Draw a straight line through the centre, so as to divide the annular space between them into two equal parts. Cover one of these spaces with white paper. Cut out the card along the outer circle and fix it to the revolving disk.

If the rate of revolution is gradually increased, the moment can be determined at which the sensations due to successive exposures of the white sector become blended. It will be found that this happens when the rate of revolution is such that the white is visible each revolution for from $0^{\prime \prime} \cdot 15$ to $0^{\prime \prime} \cdot 2$; for the time required for the light given off by a white surface in common daylight to produce its full sensational effect, is about a sixth of a second. If the rate of revolution is further increased, the subjective luminosity diminishes, but finally becomes constant. Its brightness is then just half of that of the white paper at rest.

\section{Diminution of sensational effect in continued exci-} tation of the Retina.-To prove that when the eye is exposed to the light from a bright surface, the apparent luminousness of the surface after culminating gradually diminishes, fix against a wall a black sheet of paper with a small white square in the middle, and place beside it a white sheet of similar size. Having fixed the eye steadily on the white square, suddenly direct it to the adjoining white surface. A grey square is seen on a white ground, of which the shade differs according to the number of seconds that the white square has been contemplated.

. S. Smallest perceptible difference.-Prepare a piece of black paper, six centimeters in length, and varying in width from 2 millims. to 8 millims. Cut it transversely into six bits, and apply the smallest to a white disk, half way between centre and circumference, with its long edge against a diameter of the disk. Set the disk in rapid revolution and observe the effect. ' Replace the bit of black paper by the one next it in width, and repeat the observation. Proceed in this way until a faint grey ring is seen, when the disk is in revolution. This happens when the width of the black surface is about one hundredth of the circumference of the ring.

9. Visual perception of Motion.- - When a disk on which a number of concentric spirals at equal distances from each other are inscribed, is contemplated in rapid revolution, radial motion is perceived, which is centripetal or centrifugal, according to the direction of rotation. If the eye is suddenly directed to a blank surface, radial motion is still for a time perceived, but it is in the opposite direction. This experiment serves not only to illustrate the principle enunciated on p. 97, but to prove that the subjective perception is not due, as has been supposed in other similar cases, to felt motions of the eyeballs.

For experiments relating to the blending of sensations of colour (p. I I2), disks are used, each of which has a radial cut extending from the circular hole in the centre, to the circumference. Two or more of these cardboard disks can be fixed to the brass disk, in such a way that a sector of each colour may be exposed, and that their relative areas may be varied at will. For many purposes of study, the following method of blending is more useful :- 
Fix a pane of plate glass vertically across the middle of a board about 16 inches long by 8 wide. On either side place a sheet of paper of the colours which it is desired to blend. Arrange the board so that the illumination of each sheet may be varied, independently of that of the other, and that one sheet is seen through the glass, the other by reflection.

Io. The angle of rotation (see p. I13).-Draw on a wall of a moderately dark room, a horizontal line, at a height of a couple of feet above that of the eyes. In a black card, cut out a cross, each bar of which should be about a twentieth of an inch in width. Close one eye, and place the cross between the other and a bright lamp, and fix the eye on the luminous cross for several seconds. Then turn to the wall, which should be at a distance of four or five feet, and direct the eye to a point exactly opposite it and at the same level. If now the eye is fixed on a point in the horizontal line immediately above the first (the position of the head being unaltered), it is seen that the transverse bar of the bright image of the cross coincides with the line. But if (the eye remaining fixed) the head is turned to the right, the image gradually assumes an appearance of distortion, the upper end of the upright bar seeming to incline to the left, and the outer end of the horizontal bar to incline upwards. As in reality the horizontal bar coincides with the horizontal meridian line of the retina, it is clear that the retinal image of the horizontal line crosses the meridian line at an acute angle. This angle is the angle of rotation for the particular (tertiary) position assumed by the eye.

II. Judgment of Form.-For experiments on this subject pairs of diagrams representing respectively the right and left aspects of characteristic objects are used, of which the retinal images are blended by means of the stereoscope. The most important observations are the following:- $(a)$ If two diagrams representing the right and left aspects of a pyramid are imaged on the right and left retina, and the images blended by giving the eyes the degree of convergence necessary to unite the apices, a solid pyramid is seen. If the diagrams are transposed and the process repeated the pyramid appears hollow. (b) If two similar diagrams are viewed stereoscopically, of which one is represented white with black edges on a black ground, and the other black with white edges on a white ground, the combined image is lustrous.

12. Judgment of Distance.-If a number of balls of similar colour, but differing in size, are allowed to fall one after another before one eye, the the other being closed, at such distances that in each case their retinal images are equal, and at such velocities that their images pass over the same retinal distance in the same time, the observer is unable to form any judgment either as to their size, distance, or rate of motion. All of these can be judged of at once if the other eye is opened. For this experiment an apparatus is used. 

DEMONSTRATIONS

RELATING TO THE FUNDAMENTAL PHENOMENA

OF

CIRCULATION AND RESPIRATION,

\author{
AND TO THE \\ ELECTROMOTIVE PROPERTIES OF MUSCLE.
}

\title{
I.-Mode of Measuring and Recording the Arterial Pressure. Use of Recording Apparatus.
}

The instrument used is called a kymograph (see p. 6r). The arteriat cannula is a T-shaped tube of glass. By its stem, it is connected with the manometer (a $\mathrm{U}$-shaped glass tube containing mercury). One branch of the $T$ is drawn out and bevelled so as to be easily introduced into the artery : to the other is fitted a short piece of indiarubber tubing, guarded by a steel clip. The stem of the cannula communicates with the proximal arm of the manometer by an unyielding tube of lead or guttapercha. The proximal arm (that connected with the cannula) also communicates by a long flexible tube with a bottle containing solution of bicarbonate of sodium under pressure. The manometer is fixed to the recording apparatus, so that its oscillations are inscribed on the moving surface. This is effected by means of a style carried by a vulcanite rod, which floats on the surface of the mercury in the distal (open) limb of the manometer. The recording cylinder is driven by clockwork: it is either covered with smoked glazed paper, or is fed by an endless roll of paper, in which case a sable pencil, clarged with coloured ink, is substituted for the style. The paper surface in either case moves at a uniform. rate of 20 inches per minute.

The artery used is the carotid of the rabbit. The distal end of the prepared part of the vessel is ligatured. The proximal end is temporarily closed by a spring-clip. The vessel having been opened near the ligature, the cannula is introduced and secured in its place by a second ligature, its drawn-out end being directed towards the heart. This done, the guttapercha tube of the manometer is connected with the stem of the cannula, and the whole system filled with solution of sodic bicarbonate under a pressure of about four inches of mercury. On removing the clip on the artery, communication is established between the arterial system and the manometer, which now records the variations of arterial pressure. The tracing exhibits larger (respiratory) undulations, on each of which many smaller undulations (cardiac pulsations) are inscribed. It shows (I) that each contraction of the 
left ventricle produces a momentary increase of arterial pressure ; (2) that the pressure increases after each inspiration, and sinks in the interval ; $(3)$ that during the rise of pressure, the pulsations are more frequent than during the fall. Excitation of the Cardiac end of the divided Vagus, by faradization, produces (if weak induction currents are used) diminution of the frequency of the heart's pulsation and of the arterial pressure. If stronger currents are used, the heart is arrested in diastole (see p. 85).

[N.B. In each of the Demonstrations I., II., III., and IV., a rabbit is used, which is rendered completely insensible by a suitable anæsthetic, and is killed before recovery.]

\section{II.-The Normal Respiratory Movements. Influence of the Vagus Nerve and of its Centre. Apnoea and Dyspnoza.}

The motions of a metal plate which is kept in constant contact with the posterior surface of the central tendon of the diaphragm of the rabbit, by the pressure of a spring are communicated by a long steel wire to the vertical arm of a bell-crank lever. The horizontal arm of the lever is prolonged, and bears a style by which an enlarged record of the respiratory motion of the diaphragm is inscribed on the cylinder of the recording apparatus. The rate of movement of the cylinder is the same as in the last demonstration.

The inspiratory contraction of the diaphragm is expressed by the descent of the writing style, its relaxation by the ascent, which is at first rapid, but afterwards more gradual.

Apnœa. When by excessive artificial respiration the circulating blood becomes overcharged with oxygen, all respiratory movement ceases. On discontinuing the injections of air, the respirations after a time begin again : at first they are scarcely perceptible, but each exceeds its predecessor in extent, until the normal is reached.

Dyspnœa. When nitrogen containing an inadequate percentage of oxygen is respired, the opposite effect to that described above is produced. The respirations become more ample and more frequent, and the auxiliary muscles are brought into action. No such effect is produced by an atmosphere containing as much as ten per cent. of $\mathrm{CO}_{2}$, provided that the supply of oxygen is sufficient.

Excitation of the Superior Laryngeal Nerve.-Excitation of the central end of the trunk of the superior laryngeal nerve, by faradization, arrests the respiratory movements, the diaphragm becoming stationary in the position of expiration. When extremely feeble currents are used, rhythmical movements may continue at long intervals. Introduction of irritant gases or vapours into the larynx produces similar effects.

Similar excitation of the central end of the divided vagus, below the cricoid cartilage, produces effects which differ according to the strength of the induction currents employed. When currents of moderate strength are used, the diaphragm remains during the excitation in the position of inspiration, the state of contraction being, however, usually intercupted by momentary relaxations at short intervals. 


\section{III.-Influence of the Cardiac and Vasomotor Centres on the Circulation and on the Motions of the Heart.}

The atlanto-occipital membrane having been previously exposed, the carotid is connected with the kymograph. A record is taken, and the mean arterial pressure measured. On faradization of the spinal cord, at the level of the third vertebra, mixed effects are observed, due partly to the excitation of the vascular nerves, partly to escape of induction currents to the cardiac centre. If both vagi have been previously divided, those due to the latter cause do not appear. The cord is now severed above the seat of excitation, respiration being continued artificially : the arterial pressure sinks to a third of the previous mean. The excitation is repeated; the pressure rises rapidly, the heart beating with great frequency. On opening the thoracic cavity, the action of the heart may be studied. It is seen that so long as artificial respiration is continued, it beats regularly. If the injections of air are intermitted for a few moments, its cavities become more distended and its action more vigorous than before, and a similar effect is produced by excitation of the spinal cord.

\section{IV.-Functions of Vascular Nerves.}

Constricting Nerves.-Division of the trunk of the sympathetic opposite the cricoid cartilage is followed by dilatation of the central artery of the lobe of the ear on the same side, and increase of vascularity. On comparing the temperature of the congested lobe with that of the other side, it is found to be two or three degrees higher. The pupil of the same side is more contracted than the opposite one. Excitation of the end next the superior ganglion produces constriction of the central artery and abolishes the congestion of the lobe.

Dilating Nerves.-Excitation of the central end of the great auricular nerve (or of the posterior auricular) produces temporary vascular changes, which are identical with those permanently produced by section of the sympathetic.

Depressor Nerve.-Excitation of the central end of the divided depressor occasions general diminution of arterial pressure (dependent on dilatation of the blood-vessels supplied by the splanchnic nerves). If the vagi have been previously divided, the diminution of pressure is not associated with any change in the frequency of the contractions of the heart.

\section{V.-Movements of Circulation and Respiration in Man.}

I. The Cardiograph and Sphygmograph.-a. Two receiving tympana (cardiographs) are used. One is applied to the seat of the cardiac impulse, the other to the carotid artery. The two recording tympana with which these are severally connected, inscribe the motion of the heart and that of the artery respectively, on the same cylinder. The arterial expansion 
follows that of the heart at an interval of about eight-hundredths of a second. The duration of the ventricular impulse is about three-tenths of a second.

b. The sphygmograph having been adjusted so as to record the radial pulse, a receiving tympanum on the carotid is connected with a recording tympanum attached to the frame of the sphygmograph, so that its lever writes on the same surface as that of the sphygmograph. The interval of time between the impulse of the carotid and that of the radial is about the same as that between the carotid and the heart.

2. The Stethograph.-The changes of form of the thorax in respiration are investigated by the measurement of the diameters of the chest. The most important diameters are the antero-posterior (from upper end of sternum to third dorsal spine, I50 millims. and from lower end of sternum to eighth spine, 200 millims.); the transverse (at the eighth rib, about 230 millims.). These measurements refer to an adult male, as taken during the respiratory pause. The first of these diameters increases about a millimeter, the second about two millimeters, and the third about two and a half in ordinary tranquil inspiration. These measurements, when recorded by the stethograph, yield the "respiratory curve."

VI.-The Heart of the Frog.

I. Rhythmical Motions of the Ventricle; Influences thereon of Temperature and other External Conditions. 2. The Cardiac Vagus, and the Intracardiac Inhibitory Centre.

The experiments relating to these subjects are described in the Practical Exercises. Such of them only as can be seen at a distance are shown.

\section{VII.-Electromotive Phenomena of Muscle.}

The most important instrument used is a Thomson's Reflecting Galvanometer of high resistance, the terminals of which are connected by insulated copper wires with non-polarizable electrodes. These are in contact by their clay plugs with the two surfaces to be compared.

To the needle of the galvanometer a light concave mirror is attached, on which a beam of light falls and is focussed, after reflection, on a divided screen. Thus the smallest deflection of the needle (by which any electrical difference between the two contacts is indicated) can be exactly measured. By means of a suitable shunt, either the whole, a tenth, or other decimal fraction of any current flowing through the circuit can be led through the galvanometer.

r. Electromotive Phenomena of Muscle.-The gastrocnemius muscle of the frog is used. One of the electrodes is in contact with the convex surface of the muscle near its upper end, the other with the expansion of the 
tendo Achillis. In this arrangement the surface of the tendon is negative to that of the muscle.

2. On exciting the muscle by faradizing its nerve, a deflection takes place in such a direction as to indicate that the electrical difference between the two surfaces is diminished. After excitation the needle resumes its former position.

3. The electrode in contact with the tendinous expansion is now brought near to its fellow, so that both contacts are now muscular. They are nearly isoelectrical. On injuring the lower of the two contacts mechanically or by heat, it becomes at once strongly negative. On excitation of the nerve by induced currents, the negativity diminishes as before.

4. Electromotive Phenomena of the Ventricle of the Frog Heart.-A Stannius' Heart Preparation (see Practical Exercises) is "led off" by contacts at its apex and base. If the heart is uninjured, these surfaces will be found to be nearly isoelectrical. On injuring either surface it becomes negative.

2. A normally contracting heart is led off by contacts similarly situated. Each contraction is accompanied by a deflection of the needle, indicating that the apex becomes first positive then negative. By injuring the apex, mechanically or otherwise, the deflection becomes entirely positive.

3. A "ventricle preparation" is led off at apex and cut surface. During contraction, the effect is similar, but the negative deflection is much larger.

4. A ventricle apex preparation (which does not contract spontaneously) is led off as above. Its cut surface is at first strongly negative to the apex. On excitation at the base by a single induction shock, the ventricle contracts, its contraction being accompanied by a deflection indicating that the apex becomes negative.

H. K. Lewis, Printer, I36 Gower Street, Lonnon. 


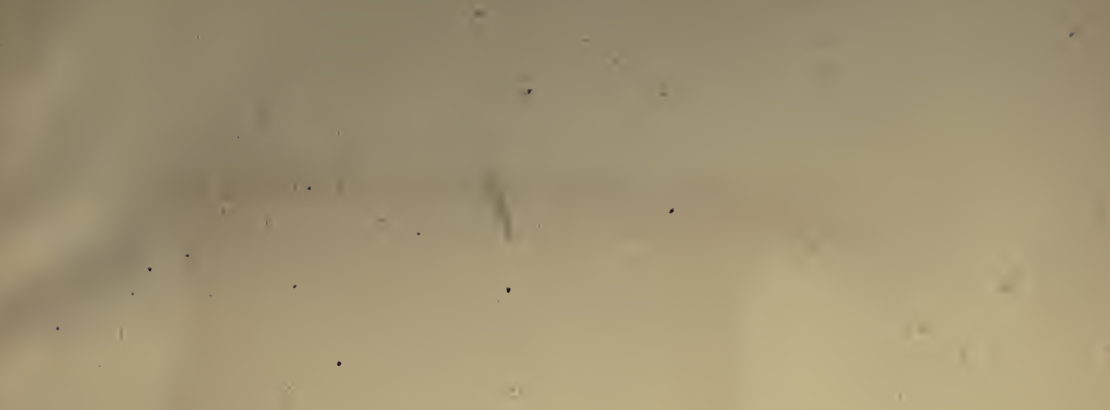



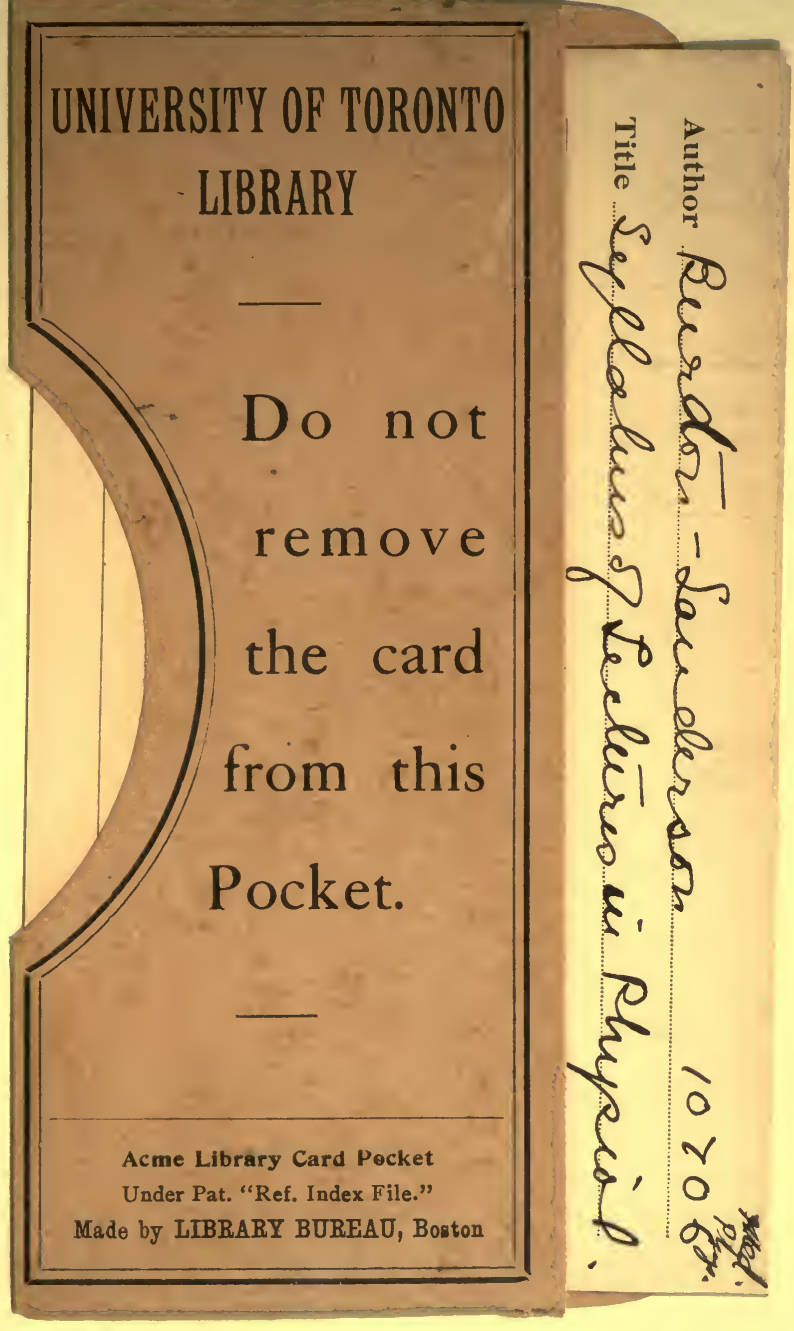




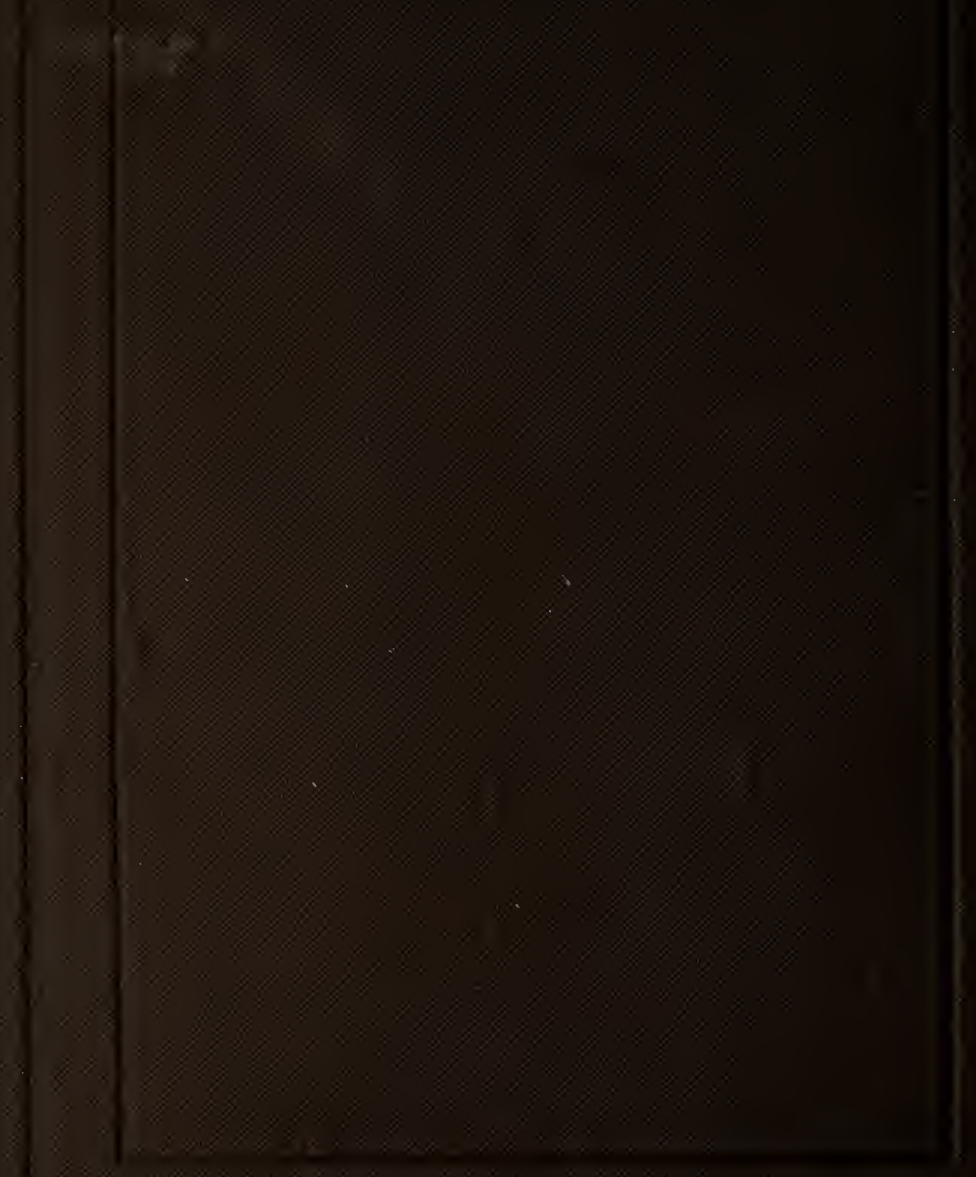

